\title{
Chemical and Genetic Diversity in Sesame (Sesamum indicum L.)
}

\author{
Dissertation \\ to obtain the Ph. D. degree \\ in the International Ph. D. Program for Agricultural Sciences in Goettingen (IPAG) \\ at the Faculty of Agricultural Sciences, \\ Georg-August-University Göttingen, Germany
}

presented by

Rehana Naz, Syed

Born in Karachi, Pakistan.

Göttingen, November 2011 
D7

1. Name of supervisor: Prof. Dr. Petr Karlovsky

2. Name of co-supervisor: Prof. Dr. Anthony Whithbread

Date of dissertation: 28-10-2011 
'Dedicated to my parents who have given me education even when they had less money and they send me abroad in the age when they need my care'. 


\section{Contents}

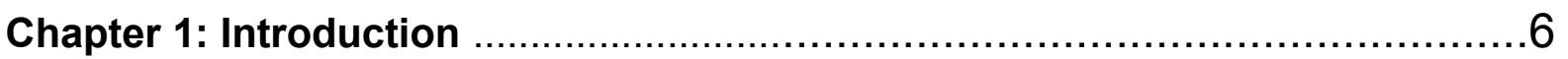

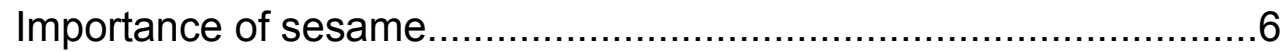

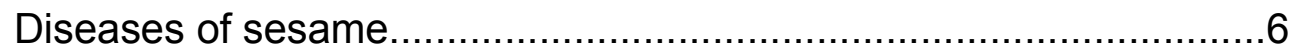

Sesame secondary metabolites with special refrence to resistant

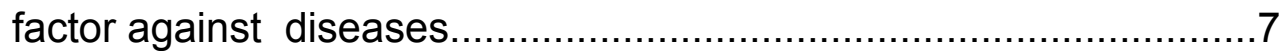

Molecular marker in sesame with special refrence to diversity

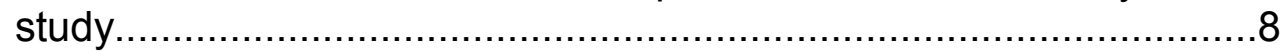

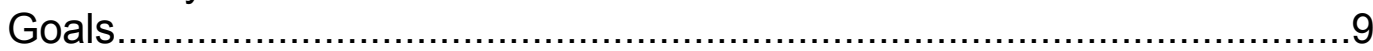

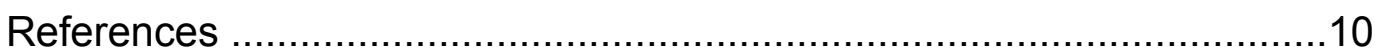

Chapter 2: Diversity and variance in phytohormone content of sesame

(Sesamum indicum L.).......................................................................14

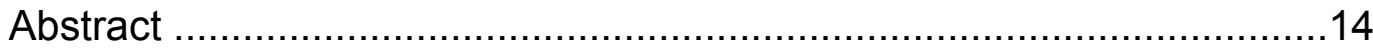

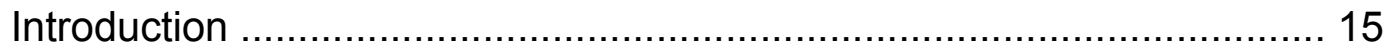

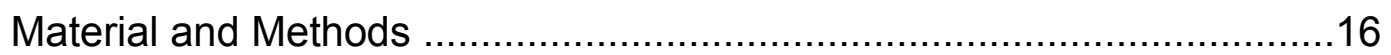

Plants growth conditions..........................................................

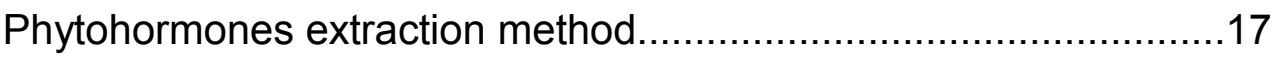

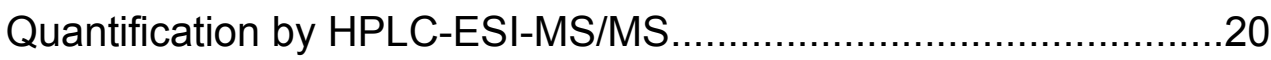

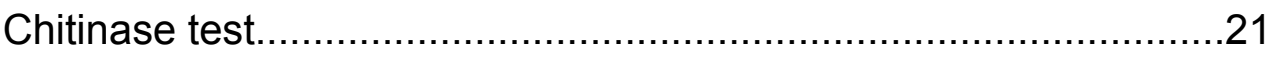

Amplified Fragment Length Polymorphism (AFLP).......................22

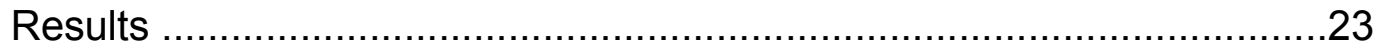

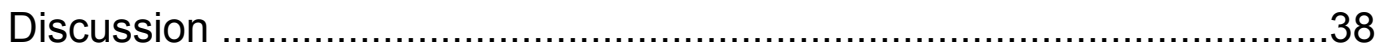

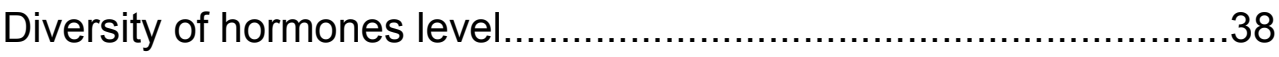

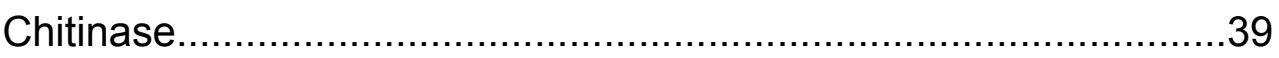

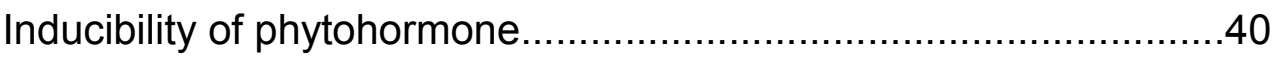

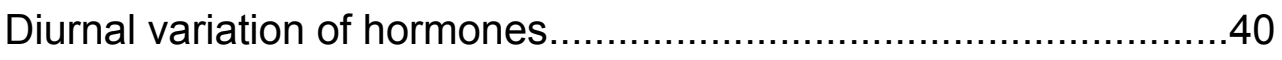

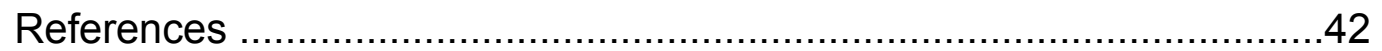

Chapter 3: Antifungal properties of sesame (Sesamum indicum L.) crude extract and purified sesame lignans.................................................46

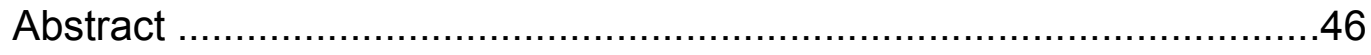

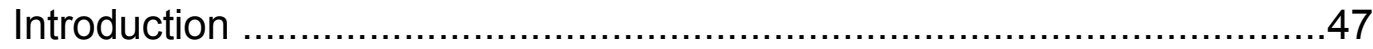

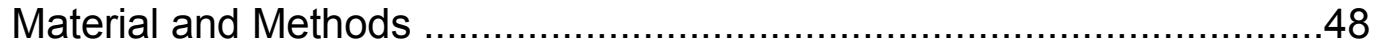

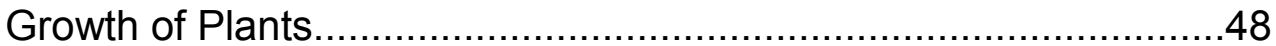

Extraction and fractionation for anti fungal ..................................49

Inoculums Preparation..............................................................50 


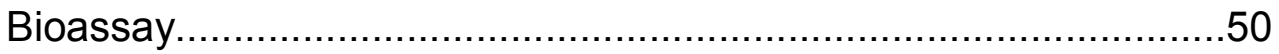

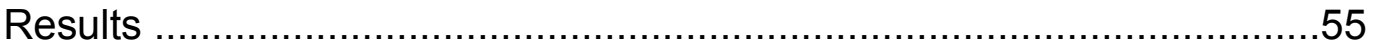

Antifungal activity of sesame plant extract extract..........................55

Antifungal activity of purified compounds.....................................56

Cross contamination of sesamol and DNP in neighbouring wells....56

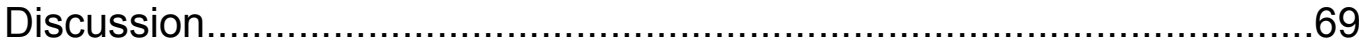

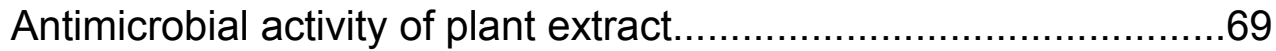

Antimicrobial activity of purified sesame lignans...........................70

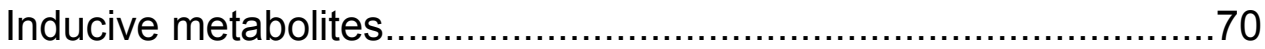

Cross contamination by sesamol and DNP in neighbouring wells

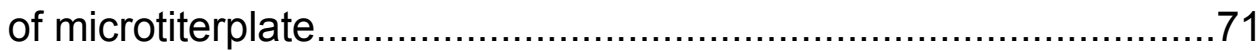

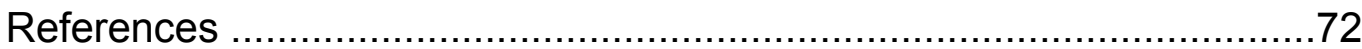

Chapter 4: Generation of recombinant inbread lines (RILs) for genetic mapping and studies of the inheritance of metabolic synthesis in sesame

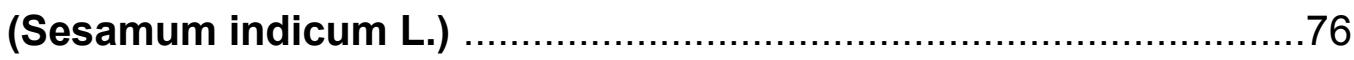

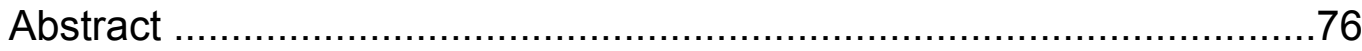

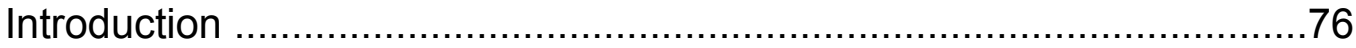

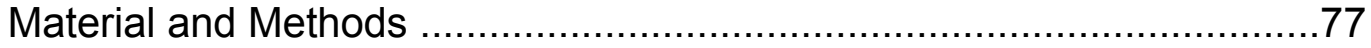

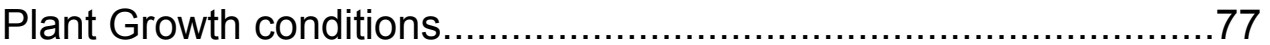

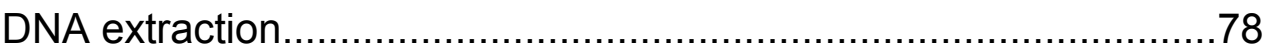

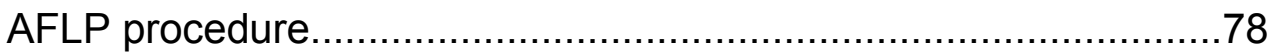

Extraction method for metabolic fingerprinting..............................79

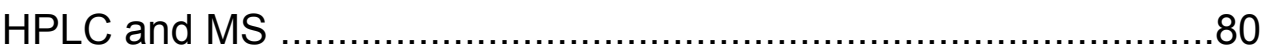

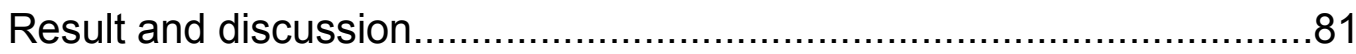

Advancement of RILs and segretation of flower color ...................81

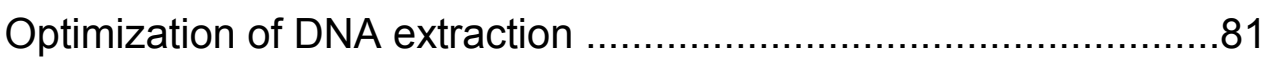

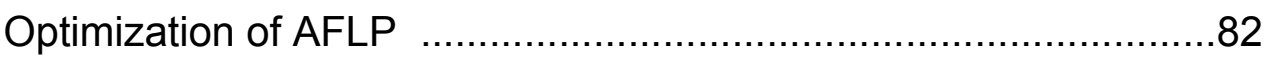

Segregation of parental AFLP fragments ..................................... 84

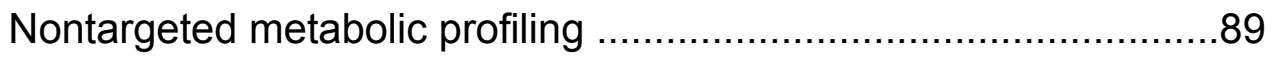

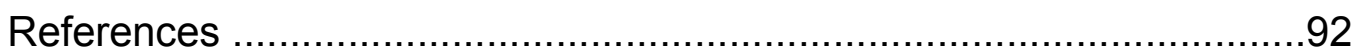

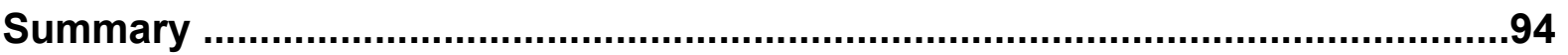

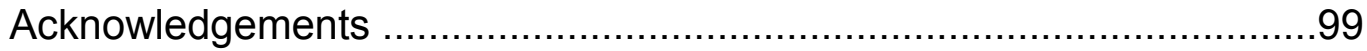

Scientific and authers contribution....................................................100

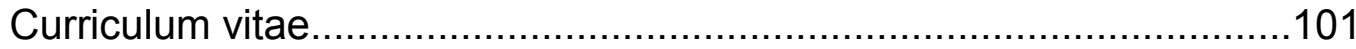




\section{Chapter 1 - Introduction}

\section{Importance of sesame}

Sesamum indicum L. is an important oil seed crop cultivated in tropical and subtropical areas of Asia, Africa, South and Central America. According to the Food and Agriculture Organization the united nation (FAO), Myanmar (Burma) was the world's largest producer of sesame in 2009, followed by India and then China (FAOstats 2010). Nearly 70 percent of the world production is in Asia. Africa grows about 25 percent of the world's sesame, with Sudan, Ethiopia and Uganda being key producers (Hansen 2011). The crop has food, industrial, nutraceutical, and pharmaceutical uses (Morris 2002)and has got the title "queen of oil seed crop" because of its high oil yield, mildness and pleasant taste. It is also recognized as an important source of protein, calcium, phosphorus and iron (Al-Yemeni 2000) Sesame seeds contain approximately $50 \%$ oil and $25 \%$ protein. The seed contain high range of (224-1148mg / 100g seeds) lignana (Moazzami and Kamal-Eldin 2006), sesamin and sesamolin are most prominent one. Sesame lignans and tocopherol are well known due to their antioxidant properties and health promoting effects.

\section{Diseases of sesame}

The crop is infected by many fungal, bacterial, viral, mycoplasma and non-parasitic diseases around the world. Among the fungal phytopathogens, the Macrophomina phaseolina is a virulent fungus causing charcoal rot or stem rot disease in Sesame, this leads to heavy economic losses for farmers(Papavizas 1977), reducing the oil content significantly level if the crop is attacked near maturity (Javed et al., 1995). The range of plants hosting M. phaseolina is around 500 economically important plants causing diseases commonly known as charcoal rot (Sinclair, 1982). Alternaria sesame causes damage due to reduction in photosynthetic area due to leaf damage and premature defoliation (Kolte, 1985), elongated lesion on capsules and considerable yield damage. Fusarium oxysporum f. sp. sesame causes seedling blight and fusarium wilt of sesame (Cho and Choi, 1987) and is one of the soil borne vascular pathogens causing wilting by blocking the root xylem vessels (Bateman et al., 1996). Beside these, other seed borne fungi of sesame including three Aspergillus species. A. flavus, A. ochraceus, and A. tamarii, Penicillium citrinum and 
two Fusarium sp. recorded in Sierra Leone and Aflatoxin B1 and G1 were also detected from seed samples (Jonsyn, 1988).Cercospora sesami Leaf spot disease Zimm, prevalent in most sesame growing areas of Nigeria and in other parts of Africa (Nyanapah et al., 1995).

Diseases are controlled by cultural, biological and chemical methods. Plant resistant cultivars are one of the most efficient methods for disease control. Host resistant eliminates or minimizes the losses due to diseases and reduces the need for and cost of other controls. To develop disease resistant cultivars, sources of resistant must be combined in cultivars that have desirable traits (Jerlad 2004).

\section{Sesame secondary metabolites with special refrence to resistant factor against diseases.}

Plants represent a nearly unlimited source of photochemicals or metabolites of primary and secondary metabolism. Plant secondary metabolites have important ecological function not only as attractant for pollinators and seed dispersing animals but also as resistantce factor against pathogens. A review by Cowan (1999) gives a brief history of plant products as antimicrobial agents. Useful antimicrobial plant compounds include several categories: phenolics, terpenoids, essential oils, alkaloids, lecitins, polypeptides and polyacetylenes. Sesame plant also contains some unique chemicals such as sesamin, sesamol, sesamolin, sesaminol, anthrasesamone, chlorosesamone A, B, C, D and E, hydroxysesamone, 2,3epoxysesamone, and anthraquinone pinoresinol. Sesamin inhibit the growth of Bombyx mori (L) shows anti feeding activity against Spilarctia obliqua (Walker) larvae (MacRae and Towers,1984; Srivastava et al., 2001), synergistic to several synthetic insecticides (MacRae and Towers,1984) potential insecticide for the control of velvet bean caterpillars Anticarsia gemmatalis (Nascimento et al., 2003). Sesamol helps the plant by inhibiting the growth of invading pathogens, significantly decreasing the charcoal rot (M. phaseolina) symptoms of soybean in vivo experiments (Broker et al., 2000), and was inhibited growth and lipid production of Mucor circinelloides (Wynn et al., 1997), showed anti feeding activity against stored product pests: Sitophilus granarius, Tribolium confusum, and Trogoderma granarium (Harmatha and Nawrot, 
2002). Sesamol inhibits lipid biosynthesis/accumulation in Mucor circenelloides (Wynn et al., 1997 as cited by Jacklin et al., 2000) and F. moniliforme via accumulation of secondary metabolite (GA3) by acetyl-CoA destined for fatty acid by metabolic switching (Jacklin et al., 2000). The antimicrobial activity of plant extracthave been shown in a number of publications. Sesame leaves extracts were found to have inhibitory against Streptococcus pneumoniae, Candida albicans (Ahmed et al., 2009; Shittu et al., 2006), Staphylococcus aureus (Ahmed et al., 2009), against symbiotic fungus (Leucoagaricus gongylophorus) of Atta sexdens L (Riberio et al., 1998). Sesame leaves, stem and root extracts showed inhibitory activity against M. phaseolina and F. oxysporum (Laurentin, 2007). Antimicrobial compound, 2-isopropenylnaphthazarin-2,3-epoxide, was isolated from hairy roots of Sesamum indicum which had been established by transformation of the mother plant with Agrobacterium rhizogenes (Ogsawara et al., 1993). Insect baits of sesame leave flour $(15 \%)$ showed promising result in the control of lemon leaf cutter anthills, Atta sexdens rubropilosa (Filho and Dorval, 2003). Fungi toxicant compounds demonstrated to present in all the accessions but the final effect depends on balance proportion of each compound (Laurentin, 2007).

\section{Molecular marker in sesame with special refrence to diversity study}

Molecular markers are crucial tools used in plant breeding. In sesame most of molecular study restricted to diversity study using anonymus markers. Random Amplified polymorphic DNA (RAPD) (Bhat et al. 1999) microsatellite sequences (SSRs) (Dixit et al 2005) amplified fragment length (Ghulm et al. 2006. Laurentin et al. 2008) agro-morphological and ISSR marker traits(Parsaeian et al. 2011) for study of genetic diversity, Inter-simple sequence repeats (ISSR) polymorphism (Kim et al 2002) and AFLP( Laurentin and Karlovsky 2006) to determine genetic relationships. AFLP for some domesticated trait including claused capsules QTLs (Bulent Uzan 2003), identification for marker linked with determinant growth habit using RAPD and ISSR (Bulent Uzan and Ilhan Cagirgan 2009) expressed sequence tag-simple sequence repeat (EST-SSR) (Li-Bin wei 2008) have been reported. AFLP has been used in large numbers of studies of studies to use genetic diversity in sesame, these markers have not been used for the construction of a linkage map . 
GOALS:

A. Characterization of sesame accessions for phytohormone content

- Determination of phytohormone levels in sesame.

- Investigation of the inducibility of phytohormones by exposing the plant to ultraviolet light, heavy metals and by inoculating pathogenic fungi.

- Study of the circadial dynamic of phytohormone levels.

B. Characterization of sesame extracts for antifungal effects

- Characterization of the effects of sesame extracts (leaves, stem and roots) on pathogenic fungi.

- Investigation of the inducibility of antifungal metabolites in sesame by exposing the plant to ultraviolet light, heavy metals and by inoculating pathogenic fungi.

- Bioassays and determination of the minimum inhibitory concentration (MIC) of purified sesame lignans.

C. Production of recombinant inbread lines for molecular marker studies and analysis of the inheritance of metabolite synthesis

- Generation of near-isogenic population (F6) KorAf by selfing progenies of the cross between sesame accessions Korea1 with Africa3.

- Characterization of KorAf concerning AFLP markers.

- Characterization of metabolic profiles of a subset of the segregating population. 


\section{REFRENCES}

1) Ahmed, T., Shittu, L. A. J., Bankole, M. A., Shittu, R. K., Adesanya, O. A., Bankole, M. N. and Ashiru, O. A. 2009 Comparative studies of the crude extracts of sesame against some common pathogenic microorganisms. Scientific Research and Essay, 4:584-589.

2) Al-Yemeni, M. N., M. A. Hussain and A. Y. Basahy. 2000 Mineral composition of some sesame seeds grown in the Gizan area of Saudi Arabia. Phyton. Int. J. Exp. Bot. $67: 121-125$

3) Ali Moazzami, A. and Afaf Kamal-Eldin. 2006 Sesame Seed Is a Rich Source of Dietary Lignans, JAOCS 83, 719-723.

4) Bateman, G.L., Kwasna, H. and Ward, E. 1996 Relationship among Fusarium spp. estimated by comparing restriction fragment length polymorphism in polymerase chain reaction amplified nuclear DNA. Can. J. Microbi. 42:12321240.

5) Bhat, KV., Babrekar, PP., Lakhanpaul, S. 1999. Study of genetic diversity in Indian and exotic sesame (Sesamum indicum L.) germplasm using random amplified polymorphic DNA (RAPD) markers. Euphytica 110:21-33

6) Brooker, N. L., Long, J. H. and Stephan, S. M. 2000 Field assessment of plant derivative compounds for managing fungal soybean diseases. Biochem. Soc. Trans. 28:917-920.

7) Cho, E. K. and Choi, S. H. 1987 Etiology of half stem rot in sesame caused by Fusarium oxysporum. Korean J. Plant Prot. 26:25-30.

8) Cowan, M. M. 1999 Plant products as antimicrobial agents. Cli. Microbiol. Rev. 4:564-582.

9) Dixit, A., Jin MH., Chung JW. 2005 Development of polymorphic microsatellite markers in sesame (Sesamum indicum L.). Mol Ecol Notes 5(4):736-738

10)Filho, O. P. and Dorval, A. 2003 Effect of granulated formulations composed by chemical products and leaves and seeds of sesame, Sesamum indicum, to control nests of Atta sexdens rubropilosa Forel, 1908 (hymenoptera: formicidae). Ciência Florestal, Santa Maria, 13:67-70. 
11) Ghulam, M. A., Sirato, Y., Masumi, S. K. 2007 Assessment of genetic diversity in sesame (Sesamum indicum L.) detected by Amplified Fragment Length Polymorphism markers. Electron. J. Biotechnol.10(1):12-23.

12) Hansen, R. 2011 Revised August 2011 by Diane Huntrods, AgMRC, lowa State University. Sesame profile http://www.agmrc.org/commodities __products/grains_oilseeds/sesame_profile.cfm

13)Harmatha, J. and Nawrot, J. 2002 Insect feeding deterrent activity of lignans and related phenylpropanoids with a methylenedioxyphenyl (piperonyl) structure moiety. Entomologia Experimentalis et Applicata, 104:51-60.

14)Jacklin, A., Ratledge, C. and Wynn, J. P. 2000 Lipid-to-gibberellin metabolic switching in Fusarium moniliforme via the action of sesamol. Biotechnol. Lett. 22:1983-1986.

15)Javed, M. S., Wahid, A. and Idrees, M. 1995 Fungi associated with sesamum seed and their frequency. Pak. J. Phytopathol. 7:174-176.

16)Jerald , K., Pataky, Martin L. Carson. 2004 Plant Pathology Concept of laboratory Exercise. (Host Resistance) CRC Press Raton London New York Washington D.C. 295-311

17)Jonsyn, F. E. 1988 Seedborne fungi of sesame (Sesamum indicum L) in Sierra Leone and their potential aflatoxin/mycotoxin production. Mycopathologia, 104:123-127.

18)Kim, DH., Zur G., Danin-Poleg Y. et al. 2002 Genetic relationship of sesame germplasm collection as revealed by inter-simple sequence repeats. Plant Breed 121:259-262.

19) Kolte, S. J. 1985 Disease of annual edible oil seed crops: rapeseed, mustard, safflower and sesame diseases. Vol II, CRC Press Inc., Boca Raton, Florida. 232pp.

20)Laurentin, H. 2007 Genetic diversity in sesame: molecular markers, metabolic profiles and effect of plant extracts on soil-borne pathogenic fungi. A Ph.D thesis, Georg August University, Goettingen, Germany. 
21)Laurentin, H. and karlovsky, P. 2006 Genetic relationship and diversity in sesame (Sesamum indicum L.) germplasm collection using amplified fragment length polymorphism. BMC Genetics 7:10

22)Laurentin, H., Ratzinger, A., and Karlovsky, P. 2008 Relationship between metabolic and genomic diversity in sesame. BMC Genomics. 9:250.

23)Li-Bin-Wei, Zhang, H. Y., Guo, W. Z. 2008. Developing EST-Derived Microsatellites in Sesame (Sesamum indicum L.) Acta agronomica sinica. $34: 2077-2084$

24)MacRae, W. D. and Towers, G. H. N. . 1984. Biological activities of lignans. Phytochem. 23:1207-1220.

25)Marris, J. B. 2002. Food, industrial, nutraceutical and farmaceutical uses of sesame genetic resources. In J. Janic and A Whipkey (eds), Trends in new crop and new uses. 153-156

26)Nascimento, I. R., Murata, A. T., Bortoli, S. A. and Lopes,L. M. 2003 Insecticidal activity of chemical constituents from Aristolochia pubescens against Anticarsia gemmatalis larvae. Pest Manag. Sc. 60:413-416.

27)Nyanapah, J. O., Ayiecho, P. O. and Nyabundi, J. O. 1995 Evaluation of sesame cultivars to resistance to Cercospora leaf spot. E. Afr. Agric. For. J. 6: $115-121$.

28)Ogasawara, T., Chiba, K. and Tada, M. 1993 Production in high-yield of a naphthoquinone by a hairy root culture of Sesamum indicum. Phytochem. 33:109-1098.

29)Papavizas, G. C. 1977 Some factors affecting survival of sclerotia of Macrophomina phaseolina in soil. Soil Biol. Bichem. 9:337-341

30)Parsaeian, M., Mirlohi A., Saeidi G. 2011 Study of genetic variation in sesame (Sesamum indicum L.) using agro-morphological traits and ISSR markers. Genetika. 47(3):359-67.

31)Ribeiro, S. B., Pagnocca, F. C, Victor, S. R., Bueno, O. C., Hebling, M.J ., Bacci Jr, M., Silva,O. A., Fernandes, J. B., Vieira, P. C. and Silva,M. F. G. F. 
1998 Activity of sesame leaf extracts against the symbiotic fungus of Atta sexdens L. An. Soc. Entomol. Brasil. 27:421-426.

32)Shittu, L. A. J.,Bankole, M. A., Ahmed, T., Aile, K., Akinsanya, M. A., Bankole, M. N., Shittu, R. K., and Ashiru, O. A. 2006 Differential antimicrobial activity of the various crude leaves extracts of Sesam radiatum against some common pathogenic micro-organisms. Scientific Res. and Essay, 1:108-111.

33)Sinclair, J. B. 1982. Compendium of Soybean Diseases. American Phytopathol. Soc. St. Paul, MN. 2:30-33.

34)Srivastava S., Gupta, M. M., Prajapati, V., Tripathi, A. K. and Kumar, S. 2001 Sesamin a potent antifeedant principle from Piper mullesua. Phytother. Res. 15:70-72.

35) Uzan, B. and Cagirgan, M. J. 2009 Identification of molecular markers linked to determinate growth habit in sesame. Euphytica.166(3): 379-384

36) Uzun, B, Lee, D., Donini, P. et al. 2003 Identification of a molecular marker linked to the closed capsule mutant trait in sesame using AFLP. Plant Breed 122:95-97

37) Wynn, J. P., Kendrick, A. and Ratledge, C. 1997 Sesamol as inhibitor of growth and lipid metabolism in Mucor circenelloides via its action on malic enzyme. Lipids 32: 605-610 


\section{Chapter 2- Diversity and variance in phytohormone content of sesame (Sesamum indicum L.)}

\section{ABSTRACT}

The level of a metabolite is affected by a number of factors (availability of precursors, activity of biosynthetic enzymes and transformation to other products), all of which are subject to complex regulations. HPLC system coupled with a triple quadruple mass spectrometer was used to study phytohormone content in sesame. The following questions were addressed: the variation in phytohormone content among sesame accessions of different geographical origin, the effect of circadial rhythm, differences among plant organs, and stress-induced changes in phytohormone levels. Most accessions out of sixteen showed similar hormone levels, but one accession originating from Japan showed ten times higher levels of salicylic and jasmonic acid in leaves and roots. Consistent with this result, the accession was found to produce large activity of chitinase, which is an important enzyme in plant defense reaction. Among the sixteen accessions, $75 \%$ of variation in salicylic acid could be explained by chitinase. Plants of the accession originating from japan were shorter in height, had smaller capsules and produced significantly lower capsules than the other accessions. We speculate that the constitutively increased levels of two stress hormones exerted a negative effect on the fitness of the plants. Characterization of accessions by AFLP reveled that "Japan 2" was not genetically more distant from the other accessions than the average distance within the collection. Circadian clock is known to control various biological processes. The effect of circadian rhythm was studied on the accessions by sampling leaves, stems and roots every 3 hours, but no circadian influence was detected in abscisic acid, salicylic acid, jasmonic acid, and indole-3-acetic acid (jasmonic acid and indole-3acetic acid were below detection limit for most samples). Concentration of hormones varied in different parts of the plants. The effects of biotic and abiotic stress on phytohormone level were also studied. Among the treatments used, spraying plants with $2 \mathrm{mM} \mathrm{CuCl}_{2}$ significantly increased the concentration of salicylic acid. 


\section{INTRODUCTION}

Biological diversity comprises of differences in species abundances among biota and intraspecies differences among populations and individuals. Intraspecies diversity has been extensively studied at genome level in both wild and cultivated plants. In many crops, but rarely in wild species, diversity of the macroscopic phenotype (morphology, color and agronomically relevant traits) has also been surveyed. Intraspecies diversity in metabolic constitution of crops has been studied in a handful of publications so far.

Untargeted metabolic profiling in rice (Katharine et al., 2009) and sesame (Laurentin et al., 2008) revealed a high variability in the levels of small molecules. Moreover, the differences among metabolic profiles of the accessions were not concordant with their genetic distance. We hypothesize that this finding can be accounted for by the fact that the majority of metabolites surveyed in these studies can be regarded as end products of gene expression. Because each of these metabolites delivers only minor contributions to the fitness and/or the phenotype affecting artificial selection during domestication and breeding, diversification of metabolic constitution has been counteracted mainly by genetic drift and only to a limited extent by selection. As the level of a metabolite is affected by a number of factors (availability of precursors, activity of biosynthetic enzymes and transformation to other products), all of which are subject to complex regulation, the rate of diversification is high as compared to the rate of homogenization by drift, leading to a high level of intraspecies metabolic diversity.

While this reasoning is straightforward for secondary metabolites with functions directed towards the environment (e.g., antibiotics and virulence factors), it does not hold for metabolites playing roles of regulators of developmental processes and defense responses. These metabolites are components of signal pathways rather than traits of the chemical phenotype. Due to their role in controlling fundamental cellular processes, variation in their concentrations is likely to considerably affect the fitness. We therefore hypothesize that the diversification of the levels of metabolites with regulatory functions is controlled by selection rather than genetic drift. To test the hypothesis, we selected a group of metabolites involved in the development 
(phytohormones) and defense (stress hormones) in sesame, quantified circadial and random variation of metabolic levels in a single accession and studied the metabolic diversity in a set of accessions well characterized at the genome level. Previously we showed that patterns of diversity at genomic level revealed by AFLP and metabolites with ecological roles which are strictly not necessary for the survival and reproduction of the crop does not correlate (Laurentin et al., 2008). Here we investigated the variability of phytohormones, chitinase activity together with genetic diversity among 16 accessions and diurnal variation of one accession. To our knowledge no publication exist on phytohormones in sesame. We established the effect of circadial rhythm on phytohormone levels and determined the difference among organs. Apart from the academic interest in metabolic diversity, stress hormones also have important role in defense against pathogens. Phytohormones level are also relevant from practical point of view because seeds of sesame sometimes germinate spontaneously while capsules still attached to the plants and are green (Fig.1). This phenomenon is termed vivipary and highly undesirable because these seeds are lost. Mycoplasma-like organisms have been associated with sesame phyllody in Iran with typical symptoms of yellowing, cracking of seed capsules, germination of seeds in capsules and formation of dark exudates on foliage (Salehi and Izadpanah, 1992). Maize mutants blocked in carotenoid pathway producing reduced $A B A$ and also exhibit vivipary (the precocious germination) of seed while cob still attached to plant. Vivipary in seed is associated with ABA deficiency (Finkelstein, 2006).In sesame to the best of our knowledge, the causes of vivipary are unknown, but similarly to other plants it could be triggered by changes in phytohormones levels.

\section{MATERIAL AND METHODS}

\section{Growth conditions}

Sesame seeds from accessions or cultivars (Table 1 and 2) were grown in small pots containing white autoclaved silica sand, one plant per pot (Fig. 2). The pots were irrigated every day while fertilized with 25 mg of NPK (15-11-15) every third day, starting after the seventh day of germination. This system was used to harvest clean 
roots without adhering to the soil or organic particle and similar to the method used by Eynck et al. (2007). Pots were kept in phytochamber under controlled environmental conditions $14 \mathrm{~h}$ light $(20 \mathrm{Lux}), 26^{\circ} \mathrm{C}$ and relative humidity of $60 \%$. Plants were then uprooted washed with tape water and immediately frozen with liquid nitrogen and stored at $-20^{\circ} \mathrm{C}$ until use. Sesame seedlings were subjected to biotic and abiotic stresses. Briefly, soil was inoculated with sclerotia of Macrophomina phaseolina or kept under UV at $20^{\circ} \mathrm{C}$ for 10 min continuously for 10 days or $2 \mathrm{mM}$ $\mathrm{CuCl} 2$ solution was sprayed with laboratory sprayer once on leaves 9 days before harvesting. Because of necrotic symptoms on leaves, further sprays before 6 and 3 days of harvesting were done on stems

\section{Phytohormones extraction method}

Samples were homogenized with peistel and mortar in the presence of liquid nitrogen and subjected for phytohormone extraction in the dark. $1 \mathrm{ml}$ the extraction solution which was composed of $20 \%$ acetone, $79 \% \mathrm{H}_{2} \mathrm{O}$ and $1 \% \mathrm{CH}_{3} \mathrm{COOH}$ (spiked with D6-SA and D6-ABA internal standerd) was added to $100 \mathrm{mg}$ of grounded tissues, vortexed and shaken (100rpm) with ice for $45 \mathrm{~min}$. The extracts were re-extracted with $(2 X) 1 \mathrm{ml}$ of cold ditheylether (DEE) was added twice, the solutions were shaken (100rpm) again for $30 \mathrm{~min}$. The upper DEE phase of the 2 consecutive extractions were pooled and transferred to new eppendorf after centrifugation for $5 \mathrm{~min}$ at $13000 \mathrm{~g}$. The extractions were evaporated to complete dryness under vacuum and stored at $-20^{\circ} \mathrm{C}$ to ensure stability. For analysis with HPLC samples were re-dissolved in $200 \mathrm{ul}$ of HPLC solvents (MeOH: $\mathrm{H}_{2} \mathrm{O} 1.1+7 \mathrm{mM} \mathrm{CH} \mathrm{CHOH}_{3} \mathrm{COO}$ for at room temperature, shortely vortexed and centrifuged at 12000rpm for $5 \mathrm{~min}$ to remove undissolved particles.. For testing the effect of biotic and abiotic stresses on phytohormone levels in sesame, plant samples were first extracted with $80 \%$ ethanol according to Laurentin (2007) part of these extracts were used for bioassays ( data not shown). For phytohormone quantification, the $80 \%$ ethanol extracts were reextracted with the above mentioned extraction method. 

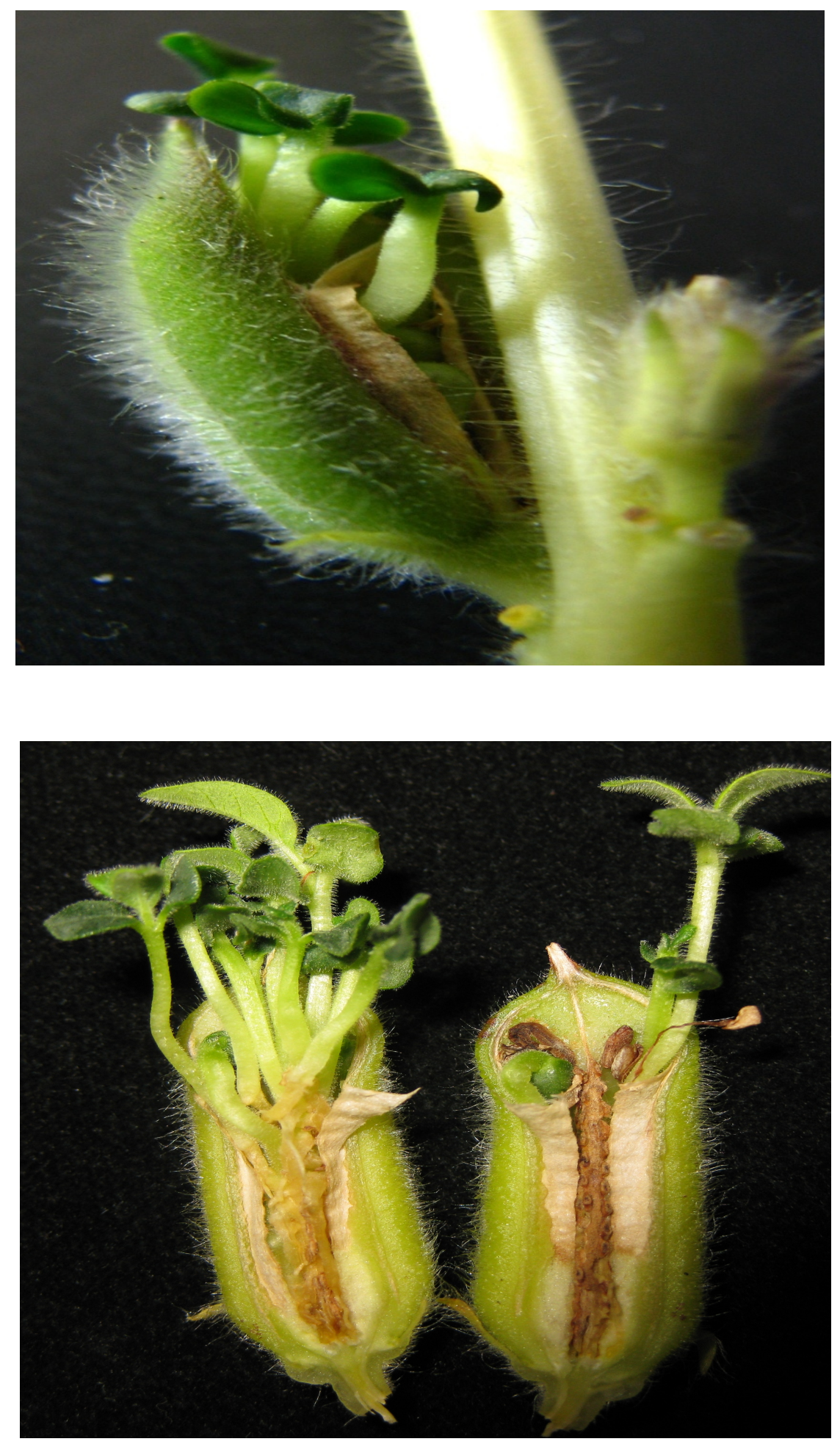

Figure 1. Sesame seed vivipary. Cracked capsule and germinated seeds. The causes of this phenomenon are unknown for Sesame. 


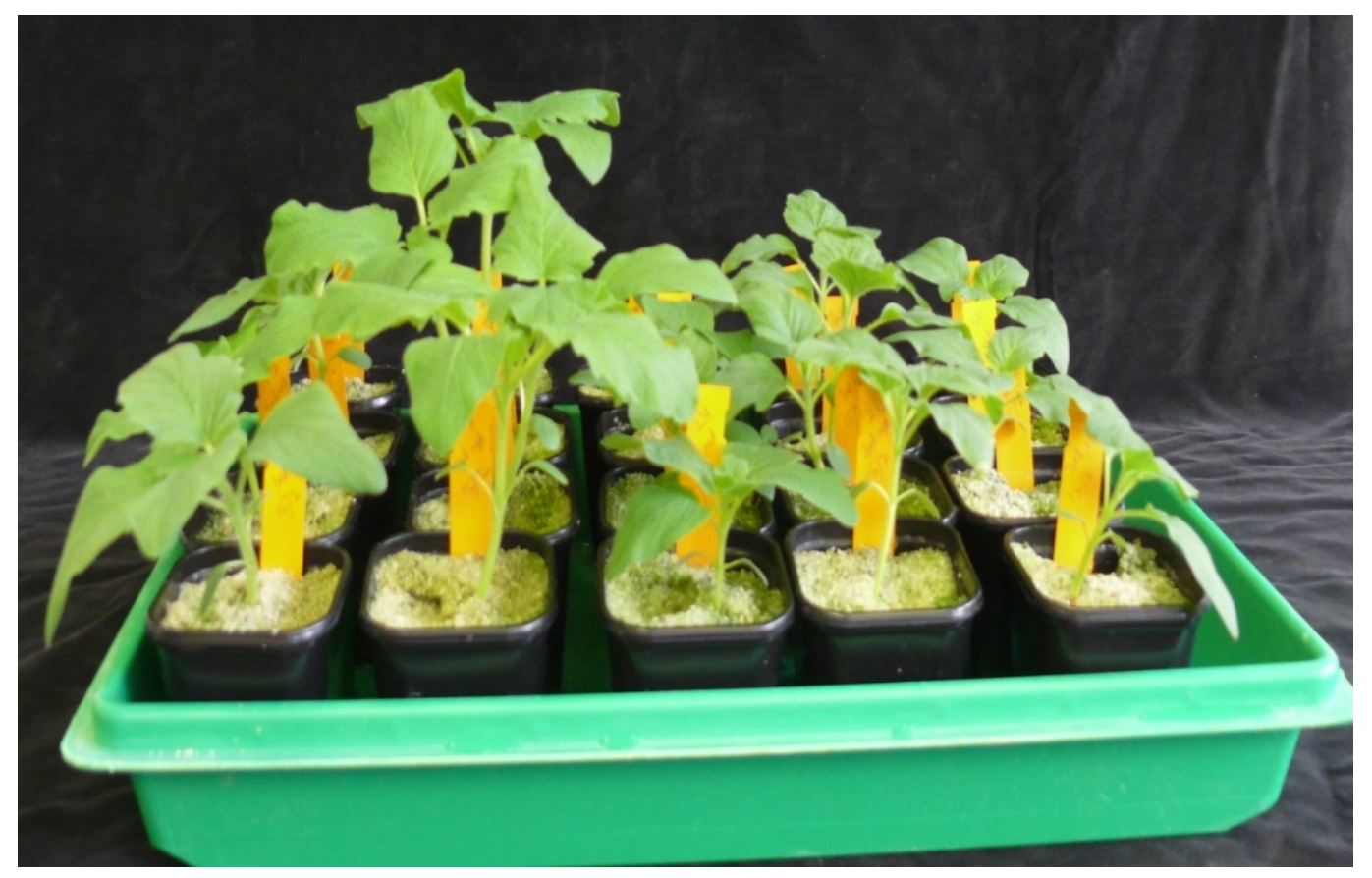

Figure 2. Growth of different sesame accessions in white sand.

Table 1. Accessions used for phytohormone analysis, collected by Hernana Laurentin from Centro Nacional de Investigaciones Agropecuarias (CENIAP) Germplasm Bank (Venezuela)

\begin{tabular}{|l|l|l|l|}
\hline Accessions & Country of Origin & \multicolumn{1}{|c|}{ Working code } & Diversity Center \\
\hline $93-2223$ & India & India 1 & India \\
\hline $95-469$ & India & India 3 & India \\
\hline $95-464$ & India & India 7 & India \\
\hline $92-3091$ & Korea & Korea 1 & China-Japan-Korea \\
\hline $92-2922$ & Turkey & Turkey & Western Asia \\
\hline $93-2022$ & Syria & Syria & Western Asia \\
\hline $92-310$ & Sudan & Sudan 2 & Africa \\
\hline $95-223$ & Unknown & Africa 3 & Africa \\
\hline $92-3030$ & Japan & Japan 2 & China-Japan-Korea \\
\hline $95-383$ & China & China 2 & China-Japan-Korea \\
\hline
\end{tabular}


Table 2. Commercial cultivars or elite lines from Venezuelan sesame breeding program used for phytohormone analysis.

\begin{tabular}{|l|l|}
\hline $\begin{array}{l}\text { Commercial cultivars } \\
\text { or experimental lines }\end{array}$ & \multicolumn{1}{|c|}{ Origin } \\
\hline Venezuela 51 & $\begin{array}{l}\text { Originated by individual selection from the offspring of a } \\
\text { Chinese accession (Langham and Rodriguez, 1946). }\end{array}$ \\
\hline UCV-1 & $\begin{array}{l}\text { Elite line selected from first cycle of recurrent selection } \\
\text { toward high yield. The original population was obtained by } \\
\text { cross, one to one, among } 50 \text { exotic accessions (Laurentin } \\
\text { et al., 2000). }\end{array}$ \\
\hline Maporal & $\begin{array}{l}\text { Selected from cultivar Arapatol, from Ethiopia (Mazzani et } \\
\text { al., } \\
1973)\end{array}$ \\
\hline Inamar & $\begin{array}{l}\text { Individual selection from the offspring from the same } \\
\text { Acarigua's parents (Mazzani, 1953). }\end{array}$ \\
\hline UCLA1 & $\begin{array}{l}\text { Individual selection from a USA accession (Montilla and } \\
\text { Teran, 1996). Unknown origin }\end{array}$ \\
\hline
\end{tabular}

\section{Quantification by HPLC-ESI-MS/MS}

Quantification of phytohormones in sesame was carried out on a Varian (Darmstadt, Germany) HPLC system equipped with a ProStar 210 binary pump system , a ProStar 430 autosampler and a reversed-phase column (Kinetex® C18, 50 x $2.1 \mathrm{~mm}$; core-shell particle

size $2.6 \mu \mathrm{m}$, mounted with a C18, $2 \mathrm{~mm}$ guard column, both from Phenomex Inc., Aschaffenburg, Germany). Samples of $10 \mu \mathrm{L}$ were injected and eluted at $40^{\circ} \mathrm{C}$ (column oven temperature) with a flow rate of $0.2 \mathrm{ml} \mathrm{min}^{-1}$ with the following solvents:

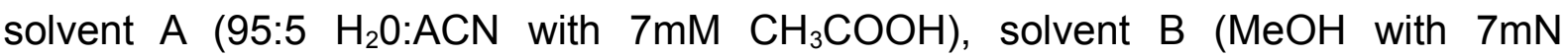
$\mathrm{CH}_{3} \mathrm{COOH}$ ). The elution program was $20 \%$ solvent $\mathrm{B}$ for $40 \mathrm{sec}$, followed by a ramp to $98 \%$ solvent B in $50 \mathrm{sec}$, with an additional $2 \mathrm{~min} 20 \mathrm{sec}$ at $98 \%$ solvent $\mathrm{B}$. The detector consisted of a triple quadruple mass spectrometer (1200LC Varian) equipped with an electrospray interface. Drying gas $\left(\mathrm{N}_{2}\right)$ pressure was set to $18 \mathrm{psi}$ and nebulizing gas (air) was set to $50 \mathrm{psi}$. Collision gas (argon) pressure was 1.4 mTorr. Voltage: $-4400 \mathrm{~V}$ (needle), $-600 \mathrm{~V}$ (shield) and $40 \mathrm{~V}$ (capillary). Detection of 
phytohormones in the mass spectrometer was performed as multiple reaction monitoring (MRM) using the following mass transitions IAA 173.9/130.0 (Collision energy [CE] 9.0 eV), JA 208.9/59.0 (9.5 eV); SA 136.8/93.0 (CE 14.5 eV); D6-SA 140.9/97.0 (18.5 eV); ABA 262.8/153.0 (8.0 eV); D6-ABA 268.9/159.0 (CE 9.0 eV); $\mathrm{GA}_{4} 331.0>213.0$ (CE $33.0 \mathrm{eV}$ ) and 331.0/243.0 (CE 18.5 eV). For the quantification of $A B A$ and $S A$, a calibration curve of the ratio of peak areas of unlabeled standards to peak area of deuterium-labelled standard was used. The other hormones were quantified using external standards calibration curves.

\section{Chitinase test}

Crude proteins were extracted from the homogenized (for phytohormone extraction) leaves and roots sample $(200 \mathrm{mg})$ with $1 \mathrm{ml}$ of $0.2 \mathrm{M}$ potassium phosphate buffer (PH 5). The homogenate were centrifuged, the upper phase was filtered and protein concentrations were determined by Bredford method. Equal quantities $(10 \mu \mathrm{g})$ were loaded on the gel containing glycol chitin as a substrate for the visualization of chitanase activity with the method developed by Zou et al. (2002). Gel pictures were recorded with transilluminator camera (Figure. 3 ) and later hydrolyzed chitin areas (cm) were measured with software program imageJ (http://rsb.info.nih.gov/nihimage).

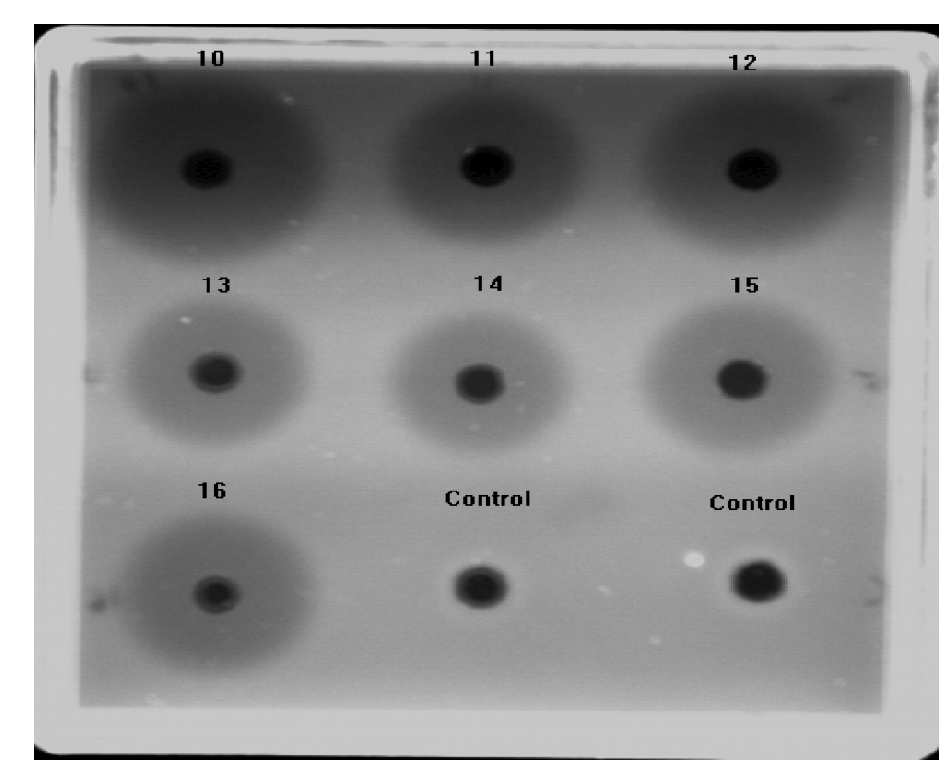

Figure 3. Gel-diffusion assays for chitinase activity in leave tissues of different sesame accessions. Wells from 10 to 16 contains $10 \mu \mathrm{L}$ of crude protein extract with potassium phosphate buffer and control well contained the incubation buffer 


\section{Amplified Fragment Length Polymorphism (AFLP)}

DNA was extracted from fresh sesame leaves by the using Qiagen $\mathrm{GmbH}$ kit (DNeasy) following the manufacturer's instruction. DNA concentration was determined on $2 \%$ agarose gel. AFLP was done with the method described by Vos et al. (1995) with folowing steps.

\section{Digesting genomic DNA}

Five microliter of genomic DNA (50 ng) was digested with $0.3 \mathrm{ul}$ of EcoRI (10 u/ $\mathrm{LL}$ ), $0.15 \mathrm{ul}$ of $\operatorname{Trul}(10 \mathrm{u} / \mu \mathrm{L})$ with $2 \mu \mathrm{L}$ of Tango buffer (10X) in 10ul of reaction mixture. The reaction was carried out via incubation for $1.5 \mathrm{~h}$ at $37^{\circ} \mathrm{C}$ in the climatic cupboard followed by $65^{\circ} \mathrm{C}$ for $1.5 \mathrm{hr}$.

\section{Ligation of adaptors}

Digested DNA was ligated with $0.05 \mu \mathrm{L}$ of EcoR1 adaptor $(25 \mathrm{u} \mu \mathrm{M})$ and $0.5 \mathrm{ul}$ of Mseadaptor $(25 \mu \mathrm{M})$ together with $0.25 \mu \mathrm{L}$ of Ligation buffer (10x) $0.05 \mu \mathrm{L}$ of T4 ligase (5 $\mathrm{u} / \mu \mathrm{L}$ ) and $1.65 \mu \mathrm{L}$ of $\mathrm{ddH}_{2} \mathrm{O}$ and incubation continued for $3 \mathrm{~h}$ at $37^{\circ} \mathrm{C}$. Then, the sample were 10 times after $3 \mathrm{~h}$ of ligation to be used in the pre-amplification process.

\section{Pre-amplification}

Pre amplification was done with $5 \mu \mathrm{L}$ of diluted ligation mixture with $5 \mu \mathrm{L}$ mixure of amplification products including $0.12 \mu \mathrm{L}$ of E-primer $(25 \mu \mathrm{M})[5$ '-GACTGCGTACC AATTCA-3'], $0.12 \mu \mathrm{L}$ of M-primer (25 $\mu \mathrm{M})$ [5'-GATGAGTCCTGAGTAAC-3'], $3.02 \mu \mathrm{L}$ of $\mathrm{ddH}_{2} \mathrm{O}, 0.5 \mu \mathrm{L}$ of $\mathrm{MgCl}_{2}(50 \mathrm{mM}), 1 \mu \mathrm{L}$ PCR buffer (10x), $0.2 \mu \mathrm{L}$ dNTP mix (10 mM) and 0.04 ul of Taq $(5 \mu \mathrm{L})$ with the PCR program [25 cycles: denaturation: $94^{\circ} \mathrm{C} 30$ sec, annealing: $56{ }^{\circ} \mathrm{C} \quad 1 \mathrm{~min}$, elongation: $72{ }^{\circ} \mathrm{C} 1 \mathrm{~min}$ ]. PCR samples were then diluted 10 times.

\section{Selective amplification}

Selective amplification was carried out with $2.5 \mu \mathrm{L}$ of diluted pre-amplified DNAtemplate with $7.5 \mu \mathrm{L}$ mixure of amplification products comprising $0.3 \mu \mathrm{L}$ of E-primer (20 uM) [EcoR1-AGC, EcoR1-ACC, EcoR1-ACA 3 nucleotide extension labelled with 
dye D680, D750, D635, respectively], $0.3 \mu \mathrm{L}$ of M-primer (20 uM) [ M-primer with CA 2 nucleotide extension], $5.66 \mu \mathrm{L}$ of $\mathrm{ddH}_{2} \mathrm{O}, 0.5 \mu \mathrm{L}$ of $\mathrm{MgCl}_{2}(50 \mathrm{mM}), 1 \mu \mathrm{L}$ PCR buffer (10x), $0.2 \mu \mathrm{L}$ dNTP $\operatorname{mix}(10 \mathrm{mM})$ and $0.08 \mu \mathrm{L}$ of Taq $(5 \mu / \mu \mathrm{L})$ with the PCR program [(denaturation: $94^{\circ} \mathrm{C} 30 \mathrm{sec}$, annealing: $65^{\circ} \mathrm{C}, 30 \mathrm{sec} / \mathrm{dt}-0.7^{\circ} \mathrm{C} / \mathrm{cycle}$, elongation: 72 ${ }^{\circ} \mathrm{C} 1 \mathrm{~min} 11$ cycles)( 30 cycles: denaturation: $94{ }^{\circ} \mathrm{C} 30 \mathrm{sec}$, annealing: $56{ }^{\circ} \mathrm{C} 1 \mathrm{~min}$, elongation: $\left.72{ }^{\circ} \mathrm{C} 1 \mathrm{~min}\right]$.

\section{Separation of DNA fragments}

Beckman Coulter CQ 8000 AFLP sequencer was used for fragment separation. A 2.5 $\mu \mathrm{L}$ of each amplification with $30 \mu \mathrm{L}$ of separation loading solution, $1 \mu \mathrm{L}$ of size standard (600) and one drop of mineral oil were loaded in the sample plate. Optimized Frag4-80 separation method was used.

\section{Analysis of AFLP data}

The binary data sets of AFLP were used to create a dendrogram by using an online dendogram constructing program [http://genomes.urv.es/UPGMA/] (Garcia-Vallve et al., 1999). For pairwise comparison of accession and cultivars similarity matrix were calculated by Jaccard coefficient and similarity coefficients were transformed into distance matrix. Cophenetic correlation coefficient (CP) was calculated and clustering were done using the Unweighted Pair Group Method with Arithmetic mean (UPGMA) algorithm using the same program.

\section{RESULTS}

To quantify the natural content of phytohormones in sesame 16 accessions were screened on the basis of polymorphism in AFLP and concentration of SA, SAG, JA, JAG and GA were recorded in four independent experiments. Accessions were monomorphic in the hormones contained but differ in their concentration. Differences in concentration were calculated based on one way ANOVA with all pairwise multiple comparison procedures (Tukey test) at $P<0.05$. For ABA and SA internal standards were used for the quantification of the absolute amount of hormone contained. Average ABA contained ranged from $1.46^{*} 10^{-3}$ to $7.11^{*} 10^{-4}$ and $2.10^{*} 10^{-3}$ to $8.28^{*} 10^{-4}$ 
$\mathrm{mg} / \mathrm{g}$ of root and leave tissues, respectively. The highest amount of ABA was found in UCLA1 $\left(1.46^{*} 10^{-3}\right.$ and $\left.2.10^{*} 10^{-3}\right)$ in both organs and lowest in Africa3 $\left(7.11^{*} 10^{-4}\right)$ and india1 $\left(8.28^{* 10^{-4}}\right)$ in case of roots and leaves, respectively, while other accessions indicated no statistical differences (Fig. 4A). The average JA ranged from $3.25^{*} 10^{-3}$ to $1.25^{*} 10^{-3}$ and $6.68^{*} 10^{-3}$ to $1.73^{*} 10^{-4} \mathrm{mg} / \mathrm{g}$ of roots and leaves, respectively. JA contained in roots showed no statistical differences but in leaves of Japan2 were ten times higher $\left(1.68^{*} 10^{-3} \mathrm{mg} / \mathrm{g}\right.$ of leaves) as compared to Africa3 $\left(1.73^{*} 10^{-4} \mathrm{mg} / \mathrm{g}\right.$ of leaves) (Fig. 4B). The average SA ranged from $6.04^{*} 10^{-1}$ to $1.50^{*} 10^{-1}$ and 2.96 to $1.83^{*} 10^{-1} \mathrm{mg} / \mathrm{g}$ of roots and leaves, respectively. The Highest SA was found in Japan2 $\left(6.04^{*} 10^{-1} \mathrm{mg} / \mathrm{g}\right.$ of roots) and India3 $\left(5.85^{*} 10^{-1} \mathrm{mg} / \mathrm{g}\right.$ of roots) and the lowest in Syria $\left(1.50^{*} 10^{-1} \mathrm{mg} / \mathrm{g}\right.$ of roots) while other accessions did not differ from each other except India3 and Syria in case of roots but in leaves of japan2 about 16 times higher $\left(2.96 \mathrm{mg} / \mathrm{g}\right.$ of leaves) as compared to Africa3 $\left(1.83^{*} 10^{-1} \mathrm{mg} / \mathrm{g}\right.$ of leaves) (Fig. 4C), Japan2 indicate significant difference with Sudan 2, UCV1 and Maporal, such high contained in Japan 2 seems to effect the primary metabolism reducing the height and size and yield of capsules (data not shown). Chitinase activity showed good correlation $\left(R^{2}=0.75\right)$ with $S A$ contained in leaves (Fig. 5). The levels of SA and $S A G$ in roots and leaves extracts correlated tightly $\left(R^{2}=0.63\right.$ and $R^{2}=0.72$ in roots and leaves respectively) (Fig. 6). SAG of japan2 roots was statistically different from Sudan and Maprol while other accessions and cultivars did not differ in SAG contained (Fig. 4D). GA4 was only detectable in leaves of all samples and the concentration found statistically the same in all samples (Fig. 4E).

Genetic distance among the accessions were calculated using AFLP, three EcoR1 with $A C A, A C C$, and $A G C$ nucleotide extension and one Msel primer with $C A$ nucleotide extension generated 137 polymorphic bands, cluster analysis were done using binary data (presence of fragment=1 and absence of fragment $=0$ ) revealed that Japan2 was the most variable accession in case of SA and JA contained and did not show large genetic distance in pair wise comparison with other accessions and cultivars ranging from $0.14 \%$ to $0.3 \%$ ( 0.14 with india 3 and 0.3 with UCLA 1$)$ (Table 3). Unrooted dendogram generated by UPGMA and Cophenetic Correlation Coefficient (CP) was 0.827 . 
To induce the phytohormone, different strategies were employed in two independent experiments. Consistently greater concentration of SA was found in the treatment sprayed with $2 \mathrm{mM} \mathrm{CuCl} 2$ solution. About 3 (1.423 mg/g of leaves), $16(0.772 \mathrm{mg} / \mathrm{g}$ of stems) and 22 fold $(0.7509 \mathrm{mg} / \mathrm{g}$ of roots) higher SA were recorded in the leaves, stems and roots, respectively as compared to control plants $(0.428,0.045$ and 0.034 $\mathrm{mg} / \mathrm{g}$ of leaves, stems and roots, respectively). In the case of the other treatments inoculation with Macrophomina phaseolina and exposing the plants to UV; differences in concentration as compared to the control were not so obvious. Because we have two replications and we could not analyze the result statistically.In all treatments (UV, M. phaseolina ABA contained found decreased consistently in leaves, stems and roots about half in all the treatment (UV, M. phaseolina and $\mathrm{CuCl}_{2}$ ) while the change in JA concentration could not be detected (Table 4).

To quantify the effect of circadian clock on the internal concentration of phytohormones ABA, JA, IAA, SA and SAG were quantified. Samples were collected (leaves, stems and roots) at eight intervals of three hours during $24 \mathrm{hr}$ and with sample combined from four biological replicates (sesame plants were grown under same conditions). No diurnal variation in phytohormon concentration based on one way ANOVA with all pairwise multiple comparisons (Tukey Test) at $p<0.05$. Consistent results were found for leaves, stem and roots (Fig. 8). IAA contained in leaves and JA in roots remained below the detection limit at different time points (Fig. $9 A$ and $9 B$ ). Since there was no statistical difference between each time point, we pooled the data for each hormone irrespective of time. We found variation in different phytohormones level in leaves, stems and roots different parts (Fig. 10). ABA and JA concentrations were higher in stems as compared to roots and leaves $(p<0.05)$. However, IAA concentration was higher in stems than roots and leaves $(p<0.05)$. In the case of SA, stems, roots and leaves does not significantly vary while SAG was significantly lower in roots than stems and leaves $(p<0.05)$ 


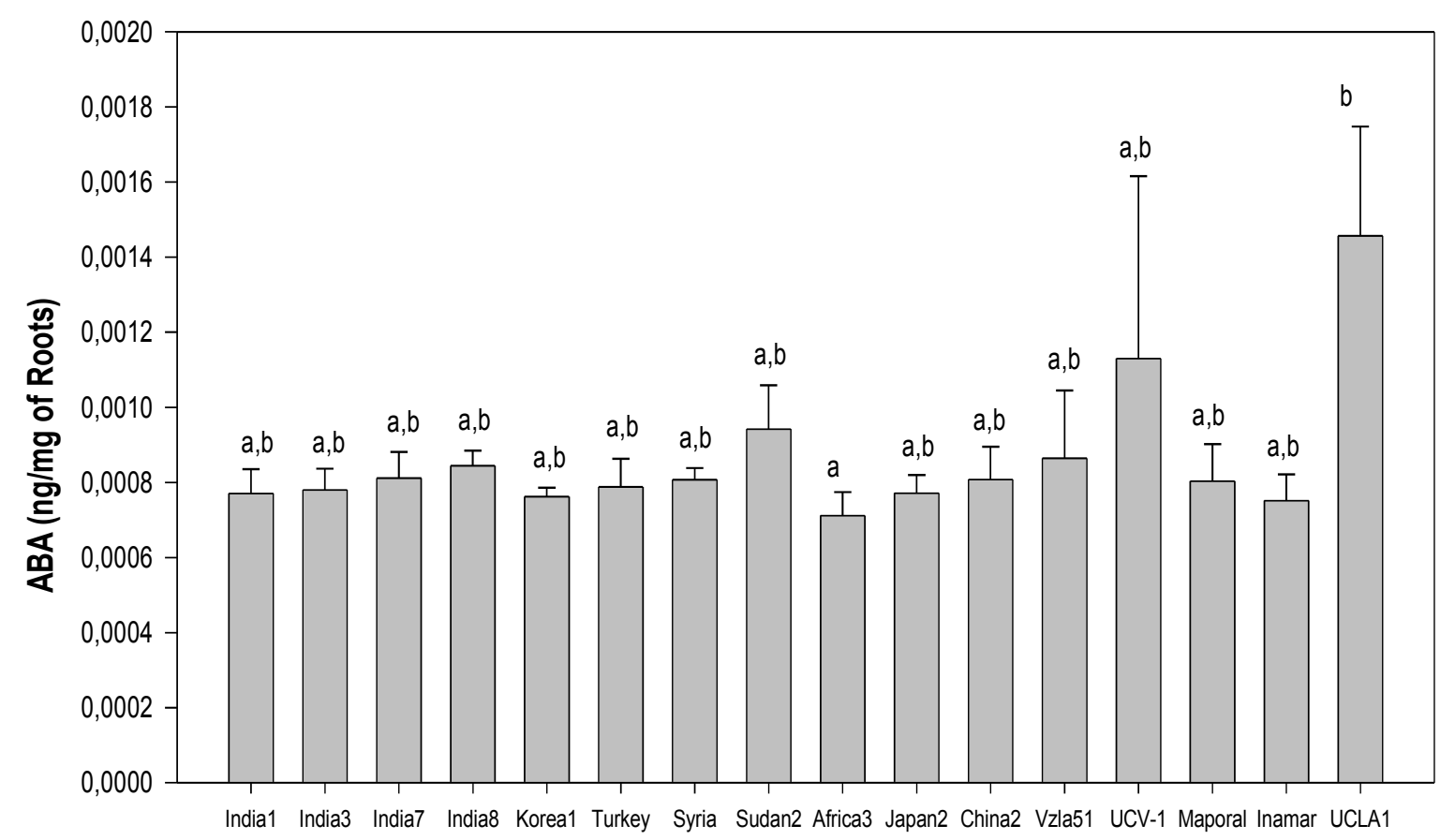

Accessions name

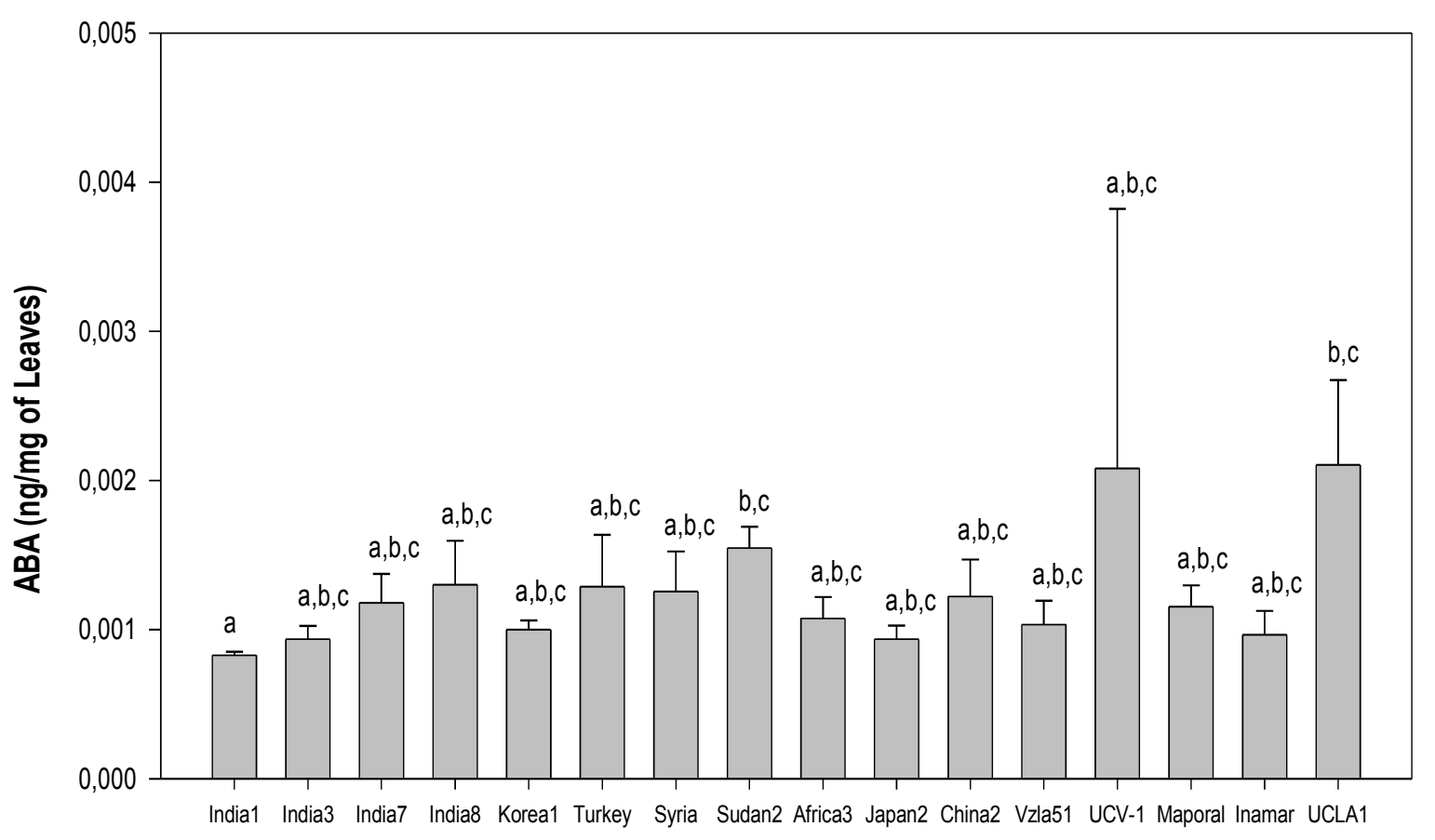

Figure 4A

\section{Accessions name}



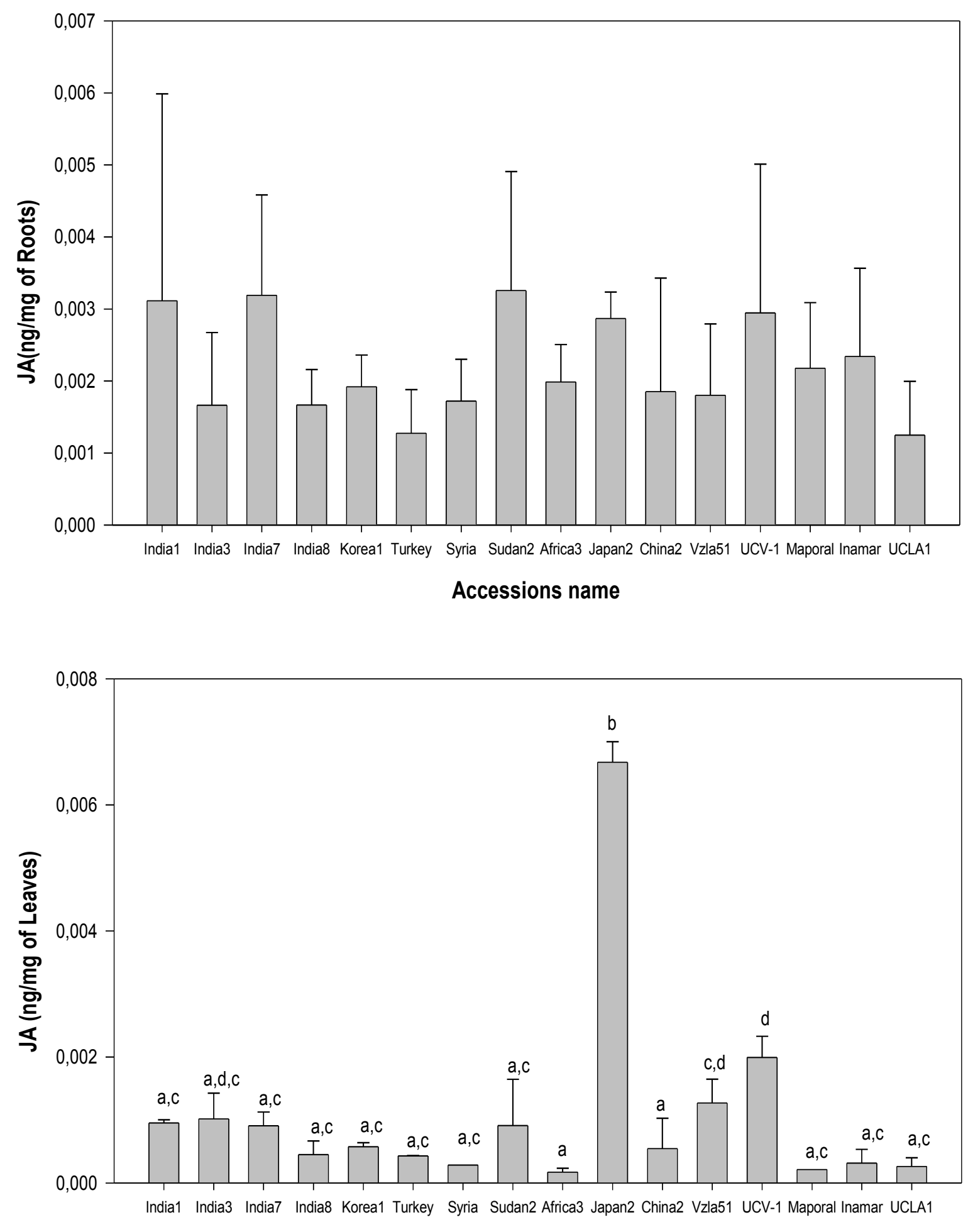

Accessions name

Figure 4B 


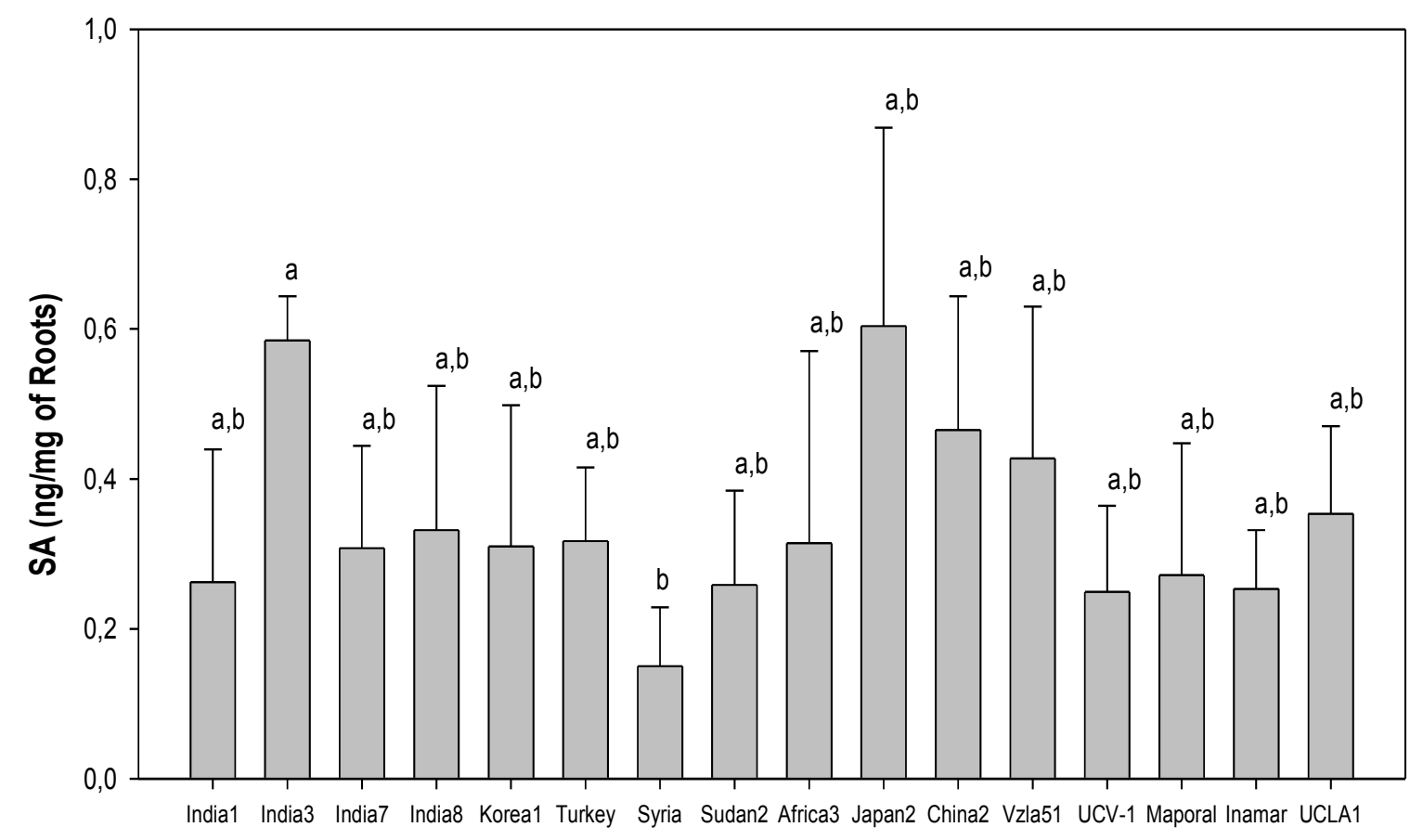

Accessions name

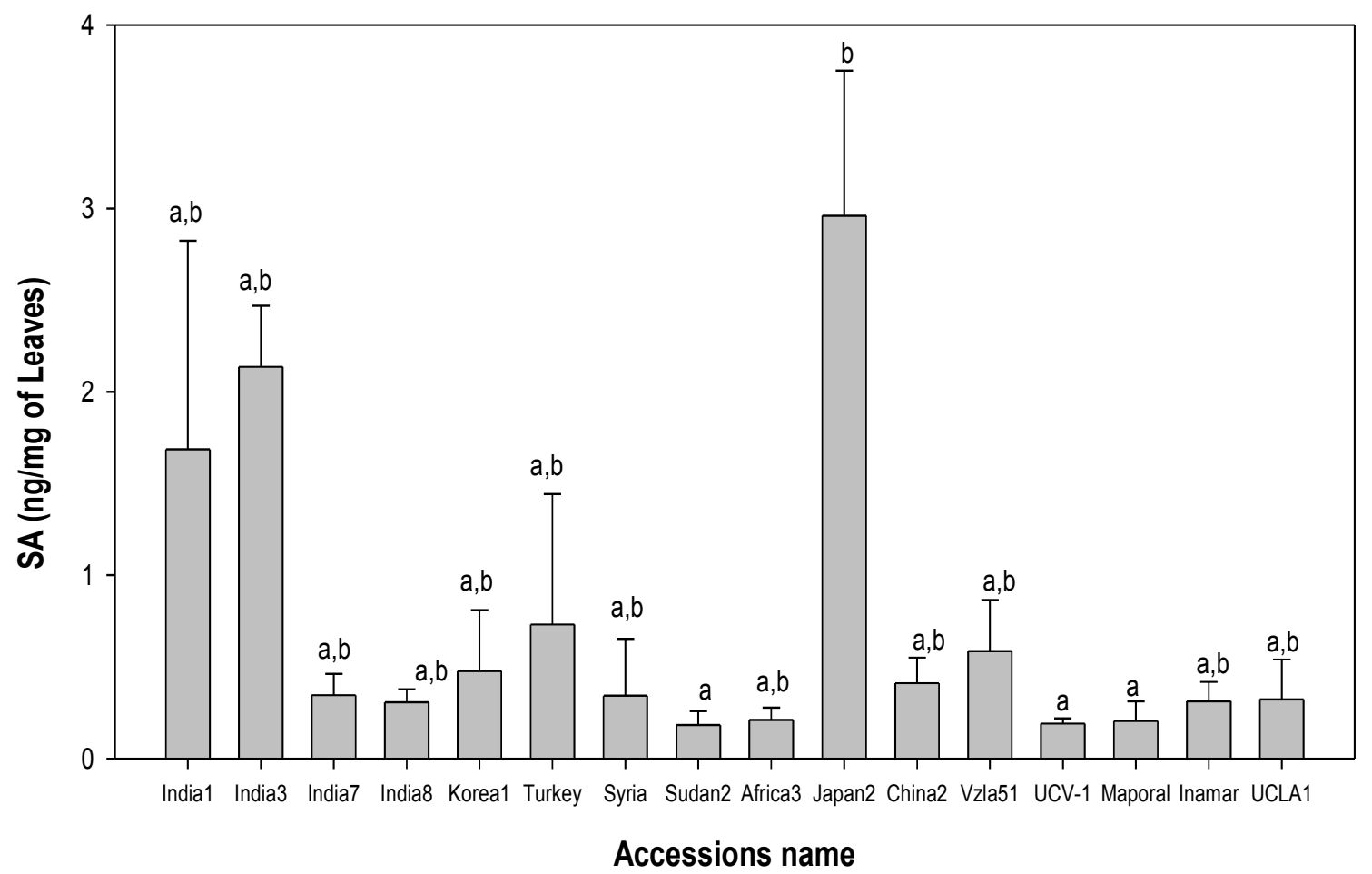

Figure 4C. 


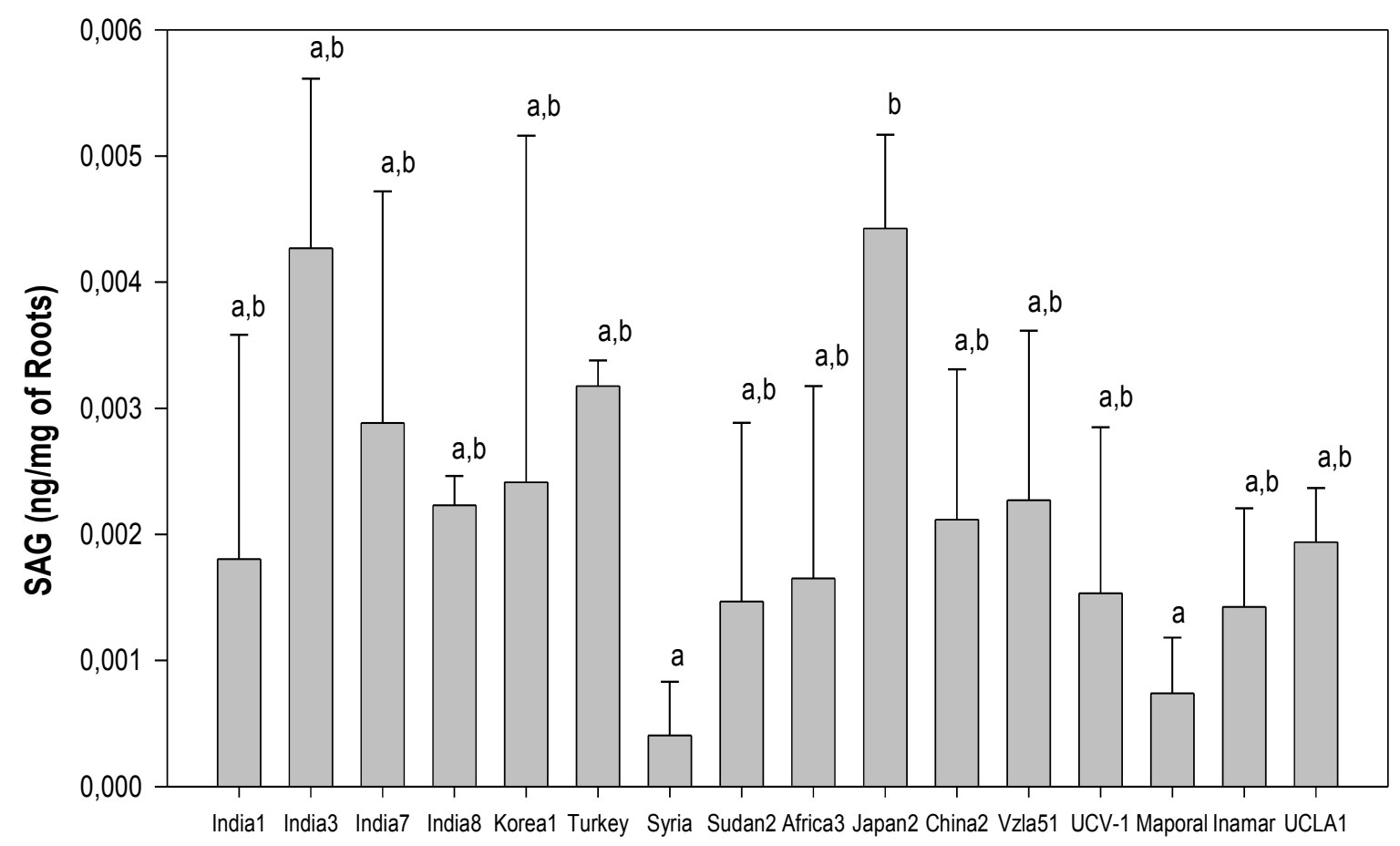

Accessions name

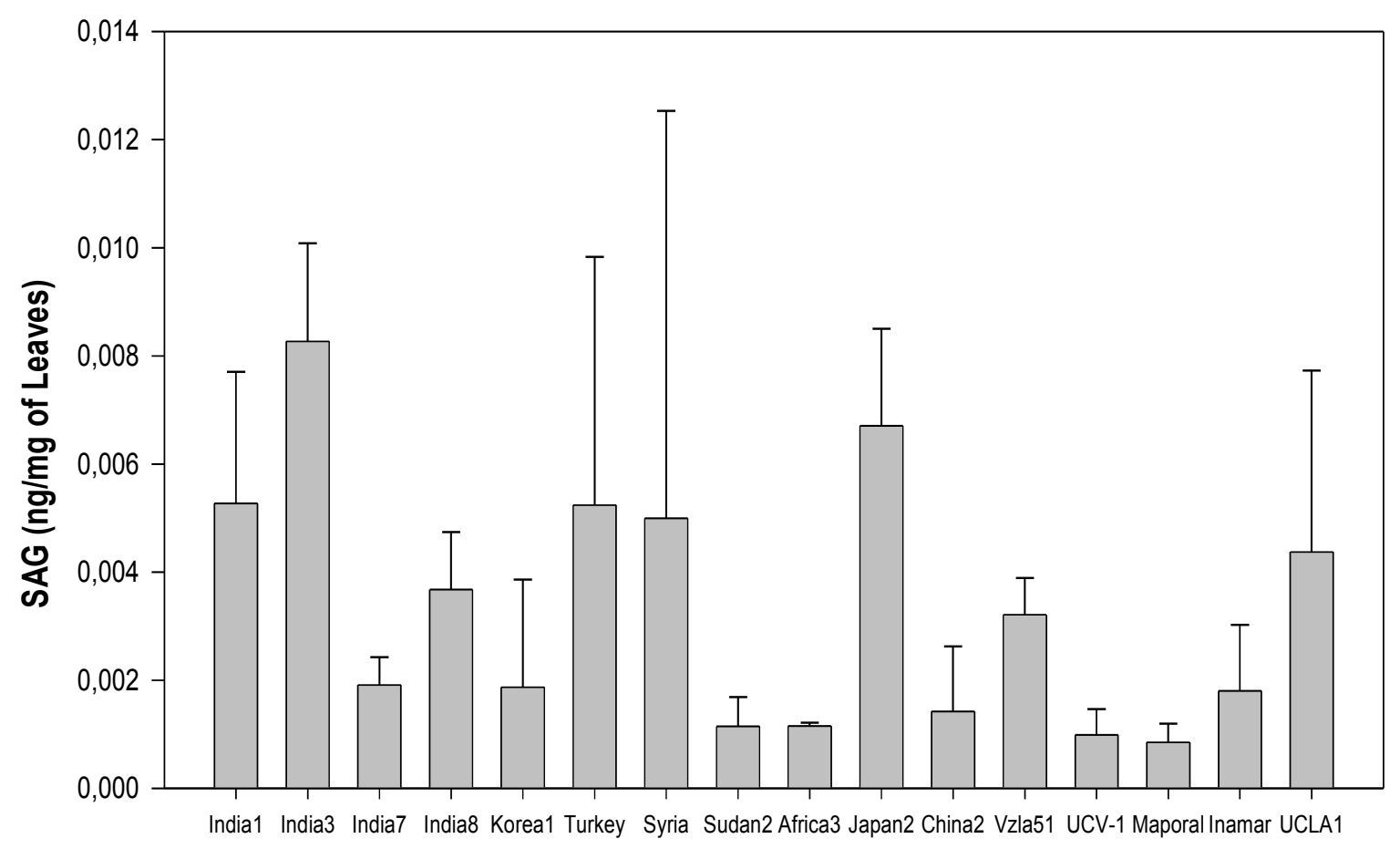

Accessions name

Figure 4D. 


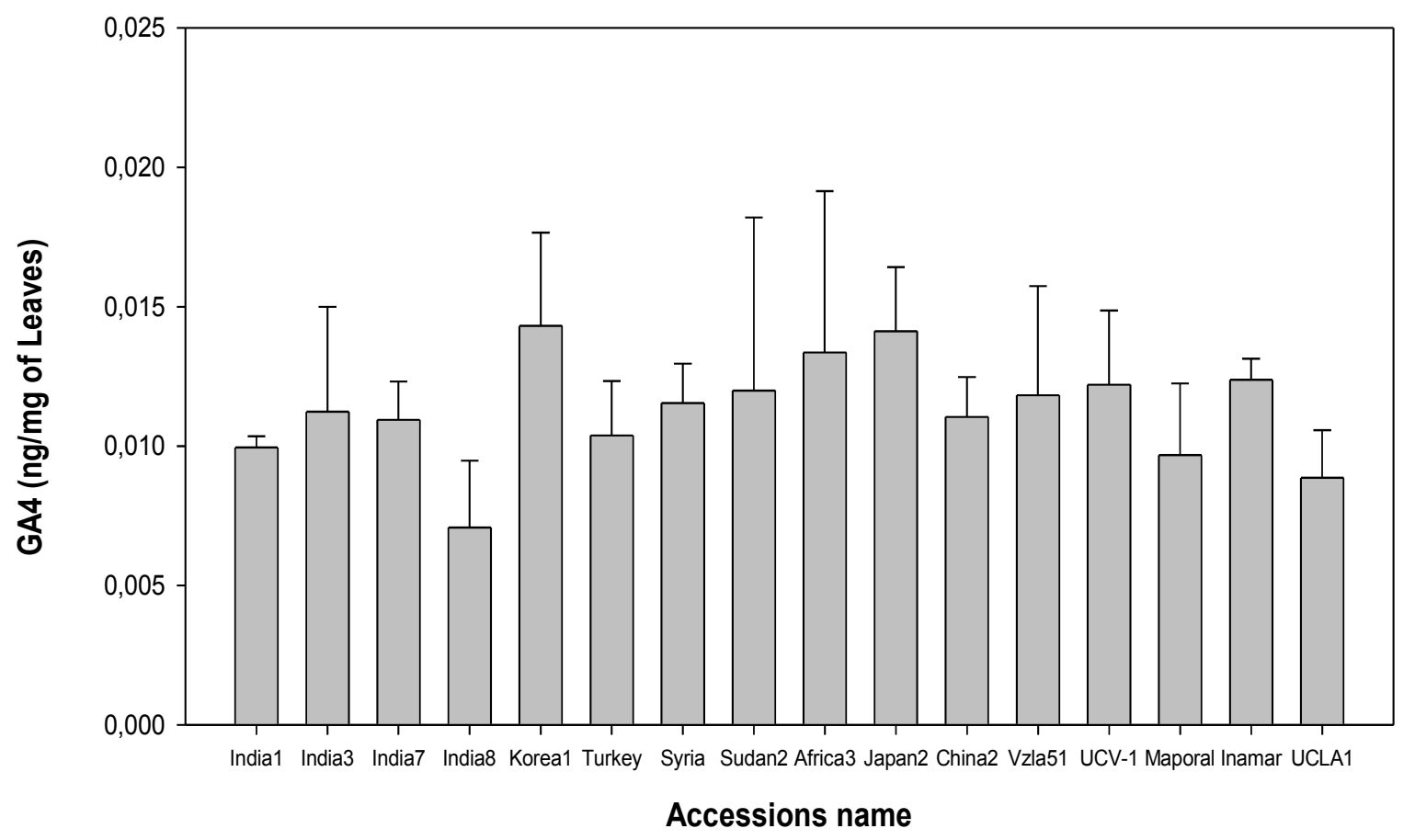

Figure 4E.

Figure 4. Diversity in concentration of (4A) ABA, (4B) SA, (4C) JA, (4D) SAG and (4E) GA4 in leaves and roots of different accession. Each bar represents the average of 4 independent replications (each replication is a sample combined from 4 plants) with error bars indicating standard deviation. Accessions bars with the same or no letter indicate no differences based on One Way ANOVA with all pairwise multiple comparison procedures (Tukey Test) at .( $P<0,05)$. 


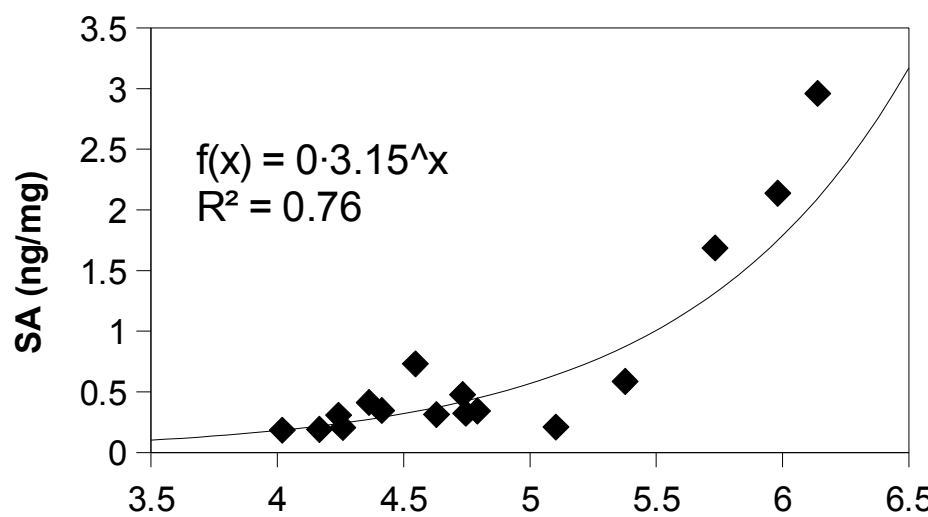

Chitinase hydrolized zone (cm2)

Figure 5. Correlation between SA concentration and hydrolyzed area of substrate by chitinase enzyme present in leaves tissues of 16 different sesame accessions and cultivars

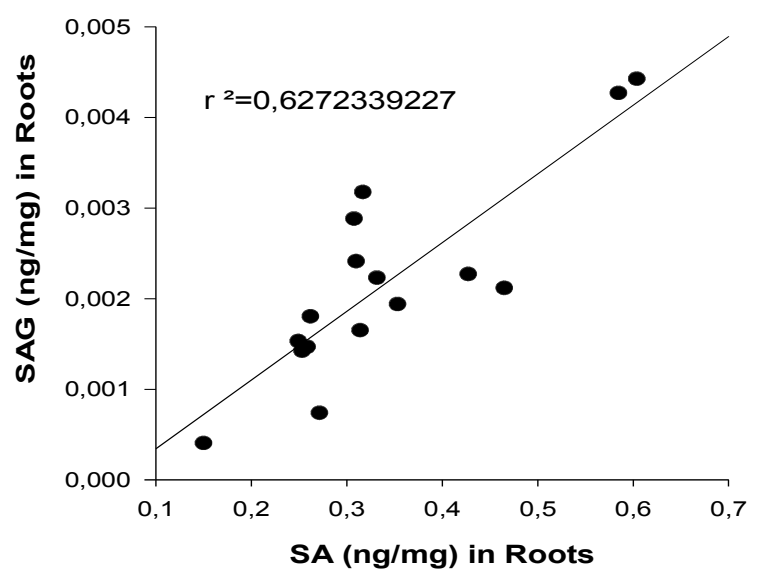

Fig. $6 \mathrm{~A}$

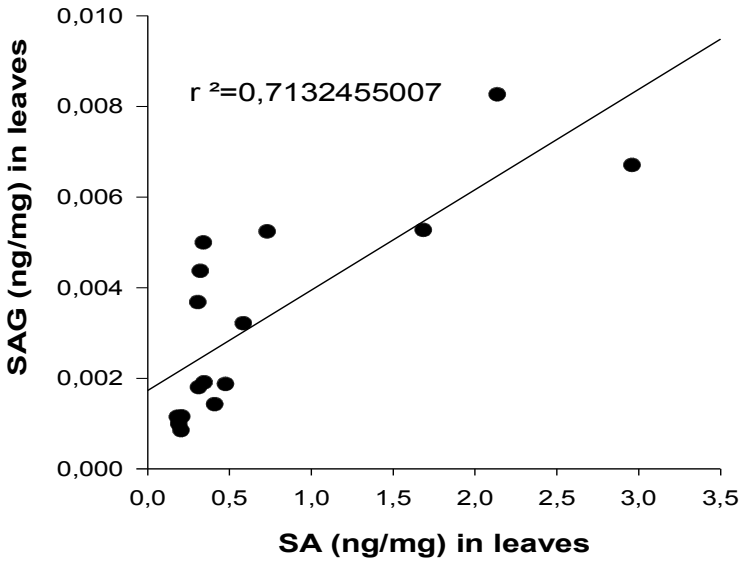

Fig. 6B

Fig. 6. Correlation between the concentration of $S A G$ and $S A(A)$ roots and $(B)$ leaves tissues of 16 different sesame accessions and cultivars 
Table: 3. AFLP distance matrix of 16 sesame accession and cultivars based on Jaccard coefficient calculated by using the online program [http://genomes.urv.es/UPGMA/] by using the binary data.

\begin{tabular}{|c|c|c|c|c|c|c|c|c|c|c|c|c|c|c|c|c|}
\hline & India1 & India3 & India7 & India8 & Korea1 & Turkey & Syria & Sudan2 & Africa3 & Japan2 & China2 & Vzla51 & UCV1 & Maporal & Inamar & UCLA1 \\
\hline India1 & 0 & 0,221 & 0,271 & 0,285 & 0,322 & 0,269 & 0,263 & 0,256 & 0,246 & 0,242 & 0,278 & 0,292 & 0,248 & 0,286 & 0,27 & 0,275 \\
\hline India3 & & 0 & 0,228 & 0,244 & 0,245 & 0,192 & 0,221 & 0,197 & 0,203 & 0,139 & 0,271 & 0,243 & 0,196 & 0,227 & 0,236 & 0,293 \\
\hline India7 & & & 0 & 0,204 & 0,203 & 0,197 & 0,209 & 0,193 & 0,159 & 0,25 & 0,225 & 0,203 & 0,182 & 0,186 & 0,186 & 0,241 \\
\hline India8 & & & & 0 & 0,259 & 0,185 & 0,177 & 0,181 & 0,187 & 0,239 & 0,174 & 0,132 & 0,18 & 0,144 & 0,144 & 0,201 \\
\hline Korea1 & & & & & 0 & 0,223 & 0,245 & 0,218 & 0,196 & 0,249 & 0,251 & 0,249 & 0,246 & 0,212 & 0,212 & 0,33 \\
\hline Turkey & & & & & & 0 & 0,151 & 0,184 & 0,141 & 0,197 & 0,186 & 0,165 & 0,153 & 0,205 & 0,176 & 0,231 \\
\hline Syria & & & & & & & 0 & 0,204 & 0,142 & 0,268 & 0,168 & 0,157 & 0,175 & 0,188 & 0,138 & 0,242 \\
\hline Sudan2 & & & & & & & & 0 & 0,167 & 0,219 & 0,219 & 0,171 & 0,169 & 0,182 & 0,192 & 0,244 \\
\hline Africa3 & & & & & & & & & 0 & 0,234 & 0,198 & 0,205 & 0,145 & 0,178 & 0,138 & 0,224 \\
\hline Japan2 & & & & & & & & & & 0 & 0,257 & 0,246 & 0,236 & 0,249 & 0,257 & 0,304 \\
\hline China2 & & & & & & & & & & & 0 & 0,193 & 0,228 & 0,195 & 0,175 & 0,221 \\
\hline Vzla51 & & & & & & & & & & & & 0 & 0,188 & 0,133 & 0,163 & 0,219 \\
\hline UCV1 & & & & & & & & & & & & & 0 & 0,19 & 0,171 & 0,207 \\
\hline Maporal & & & & & & & & & & & & & & 0 & 0,165 & 0,23 \\
\hline Inamar & & & & & & & & & & & & & & & 0 & 0,173 \\
\hline UCLA1 & & & & & & & & & & & & & & & & 0 \\
\hline
\end{tabular}

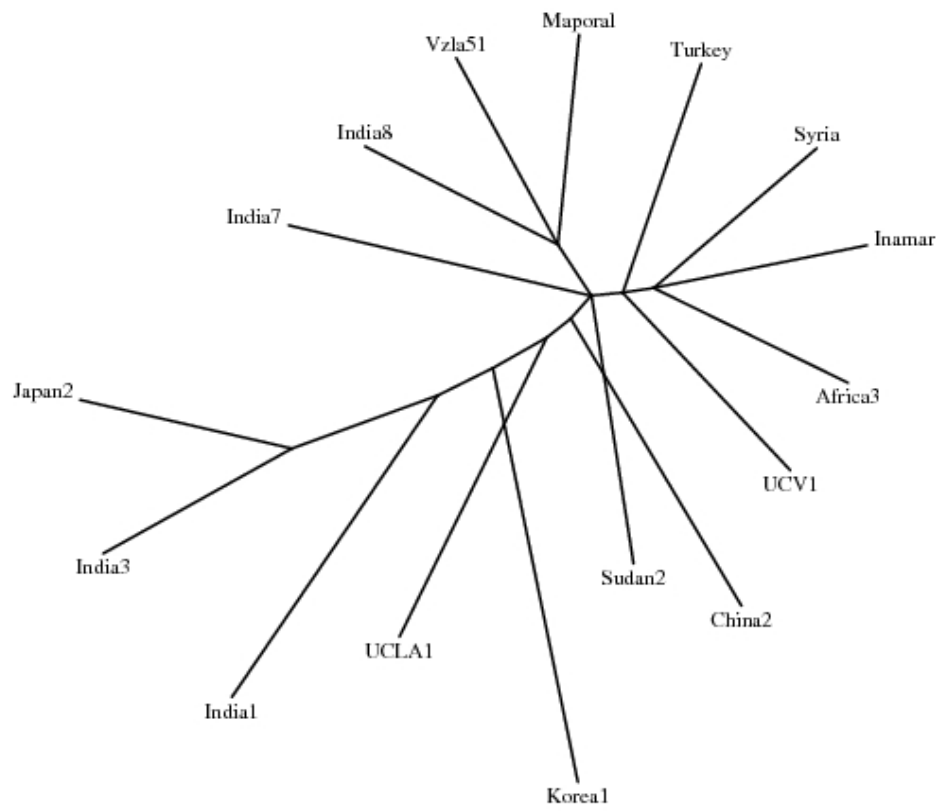

Fig. 7. Unrooted dendogram generated by UPGMA by using the online program [http://genomes.urv.es/UPGMA/] dendogram was recorded with phylowidget [http://genomes.urv.es/cgi-bin/UPGMAboot_v4.cgi] Cophenetic Correlation Coefficient $(\mathrm{CP})=0.827$ 
Table: 4. Effect of UV, Macrophomina phaseolina inoculation, and $2 \mathrm{mM} \mathrm{CuCl}_{2}$ spray on the concentration of SA, ABA and JA ( $\mathrm{ng} / \mathrm{mg}$ ) in leaves, stems and roots. Each figure is the average of two replications with 9 plants each.

Salicylic acid

$\begin{array}{lccc}\text { Treatments } & \text { leaves } & \text { Stems } & \text { Roots } \\ \text { Control } & 0.429 & 0.046 & 0.034 \\ \text { UV } & 0.251 & 0.085 & 0.068 \\ \text { M.phaseolina } & 0.369 & 0.033 & 0.010 \\ \text { CuCl2 } & 1.423 & 0.772 & 0.751\end{array}$

Abscisic acid

$\begin{array}{llll}\text { Control } & 0.088 & 0.210 & 0.041 \\ \text { UV } & 0.048 & 0.107 & 0.024 \\ \text { M.phaseolina } & 0.029 & 0.029 & 0.009 \\ \text { CuCl2 } & 0.037 & 0.048 & 0.028\end{array}$

Jasmonic acid

$\begin{array}{llll}\text { Control } & 0.032 & 0.029 & 0.033 \\ \text { UV } & 0.036 & 0.046 & 0.035 \\ \text { M.phaseolina } & 0.021 & 0.068 & 0.030 \\ \text { CuCl2 } & 0.044 & 0.019 & 0.033\end{array}$



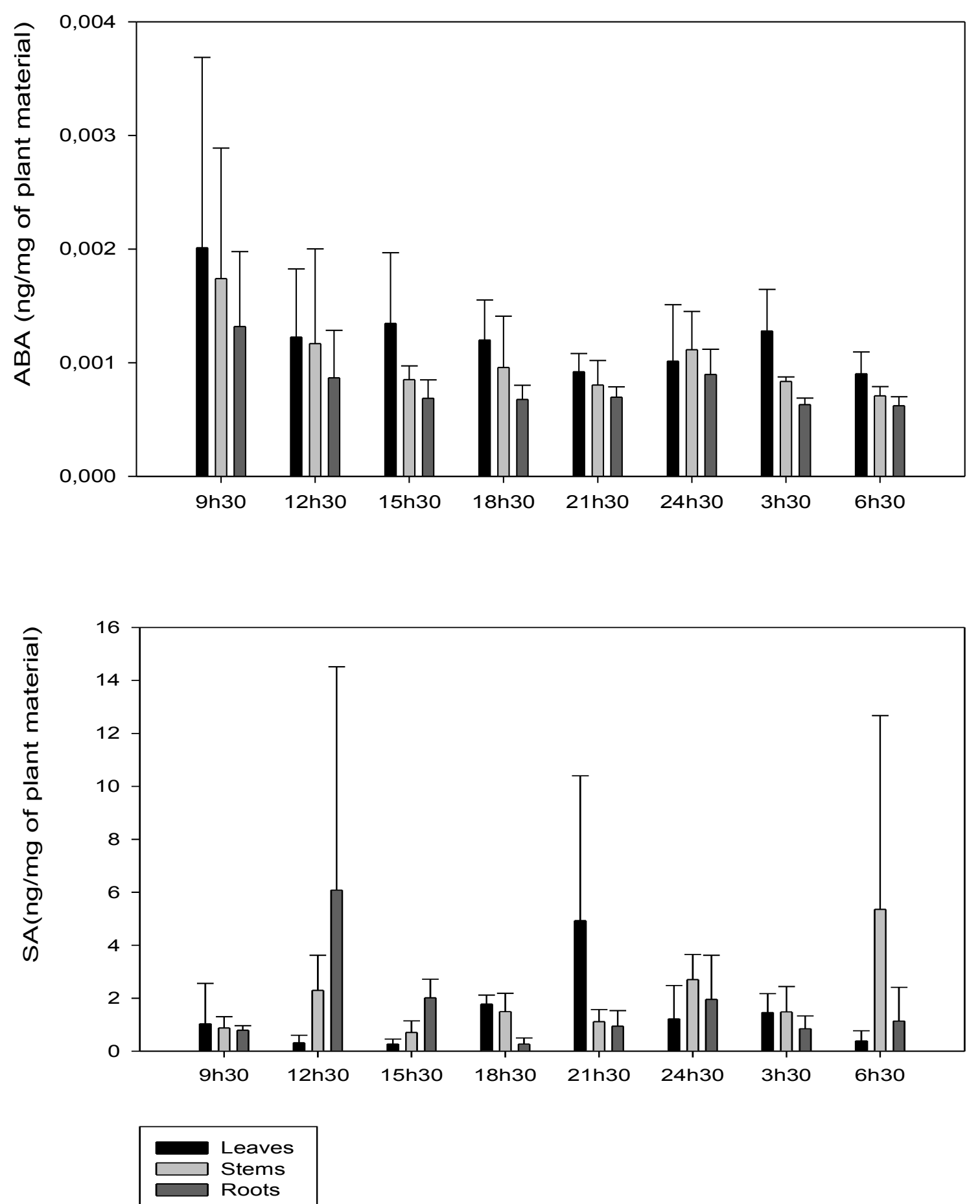

Figure 8. Concentrations of $A B A$ and $S A$ in leaves, stems and roots during eight different time point of a day. Each bar represents an average of 3 replications (each replication is pooled from 4 plants). Error bars indicate standard deviation 

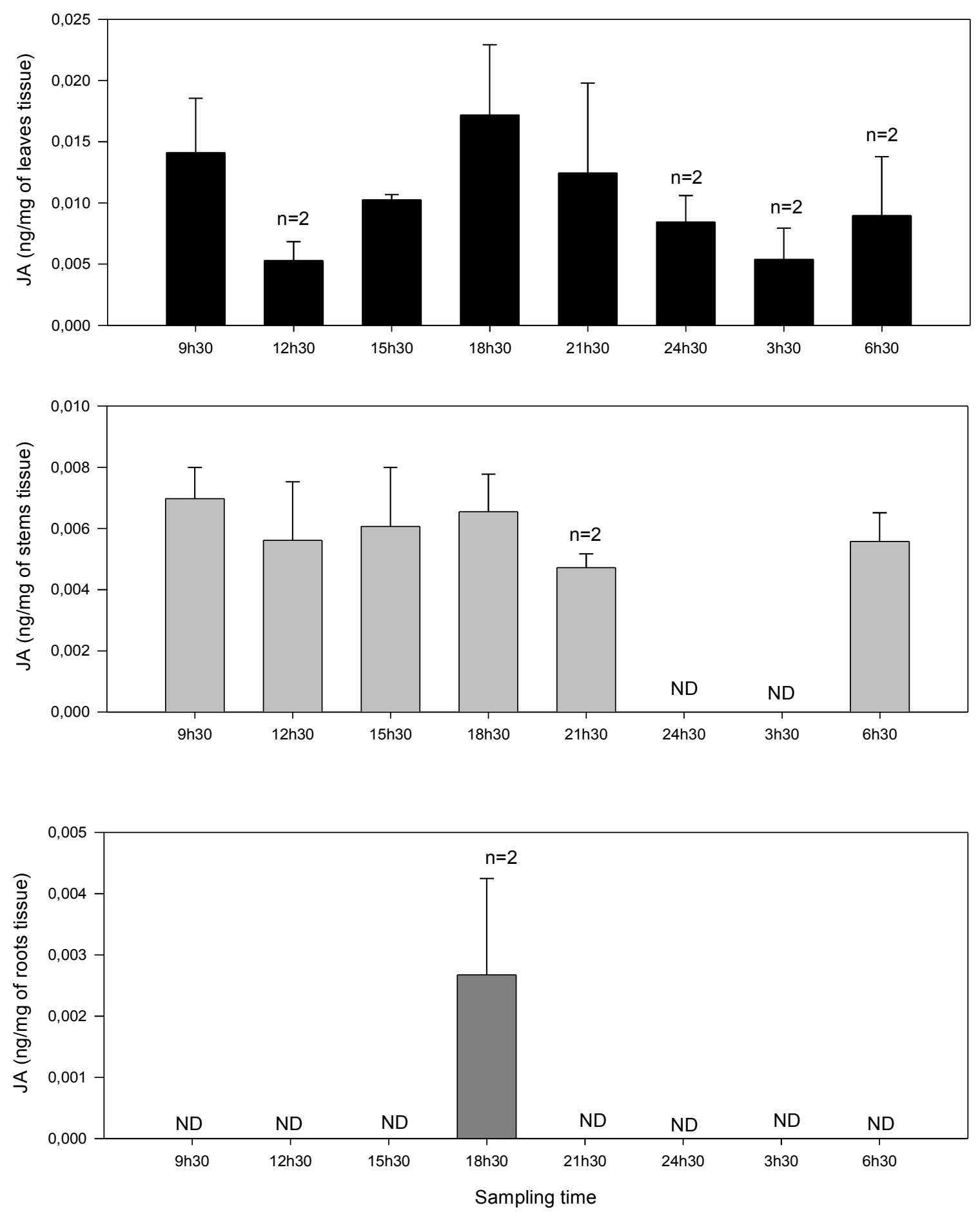

Figure 9A. 

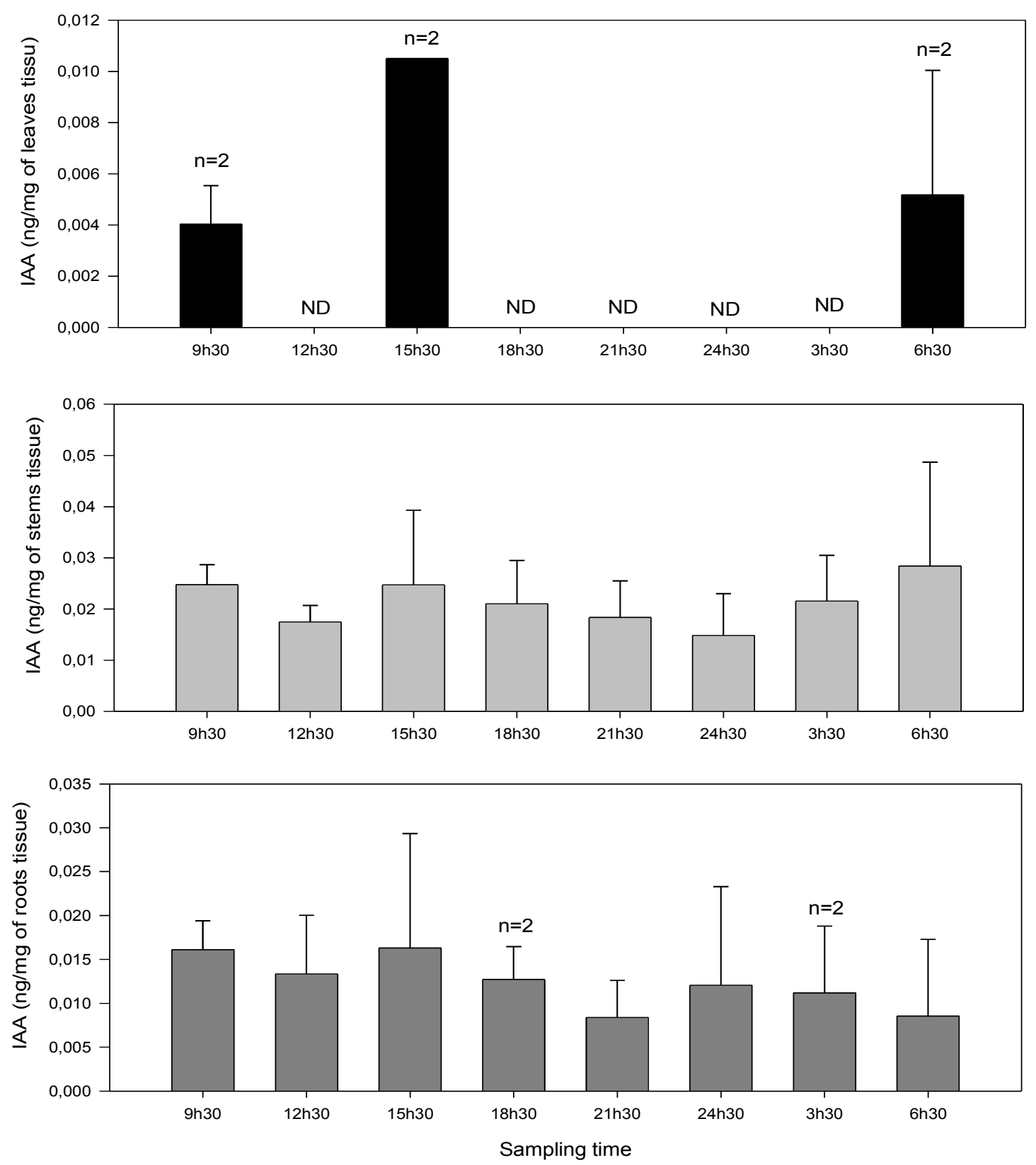

Figure 9B.

Figure 9. Concentrations of (9A) JA and (9B) IAA in leaves stem and roots sampled at eight time throughout the day. Each bar represents an average of $n$ replications ( $n$ numbers are specified in each bars) and each replication is pooled from 4 plants. Error bars indicate standard deviation. Data are not significantly different based on One Way ANOVA with Multiple Comparison Procedures at $(P \leq 0.05)$ ${ }^{*} \mathrm{ND}=$ concentration was below the limit of detection of HPLC 

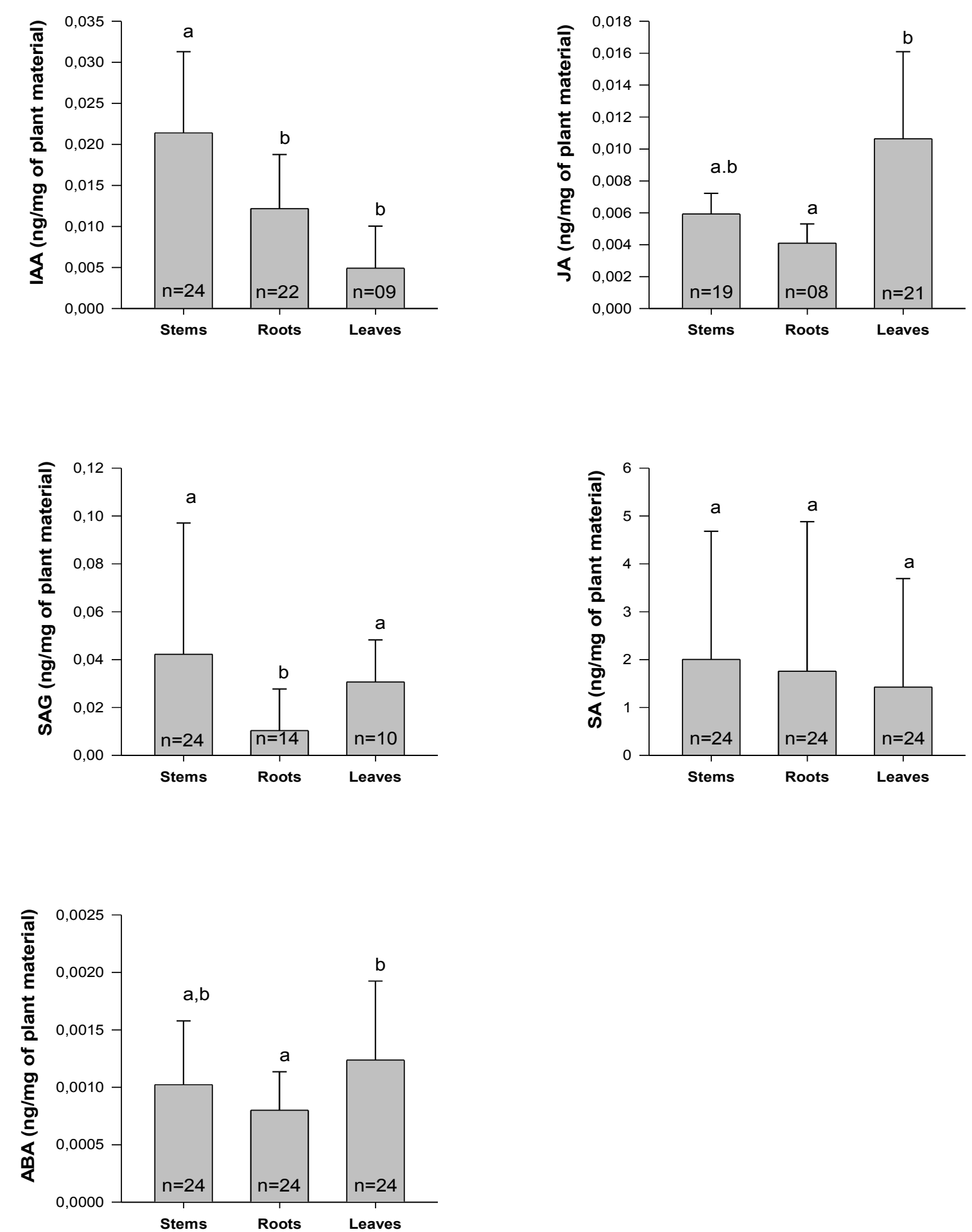

Figure 10. Concentration of $I A A, A B A$ and JA in different parts each data point represents an average hormone concentration of $n$ samples ( $n$ numbers are specified in each bar). Error bars indicate standard deviation. Data are significantly different based on One Way ANOVA with Multiple Comparison Procedures at $(P \leq 0.05)$ 


\section{DISCUSSION}

\section{Diversity of hormones level}

Phytohormones contained in leaves, stems and roots of selected sesame accessions and cultivars were analyzed. Most accessions showed similar hormones contained but, surprisingly, one accession originating from Japan content extraordinarily high amounts of salicylic acid (SA) and jasmonic acid (JA) the most variable hormone among accessions. SA and are hormones involved in plant defence against fungal accessio and against herbivores. These hormones involved in the reaction of plant to herbivore attack and fungal infection. Jasmonic acid also play important role in plant development and formation of storage organ (Ravinkar et al., 1993: Chung et al., 2009).

Elevated production of SA and JA in our sesame accessions seems to negatively affect the fitness of plant and these plants were shorter in height, produced smaller capsules as well as lower number of capsules then the other accession having lower SA and JA size and produces significantly low yield. The plant heights at the time of phytohormone analysis (27 days after seeding) were not significantly different among accession but massive decrease observed at the time of maturity. At early developmental stages, petal growth depends on cell division while on later stages it depends on cell proliferation (Symth et al., 1990). Florian et al. (2009) reported that a regulatory pathway involving jasmonate controls late developmental stages of petal growth in Arabidopsis thaliana Opr3 mutant, which are defective in an enzyme involved in synthesis of jasmonate. Mutations in genes involved in hormonal pathway production affect multiple traits (Poorter et al., 2005). Jasmonic acid is reported to enhance the number of shoot and bulb development of garlic (Allium sativum)and increased JA concentrations inhibition the development of terminal bud leaves and root with increasing JA concentration( Ravinkar et al., 1993). GA-deficient mutant plants are usually dwarf, dark-green, defective in leaf expansion, stem elongation, seed germination, altered floral initiation time, and are impaired in development of flower, fruit, and seed (Thomas and Sun, 2004). The least variable hormone in revealed significant differences between the cultivars. Good correlations were found between SA and SAG. This observation is agrement with Ratziger (2008) who 
reported a copmparable correlation between SA and SAG in oil seed rape Brassica napus Fiehn et al. (2003) reported that even metabolites belonging to different metabolic pathways closely co-regulated and cluster together and found strong correlation for glucose-6-phosphate and fructose-6-phosphate.

\section{Chitinase}

Chitinases, enzymes produced by a large number of organisms, play an important role in defense mechanisms of plants against chitin bearing organisms such as fungi by catalyzing the hydrolysis of $\beta-1,4 \mathrm{~N}$-acetylglucose amine linkage of chitin polymers present in their structure (Bol and Linthorst, 1990;, Cohen-Kupiec and Chet, 1998). Most purified plant chitinases have lysozyme activity and some are active in hydrolyzing the bacterial peptidoglycan bilayer (Boller, 1988), in inhibition of hyphal growth (Leah et al., 1991), and may be releasing signal molecules (ß-glucans and chitin/chitosan oligomers) that activate defense genes (Keen and Yoshikawa, 1983).

Treatment with exogenous salicylic acid induces pathogen related gene expression together with parallel rise in endogenous levels of salicylic acid in tobacco mosaic virus resistant plants (Jocelyn et al., 1990). Activation in SA or JA dependent pathways are correlated with the induction of pathogenesis related genes (Takahashi et al., 2004), Induction in acquired resistant and PRs is often accomplished by exogenously applied SA (Van Loon 1997).

A part of diseased plant PR protein also found in healthy plants and can be induced by various conditions for example, during natural senescence, plasmolysis, UV, wounding, ozone, artificially by the application of certain chemicals including high concentration of plant hormones, culture filtrates from pathogenic fungus or bacterium (Van Loon 1985 and 1997). Genes encoding these enzymes are the interesting features for improving disease resistance and have been exploited in a number of transgenic plants. This finding opens exciting perspectives for the use of these accessions in resistant breeding program against chitin-containing phytopathogens and in understanding the mechanism of gene regulation. 


\section{Inducibility of phytohormone}

It is recognized that local events in the region of physical injury or pathogen invasion trigger systemic events that lead to rapid and massive amplification in the response throughout the entire organ. Accumulation of defense related products may be locally and systemically distributed (Bowles, 1990). SA concentration was reported to increase when plants are subjected to biotic and abiotic stresses biotic or abiotic. In our accession "UCLA1" we could measure a considerably high concentrations of SA in the samples treated with $\mathrm{CuCl}_{2}$. In our result we found specific symptoms the following day after spray of $\mathrm{CuCl}_{2}$ and similar results were reported by Eliasova et al. (2004), which included moderate fading, rolling of leaves and leaf segments, followed by sparse dot necroses of the tissues directly affected by the aerosol drops. Malamy $\mathrm{J}$ excluding the wounding or tissue death in rise of salicylic acid induction in tobacco mosaic virus resistant plants as, no endogenous salicylic acid was detected in physically injured leaves (Jocelyn et al. 1990 ). Exposure to heavy metal causes growth inhibition and reduction in biomass (Woolhouse, 1983), increased endogenous level of growth inhibitory phytohormone ABA (Hollenbach et al., 1997). Excess $\mathrm{Cu}$ causes reduction in fresh and dry weight of roots, stems and leaves (ElTayeb et al., 2006). Cu is reported to inhibit photosystems through oxidative stress (Yruela et al., 1996), lipid peroxidation (Mazhoudi et al., 1997; El-Tayeb et al., 2006). $\mathrm{CuCl}_{2}$ some how acts as endogenous signal triggering the synthesis of SA locally and systemically. Our preliminary experiment suggests that more studies could be done to explain effect of $\mathrm{CuCl}_{2}$ in production of high amount of SA.

\section{Diurnal variation of hormones}

Circadian clock is known to control various biological processes and have been reported to influence the branches i-e proteomic, metabolomic, transcriptiomic. Integration or correlation among level of highly interdependent biomolecular organization is problematic due to fact of different time scale of change, i.e. can be rapid (gene switching) longer (protein synthesis) or enormous ranges of time (metabolites level) (Gad, 2007). As many growth and developmental processes in plants, for example, seed germination, flower induction, leaf movements, stem elongation, and de-etiolation are regulated by both light and plant hormones 
Chapter 2 Phytohormone in sesame

evaluation of diurnal variations of hormone levels may help to explain the complex network of light and hormone signal transduction pathways (Novakova et al., 2005).

No diurnal rhythm but distinct metabolic patterns differing among individual plants were found among phloem metabolites of Cucurbita maxima (Fiehn, 2003). Most enzyme activity changed more or less slowly during light/dark cycle and during several days of darkness as compare to transcript that undergo marked and rapid changes during diurnal cycle and after transfer to darkness (Gibon et al., 2006). Auxin, salicylic acid and jasminic acid content did not vary within 24 hours of sampling but concentrations of hormones varied in different plant parts. We observed a trend over sampling time on the content of abscisic acid (ABA). Peak of ABA level occurred $3 \mathrm{hr}$ after the beginning of the light phase; however, data are not significantly different. Consistent results were found for leaves, stem and roots. 


\section{REFERENCES}

1) Blanco, C. A., Aarts, G. M., Bentsink, L., Keurentjes, J. B., Reymond, M., Vreugdenhil, D., and Koornneef, M. 2009 What has natural variation taught us about plant development, physiology and adaptation? The plant cell. 21:18771896.

2) Bol, J. F. and Linthorst, H. J. M. 1990 Plant pathogenesis-related proteins induced by virus infection. Annu. Rev. Phytopathol. 28:113-38.

3) Boller, T. 1988 Ethylene and the regulation of antifungal hydrolases in plants. In Oxford Surveys of Plant Molecular and Cell Biology, 5:145-75.

4) Bowles, D. J. 1990 Defense-related proteins in higher plants. Biochem. 59:873-907.

5) Brioudes, F., Joly, C., Szecsi, J., Varaud, E., Leroux, J., Bellvert, F., Bertrand, C. and Bendahmane, M. 2009 Jasmonate controls late development stages of petal growth in Arabidopsis thaliana. The Plant $\mathrm{J}$. 60:1070-1080.

6) Chung, H. S., Niu, Y., Browse, J., Howe, G. A. 2009 Top hits in contemporary JAZ: An update on jasmonate signaling. Phytochem. 70:1547-1559.

7) Cohen-Kupiec, R. and Chet, I. 1998 The molecular biology of chitin digestion. Curr. Opinion in Biotechnol. 9:270-277.

8) Eliasova, A., Repcak, M. and Pastırova, A. 2004 Quantitative changes of secondary metabolites of Matricaria chamomilla by abiotic stress. Z.Naturforsch. 59C:543-548.

9) El-tayeb, M. A., El-Enany, A. E., and Ahmed, N. I. 2006 Salicylic Acid-induced adaptive response to copper stress in sunflower (Helianthus annuus L.). Inter. J. of Botany, 2:372-379.

10)Eynck, C., Koopmann B., Grunewaldt-Stoecker, G., Karlovsky, P., Von Tiedemann, A. 2007 Differential interactions of Verticillium longisporum and 
V.dahliae with Brassicanapus detected with molecular and histological techniques. Eur. J. Plant Pathol. 118:259-274.

11)Fiehn, O. 2003. Metabolic net works of Cucurbita maxima phloem. Phytochem. 62:875-886.

12)Finkelstein, R. 2006 A book chapter (Abscisic Acid: A seed maturation and antistress signal) from the Plant Phsiology book: 4th edition: 593-616.

13)Gad, C. Y. 2007 Handbook of pharmaceutical biotechnology, WileyInterscience; 1 edition: 1-1680.

14)Garcia-Vallve, S., Palau, J. and Romeu, A. 1999 Horizontal gene transfer in glycosyl hydrolases inferred from codon usage in Escherichia coli and Bacilluss ubtilis. Mol. Biol. Evol. 16:1125-1134.

15)Hollenbach, B., Schreiber, L., Hartung, W., and Dietz, K.J. 1997 Cadmium leads to stimulated expression of lipid transfer protein (Itp) in barley: Implications for the involvement of LTP in wax assembly. Planta, 203:9-19.

16)Katharine, Howell, A., Narsai, A. K. R., Carroll, A. , Ivanova, A. , Lohse,M., Usadel, B., Millar, H. and Whelan J. 2009 Mapping metabolic and transcript temporal switches during germination in rice highlights specific transcription factors and the role of RNA instability in the germination process. Plant Physiol. 149:961-980.

17)Keen, N.T., Yoshikawa, M. 1983. $\beta-1,3-e n d o g l u c a n a s e$ from soybean releases elicitor-active carbohydrates from fungus cell walls. Plant Physiol. 71: 460-465.

18)Laurentin, H., Ratzinger, A., and Karlovsky, P. 2008. Relationship between metabolic and genomic diversity in sesame. BMC Genomics. 9:250.

19)Leah R., Tommerup, H., Svendsen, I. and Mundy, J. 1991 Biochemical and molecular characterization of three barley seed proteins with anti-fungal properties. J. Biol. Chem. 266:1564-1573

20)Malamy J., Carr, J. P., Klessig, D. F., and Raskin, I. 1990 Salicylic acid: A 
likely endogenous signal in the resistance response of tobacco to viral infection. Science 250:1002-1004.

21)Mazhoudi S., Chaoui, A., Ghorbal, M.H., and Ferjani, E. El . 1997 Response of antioxidative enzymes to excess copper in tomato (Lycopersicum esculentum, Mill). Plant Sci. 127:129-137.

22)Novakova M., Motyka, V., Dobrev, P., Malbeck, J., Gaudinova, A. and Adomıra Vankova, R. 2005. Diurnal variation of cytokinin, auxin and abscisic acid levels in tobacco leaves. J. of Exper. Botany, 56:2877-2883.

23)Poorter H., van Rijn,C. P. E., Vanhala, T.K., Verhoeven, K. J. F., de Jong, Y. E. M., Lambers, P. H. 2005 A genetic analysis of relative growth rate and underlying components in Hordeum spontaneum. Oecologia, 142:360-377.

24)Ratzinger, A. 2008 Development and application of LC. MS based differential metabolic profiling in plant system. Ph.D thesis, Georg August University, Goettingen, Germany.

25)Ravnikar M., Zel, J., Plaper, I., and Spacapan, A. 1993 Jasmonic acid stimulates shoot and bulb formation of garlic In Vitro. J. Plant Growth Regul. 12:73-77.

26)Salehi, M. and Izadpanah, K. 1992 Etiology and sesame phyllody in Iran. J. of Phytopathol. 135:37-47.

27)Smyth, D. R., Bowman, J. L., Meyerowitz, E. M. 1990. Early flower development in Arabidopsis. Plant Cell, 2:755-767.

28)Takahashi, H., Kanayama, Y., Zheng, M.S., Kusano,T., Hase, S., Ikegami, M., and Shah, J. 2004 Antagonistic Interactions between the SA and JA signaling pathways in Arabidopsis modulate expression of defense genes and gene-for-gene resistance to cucumber mosaic virus. Plant Cell Physiol. 45:803-809.

29)Thomas, S. G. and Sun, T. 2004 Update on gibberellin signaling. A Tale of the 
tall and the short. Plant Physiol. 135:668-676.

30)Van Loon, LC. 1997. Induced resistance in plants and the role of pathogenesis-related proteins. European Journal of Plant Pathology 103: 753765, 1997.

31)Vos P., Hogers, R., Bleeker, M., Reijans, M., van De Lee, T., Hornes, M., Frijters, A., Plot, J., Peleman, J., and Kuiper, M.1995 AFLP: a new technique for DNA fingerprinting. Nucleic Acids Res. 23:4407-4414.

32)Woolhouse, H. W. 1983 Toxicity and tolerance in the responses of plants to metals. Ency Plant Physiol. 12:245-300.

33)Yruela, I., J. Puedo, Alonso, P., and Picores, R. 1996 Photoinhibition of photosystem II from higher plants: effect of copper inhibition. J. Biol. Chem. 271:27408-27415.

34)Yves Gibon, Y., Usadel, B., Blaesing, O. E, Kamlage, B., Hoehne, M. , Trethewey, R., and Stitt, M, 2006 Integration of metabolite with transcript and enzyme activity profiling during diurnal cycles in Arabidopsis rosettes. Genome Biol. 7:R76.

35)Zou, H., Nonogaki, H., and Welbaum,G. E. 2002 A gel diffusion assay for visualization and quantification of chitinase activity. Molecular biotechnology, 22:19-22. 
Chapter $3 \quad$ Antifungal properties of sesame

\title{
Chapter 3 - Antifungal properties of sesame (Sesamum indicum L.) crude extract and purified sesame lignans
}

\begin{abstract}
Plant secondary metabolites have important ecological function not only as attractant for pollinators and seed dispersing animals but also as resistance factor against pathogens. Accessions that produce high levels of such compounds are a valuable source for sesame breeding. With the aim of identifying genotypes with high content of ecological metabolites, we investigated 32 sesame accessions. Metabolites were extracted from leaves, stems and roots and tested against the plant pathogenic fungi Macrophomina phaseolina, Alternaria sesami and Fusarium oxysporum. Extracts obtained with $80 \%$ ethanol were assayed in microtiter plates, and changes in the optical density of the growing fungal cultures were recorded as optical density at $550 \mathrm{~nm}$. Most of the extracts had inhibitory effect on all the tested fungal species. Some of the root extracts supported the growth of $A$. sesami whereas some leaf extracts enhanced the growth of $F$. oxysporum as compared to the control. The variations observed amongst the different sesame accessions lead to the assumption that there could be a potential to improve plant disease resistance in sesame using metabolic pathway engineering. Crude ethanol extracts of one of the sesame accessions namely UCLA1 was fractionated with different organic solvents and assayed for effects on fungal cultures. The inhibition effect of diethylether and chloroform and hexane fractions were higher than ethanol fraction remaining after extraction with other solvents. Two purified sesame lignans were also tested and the result demonstrated that sesamin had no effect against said fungal species up to a concentration of 5000 ppm where as sesamol and 2,4-dinitrophenol (used as a control) had strong inhibitory effects. Different $I C_{50}$ values were established for each fungal species. The results revealed that sesamol may help the plant through inhibiting the growth of invading pathogens.
\end{abstract}




\section{INTRODUCTION}

Chemical diversity of natural products, specifically plant derived compounds as a resistant factor against microorganism has gained in popularity since the1990s and remains as key factor in disease management. A review by Cowan (1999) gives a brief history of plant products as antimicrobial agents. Useful antimicrobial plant compounds include several categories: phenolics, terpenoids, essential oils, alkaloids, lecitins, polypeptides and polyacetylenes. Sesame plant also contains some unique chemicals such as sesamin, sesamol, sesamolin, sesaminol, anthrasesamone, chlorosesamone A, $\mathrm{B}, \mathrm{C}, \mathrm{D}$ and $\mathrm{E}$, hydroxysesamone, 2,3-epoxysesamone, and anthraquinone pinoresinol. The crop is mainly grown for its oil due to its high yield, pleasant taste, and antioxidant activity which might be some characters of sesame being called the queen of oil seed crops (Al-Yemeni et al., 2000; Bedigian, 2000).

Sesame is infected by a number of fungal, bacterial, viral, mycoplasma and nonparasitic diseases around the world. Among the most important fungal pathogens, Fusarium oxysporum f. sp. sesame causes seedling blight and fusarium wilt of sesame (Cho and Choi, 1987) and it is one of the soil borne vascular pathogens causing wilting by blocking the root xylem vessels (Bateman et al., 1996). Macrophomina phaseolina (Tassi) Goid is a virulent fungus causing charcoal rot or stem rot disease in sesame which leads to heavy economic losses to the grower by reducing the oil content at significant level if the crop is attacked at maturity stage (Javed et al., 1995). Host ranges of M. phaseolina exceeds 500 economically important plants and causing diseases commonly known as charcoal rot (Sinclair, 1982). Alternaria sesame causes damage due to reduction in photosynthetic area due to leaf damage and premature defoliation (Kolte, 1985), elongated lesion on capsules and considerable yield damage. Besides these, other seed borne fungi of sesame include three Aspergillus species: $A$. flavus, $A$. ochraceus, and A. tamarii. Penicillium citrinum and two Fusarium sp. are recorded in Sierra Leone and Aflatoxin B1 and G1 were also detected from seed samples (Jonsyn, 1988).

Most plant disease control strategies require integration of several approaches like 
biological, chemical and cultural methods. Use of plant resistant cultivars is one of the most efficient methods for disease control. Host plant resistance eliminates or minimizes crop losses due to diseases and reduces the need for and cost of other control strategies. To develop disease resistant cultivars, sources of resistance must be combined in single cultivars that have desirable traits (Jerlad 2004). Metabolic characterization is one of the tools that breeders may use for the identification of potential cultivars, and ultimately may lead to the discovery of biologically active compounds. Metabolites have much greater variability in the order of atoms and subgroups compared to four letter code of genes (Fiehn, 2002). Diversity in host susceptibility may reduce the spread of disease epidemics but does not affect the emergence (Springbett et al., 2003). The aim of the present study is to explore the natural variation of sesame accession in antifungal contained, start purification for the compound responsible for the effect, identify the potential secondary metabolites as a resistant factor against pathogen which may be later used in functional genomic.

\section{MATERIALS AND METHODS}

All the chemicals and growth medias except V8-A including ethanol, diethyl ether, chloroform, hexane, PDA (potato dextrose agar) and PDB (potato dextrose broth) were purchased from Carl Roth $\mathrm{GmbH}$, Germany. Sesamol, sesamin and 2,4-dinitrophenol were purchased from Sigma Aldrich Chemie GmbH, Germany. Fungal strains 62743 Macrophomina phaseolina (Maubl.) Ashby, 62027 - Alternaria sesami (Kawamura) Mohanty \& Behera were obtained from DSMZ (Deutsche Sammlung von Mikroorganismen und Zellkulturen (Braunschweig, Germany)) and isolate 141118 of Fusarium oxysporum f.sp. sesami were obtained from CABI Genetic Resource Collection (CABI Biosciences, Egham, UK).

\section{Growth of Plants}

Sesame seeds from 32 accessions or cultivars (Table 1 and 2) were grown in pots containing 1:1 mixture of compost and sand with eight plants per pot (Fig. 2). The pots 
were irrigated every day and kept in phytochambers under controlled environmental conditions of $14 \mathrm{hr}$ light (20 Lux), $26{ }^{\circ} \mathrm{C}$ and $60 \%$ relative humidity. After 17 days of germination, plants were uprooted and washed with tap water. Leaves, roots and stems were separated in parts and immediately frozen with liquid nitrogen. Samples were stored at $-20{ }^{\circ} \mathrm{C}$ until use. For inducive metabolites, plants were grown in the same conditions of phytochamber but five plants per pot. Plants were treated with different treatments after 25 days of germination. Sclerotial suspensions of $M$. phaseolina were prepared with slight modification of Laurentin (2007). Ten day old fungus growing at 32 ${ }^{\circ} \mathrm{C}$ on PDA modified with $4 \%$ agar w/v medium was blended for 2 min in the presence of sterilized water with kitchen blender, and then strained with $200 \mu \mathrm{m}$ sieves. The strained mixture was then centrifuged at $4500 \mathrm{rpm}$ for $5 \mathrm{~min}$ and pellets of sclerotia were redissolved in PDB medium. PDA plates without fungus were also treated in the same fashion to serve as control. Concentration of sclerotia was determined under the microscope by placing $50 \mu \mathrm{l}$ of aliquots on a filter paper. Final concentration was adjusted to 2 sclerotia/ $\mu l$. Microsclerotia of $M$. phaseolina were inoculated into the soil around the stems of plant or kept under UV at $20^{\circ} \mathrm{C}$ for 10 min continuously for 10 days or $2 \mathrm{mM} \mathrm{CuCl} 2$ solution was sprayed with laboratory sprayer once on leaves. Necrotic symptoms were developed next day on leaves and further sprays were done on the stem 6 and 3 days before harvesting. Plants were harvested, washed, separated into plant components parts and kept in freezer in the same way as described above.

\section{Extraction and fractionation for anti fungal assay}

Extraction of metabolites from sesame leave, stems and roots of 32 accessions and cultivars (from) were carried out to investigate their activity against pathogenic fungus as described by Laurentin (2007). Briefly, $1 \mathrm{~g}$ of freezed plant tissues was grounded with pestle and mortar in the presence of liquid nitrogen. Grounded tissues were then subjected to extraction with $80 \%$ ethanol $(1 \mathrm{~g}$ fresh tissues $/ 5 \mathrm{ml}$ of $80 \%$ ethanol) overnight on a mechanical shaker $(100 \mathrm{rpm})$ and filtered with $25 \mu \mathrm{m}$ filters. Extractions were stored at $-20^{\circ} \mathrm{C}$ for further use. 
Later on, ethanol extracts of UCLA-1 having inhibitory affect in stems, leaves and roots against all the tested fungus were partitioned into different fractions using different organic solvents. Fractionations were done in two different ways to see which fractions have the most prominent inhibitory effect against the pathogens. In the first case, ethanolic extracts were mixed with equal volume of distilled water to increase its density and extracted on mechanical shaker for $2 \mathrm{hr}$ at $100 \mathrm{rpm}$ two times with equal volume of diethyl ether and centrifuged to separate the two phases of diethyl ether and ethanol. Both phases were evaporated in evaporatory rotor to dryness and re-suspended in $80 \%$ of ethanol keeping the same concentration $(1 \mathrm{~g}$ fresh weight of tissues $/ 5 \mathrm{ml}$ of $80 \%$ ethanol). In the second case, ethanolic extracts were first extracted with equal volume of hexane (two times) and separated in two phases of (ethanol and hexane fraction). The ethanol fractions were collected and re-extracted with equal volume of chloroform (two times), and separated in phases (chloroform and ethanol phase), evaporated and resuspended in $80 \%$ ethanol as described above.

\section{Inoculums Preparation}

Sclerotial suspensions of $M$. phaseolina were prepared as explained above. Spore suspensions of $F$. oxysporum were produced on mung bean media as slightly modified by Ahmed (2010) from (Bai and Shaner, 1996). 200ml mung bean media were inoculated with two plugs of actively growing $F$. oxysporum on PDA. Inoculated and uninoculated (control) mung bean liquid media were incubated at $28{ }^{\circ} \mathrm{C}$ with shaking conditions at $200 \mathrm{rpm}$. PDA plugs were separated by straining with mesh cloth directly at the top of the Erlenmeyer flask. Centrifuged for $10 \mathrm{~min}$ at $4500 \mathrm{rpm}$ and pellet of fungal spores was re-suspended in PDB. The concentration of spores were determined by placing a few $\mu \mathrm{l}$ of spore suspension in a Thoma counting chamber under microscope. The final concentration was adjusted to $1.5 \times 10^{5} / \mathrm{ml}$.

For spores' suspension of $A$. sesami, $30 \mathrm{ml}$ PDB were poured on the surface of Petridish containing seven days old actively growing fungus on V8-A medium and V8-A Petridish without fungus (serve as control). Colony of fungus were scratched with inoculating 
needle, fungal mycelium were separated by straining with mesh cloth directly on top of the Erlenmeyer flask. Concentrations of spores were checked under microscope by placing the $20 \mu \mathrm{l}$ aliquots on filter paper. Final concentration was adjusted to $2 \mathrm{spore} / \mu \mathrm{l}$.

\section{Bioassay}

Bioassays were conducted in 96 well microtiter plates to determine the effects of sesame plant extracts on fungal growth. Two hundred microliters of $80 \%$ ethanolic extracts were added in the wells of microtiter plate while $80 \%$ ethanol was added in the

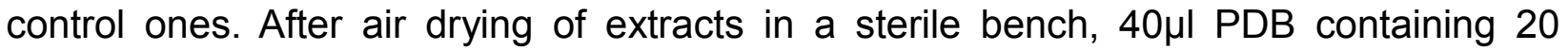
sclerotias of $M$. phaseolina, 20 spores of $A$. sesami or $1.5 \times 10^{5} / \mathrm{ml}$. Spores of $F$. oxysporum and PDB were added in control wells. Plates were enclosed in plastic box (containing sterile water at bottom of sieves to avoid the evaporation in the plate) and incubated for M. phaseolina at $32{ }^{\circ} \mathrm{C}$ and $25^{\circ} \mathrm{C}$ for $A$. sesami and $F$. oxysporum. Fungal growth in the wells was monitored every $24 \mathrm{hr}$ taking readings of optical density at 550 $\mathrm{nm}$ for five days with a microplate spectrophotometer $\mu$ Quant Universal (BioTekR Instruments, Inc. USA) and visualized by the software KC4 v.3.4 (BioTekR Instruments, Inc. USA). For assay with purified lignans, sesamol and sesamin were dissolved in four different concentrations i.e. 5000, 1000, 100 and 10 ppm and 2,4-dinitrophenol (DNP) 1000,100 and $10 \mathrm{ppm}$ in $80 \%$ ethanol and bioassays were done in the same way as described above. Sesamol and DNP showing inhibitory activity were re-assayed with a series of concentration to compute the $\mathrm{IC}_{50}$ value (the concentration at which fungus grow half of the control). Fungal growth was monitored by readings of optical density at $550 \mathrm{~nm}$ microplate spectrophotometer. Absorbance values were converted to $\mathrm{IC}_{50}$ by using four parameter logistic equations with sigma plot 11 version 11.0 (Systat software Inc, USA)

$$
y=\min +\frac{\max -\min }{1+\left(\frac{x}{E C_{50}}\right)^{- \text {Hinsiope }}}
$$


Chapter 3

Antifungal properties of sesame

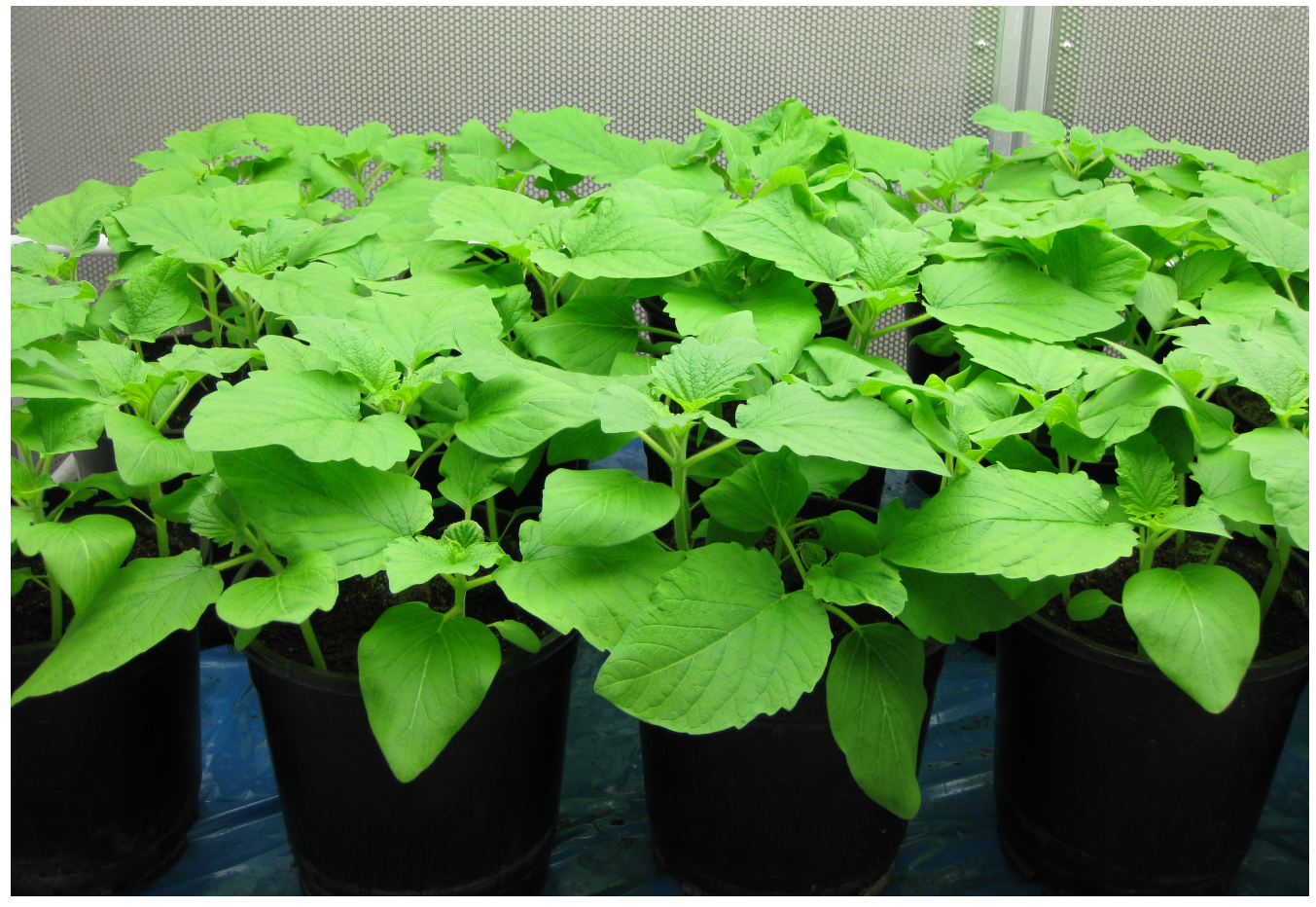

Figure: 1. Growth of sesame plants in phytochamber (17 days old) 
Table 1. Accessions from GENAP Germplasm Bank (Venezuela) and their origin country, diversity center.

\begin{tabular}{|l|l|l|l|}
\hline Accessions & Country of Origin & Working code & Diversity Centre \\
\hline $93-2223$ & India & India 1 & India \\
\hline $95-465$ & India & India 2 & India \\
\hline $95-469$ & India & India 3 & India \\
\hline $95-464$ & India & India 7 & India \\
\hline $92-2918$ & India & India 8 & India \\
\hline $92-3091$ & Korea & Korea 1 & China-Japan-Korea \\
\hline $92-3093$ & Korea & Korea 2 & China-Japan-Korea \\
\hline $92-2922$ & Turkey & Turkey & Western Asia \\
\hline $92-3125$ & Greece & Greece & Western Asia \\
\hline $93-2022$ & Syria & Syria & Western Asia \\
\hline $93-2113$ & Sudan & Sudan 1 & Africa \\
\hline $92-310$ & Sudan & Sudan 2 & Africa \\
\hline $93-2105$ & Sudan & Sudan 4 & Africa \\
\hline $93-2010$ & Ethiopia & Ethiopia & Africa \\
\hline $95-234$ & Unknown & Africa 2 & Africa \\
\hline $95-223$ & Unknown & Africa 3 & Africa \\
\hline $92-2856$ & Japan & Japan 1 & China-Japan-Korea \\
\hline $92-3030$ & Japan & Japan 2 & China-Japan-Korea \\
\hline $92-3031$ & Japan & Japan 3 & China-Japan-Korea \\
\hline $92-3108$ & China & China 1 & China-Japan-Korea \\
\hline $95-383$ & China & China 2 & China-Japan-Korea \\
\hline $92-2952$ & Turkmenistan & Turkmenistan 1 & Central Asia \\
\hline $92-2950$ & Tadjikistan & Tadjikistan 2 & Central Asia \\
\hline $92-2917$ & Tadjikistan 3 & Central Asia \\
\hline
\end{tabular}


Table 2. Commercial cultivars and experimental lines used as source of root, stem, leaf and seed ethanolic extracts

\begin{tabular}{|c|c|}
\hline $\begin{array}{l}\text { Commercial cultivars } \\
\text { or experimental lines }\end{array}$ & Country of Origin \\
\hline Felicidad & Introduced from Mexico. Unknown origin \\
\hline Venezuela 51 & $\begin{array}{l}\text { Originated by individual selection from the offspring of a } \\
\text { Chinese accession (Langham and Rodriguez, 1946). }\end{array}$ \\
\hline Acarigua & $\begin{array}{l}\text { A high performance F2 plant obtained by the cross between a } \\
\text { cultivar from Nicaragua and a cultivar from China, was crossed } \\
\text { with the cultivar Venezuela } 51 \text {, its offspring was selected for } \\
\text { three seasons, resulting in "Acarigua" (Mazzani, 1952) }\end{array}$ \\
\hline UCV-1 & $\begin{array}{l}\text { Elite line selected from first cycle of recurrent selection toward } \\
\text { high yield. The original population was obtained by cross, one } \\
\text { to one, among } 50 \text { exotic accessions (Laurentin et al., 2000). }\end{array}$ \\
\hline Maporal & $\begin{array}{l}\text { Selected from cultivar Arapatol, from Ethiopia (Mazzani et al., } \\
\text { 1973). }\end{array}$ \\
\hline Inamar & $\begin{array}{l}\text { Individual selection from the offspring from the same Acarigua } \\
\text { 's parents (Mazzani, 1953). }\end{array}$ \\
\hline UCLA1 & $\begin{array}{l}\text { Individual selection from a USA accession (Montilla and Teran, } \\
\text { 1996). Unknown origin }\end{array}$ \\
\hline Fonucla & $\begin{array}{l}\text { Selection from cultivar Arawaca (Montilla and Cedeño, 1991). } \\
\text { Arawaca was obtained by selection of the mixture of } 496 \text { F1 } \\
\text { plants obtained from crosses among } 32 \text { cultivars without } \\
\text { reciprocal. The origin of these cultivars isunknown. }\end{array}$ \\
\hline UCLA90 & $\begin{array}{l}\text { Elite lines from Universidad Centrooccidental Lisandro } \\
\text { Alvarado Sesame Breeding Program. Unknown origin }\end{array}$ \\
\hline
\end{tabular}




\section{RESULTS}

\section{Antifungal activity of sesame plant extract extract}

In order to find which sesame accessions posess antifungal compounds in vitro assays were carried out using 96 format microtiter plates. Significant variation in antifungal effects were observed among sesame accessions. All the accessions were found to have lower optical value than the control in case of $M$. phaseolina by crude extracts from leave, stem and root. Effect were recorded as change in absorbency due to fungal growth (Figure 2). Leaf and root extracts significantly supported the growth of $A$. sesami while some of the root extract found to cause lower optical density than control (Figure 3 ). In case of $F$. oxysporum, some of the leaf extracts showed higher optical values as compared to the control while all the extracts of stem and roots found to have lower optical density than the control (Figure 4). The diversity of effects observed for different accessions leads to the assumption that there is a potential to improve plant disease resistance in sesame using metabolic pathway engineering.

In a continuation of this research, original ethanolic extracts were fractioned with different methods. Original ethanolic extract and their fractions were bioassayed against M. phaseolina by keeping equal concentration of all phases $(40 \mathrm{mg}$ fresh plant tissues weight in $40 \mu \mathrm{l}$ of assay volume). The results of this part revealed that inhibitory effects were most prominent in the diethyl ether and chloroform fractions. The inhibition of a complete crude extract was slightly higher than the effect of diethyl ether fraction, followed by the effect of ethanol fraction remaining after diethyl ether extraction (Figure 5). In fraction of crude extract with chloroform and hexane inhibitory effect were most prominent in chloroform, hexane (Figure 6).

At this stage we decided to start purification from UCLA-1. So $4 \mathrm{~L}$ of $80 \%$ ethanolic extract $(1 \mathrm{~g} / 5 \mathrm{ml})$ from stem, root and leaves were extracted with $80 \%$ ethanol, filtered and then extracted twice with equal volume of diethyl ether.

We want to purify the diethyl ether fractions first and ethanol fraction will be used for the purification of other metabolites. The purified compounds were used for bioassay and 
structural elucidation. Plants treated with $\mathrm{CuCl}_{2}$ in induction experiment gave high inhibition against $M$. phaseolina and $F$. oxysporum in case of leaves extract and against F. oxysporum in case of stem extract (Figure 7).

\section{Antifungal activity of purified compounds.}

Activity of sesamin and sesamol were also checked against M. phaseolina, A. sesami and $F$. oxysporum and as a positive control we used 2,4-Dinitrophenol. Bioassays were done in the microtiter plate. We found out that all concentration of sesamin up to 5000 ppm were unable to inhibit the growth of the fungi while sesamol inhibit completely the growth at the highest used concentration of $5000 \mathrm{ppm}$ (Figure 8). To find out the effectivness of sesamol we diluted in a series of concentration ranging from 0 (blank control) to $5000 \mathrm{ppm}$ for sesamol and 0 to $100 \mathrm{ppm}$ for DNP. Finally we were able to calculate the $\mathrm{IC}_{50}$ value of sesamol and DNP. For fitting the curve the control values were entered as low dose $100 \mathrm{ppm}$ for M. phaseolina and $1 \mathrm{ppm}$ for DNP (as 0 could not be entered on log scale) and treated as they were the part of dose response curve. $I_{50}$ value in case of $M$. phaseolina is $1059 \mathrm{ppm}, A$. sesami $1269 \mathrm{ppm}$ and for $F$. oxysporum $3116 \mathrm{ppm}$ (Figure 9). I $\mathrm{IC}_{50}$ values for DNP ranges from $329-90 \mathrm{ppm}$ in case of $M$. phaseolina 137 ppm, A. sesami 325 ppm and for F. oxysporum 90 ppm (Figure 10).

\section{Cross contamination of sesamol and DNP in neighbouring wells}

While conducting the experiment with sesamol and DNP in microtiter plate for the antifungal activity we observed that adjacent zones (zone 2 and 3 ) of the test compound also showed some inhibition in growth and change of pigmentation (Fig 11, 12 and 13).We speculated that sesamol and DNP are producing some fumes passing to adjacent zones, (showing less OD and difference in biomass) or compounds entered to adjacent wells by capillary movement. The ultimate solution was to leave the adjacent wells empty while checking the pure compound of unknown nature. 
Chapter 3

Antifungal properties of sesame

(A)

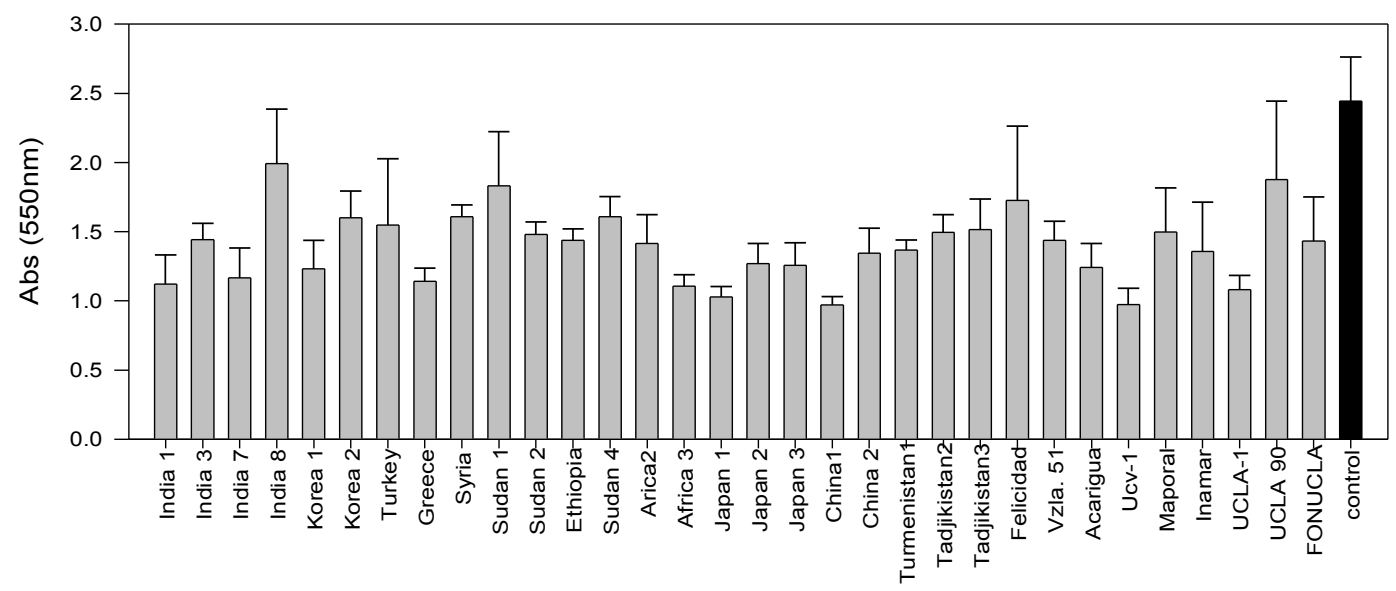

(B)

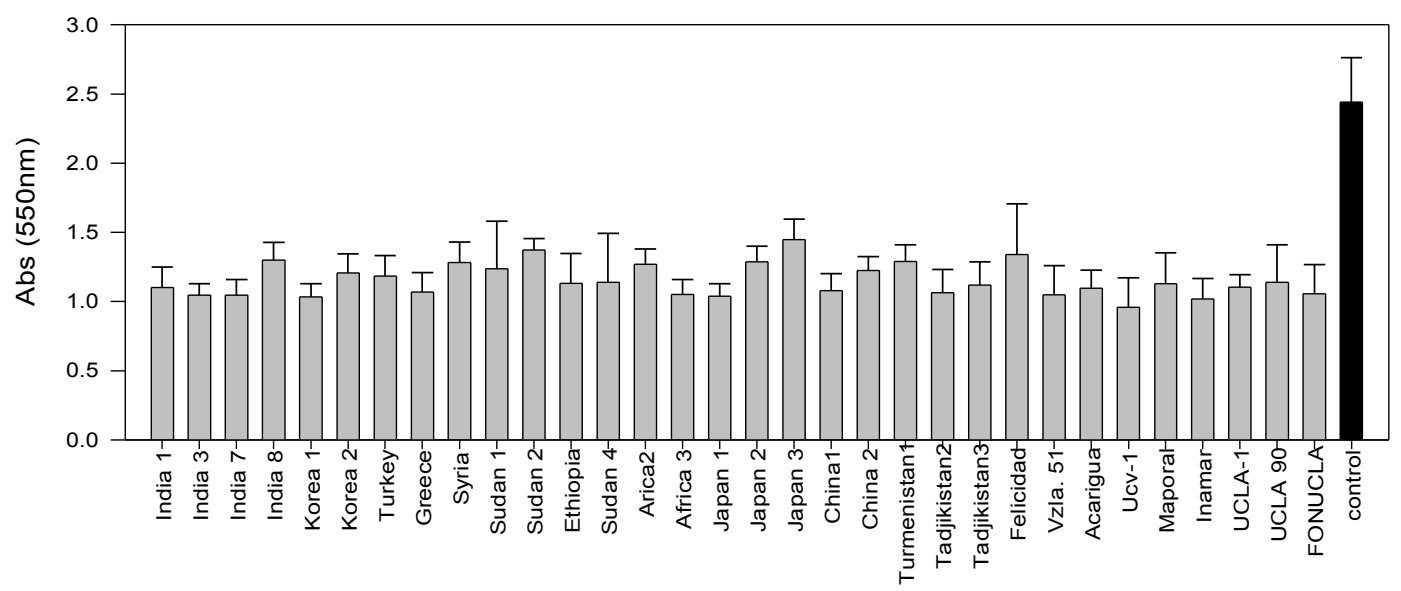

(C)

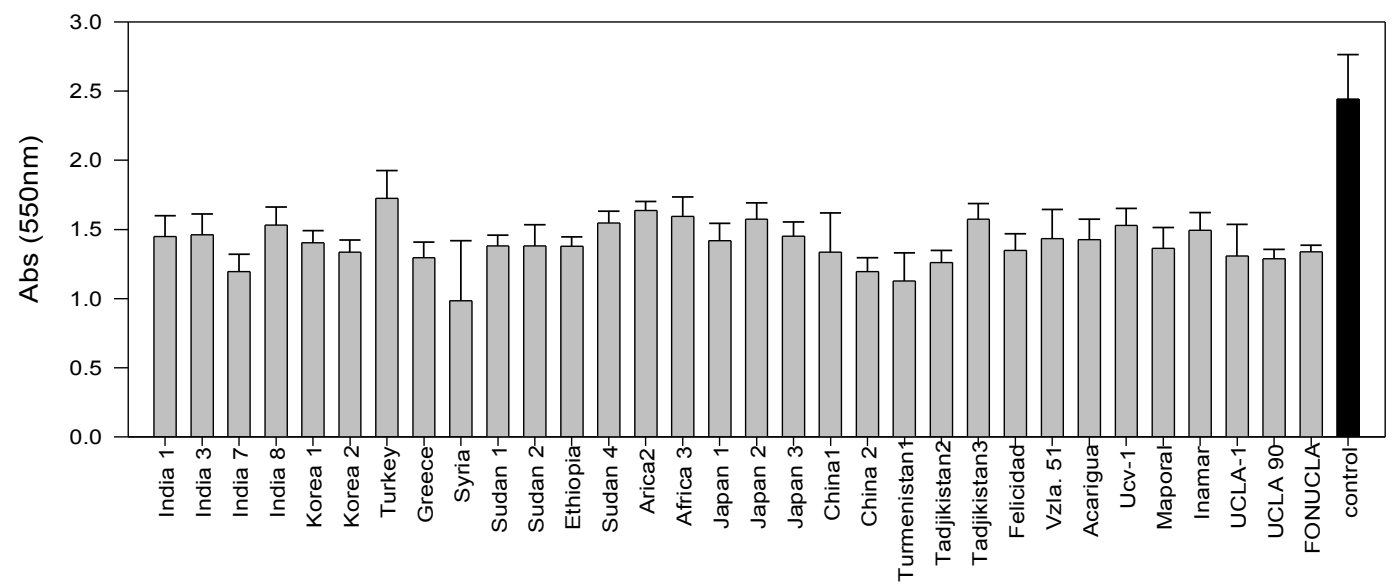

Figure: 2. Effect of $80 \%$ ethanolic extract from leaves (A), stem (B) and root (C) of 32 sesame accession on growth of $M$. phaseolina. Error bars indicate the standard deviation of the mean of three replications 24 measurement in total 
(A)

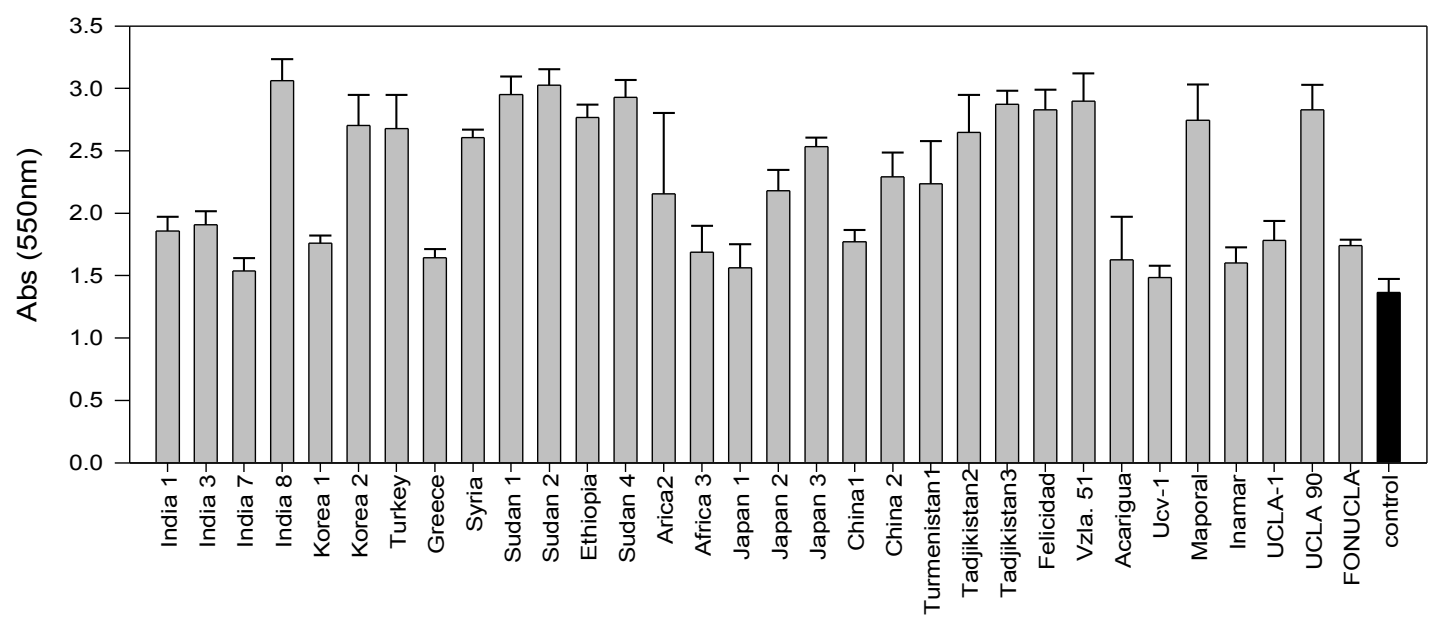

(B)

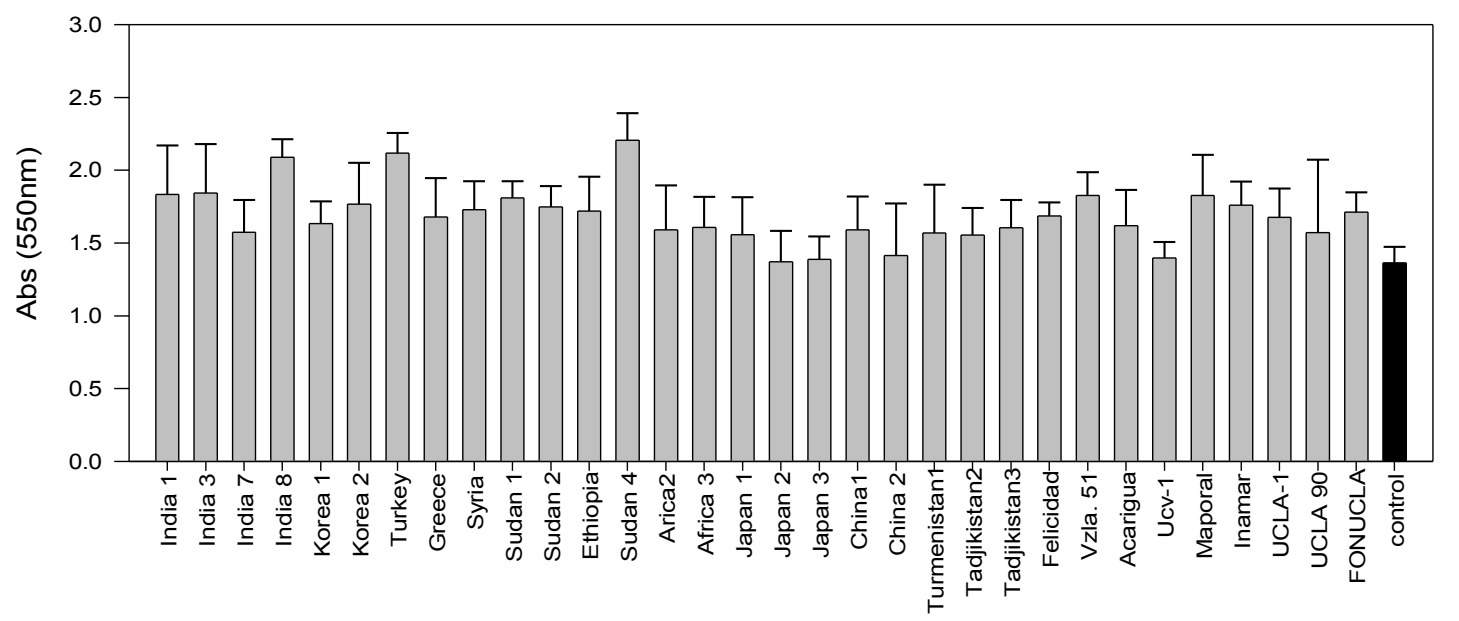

(C)

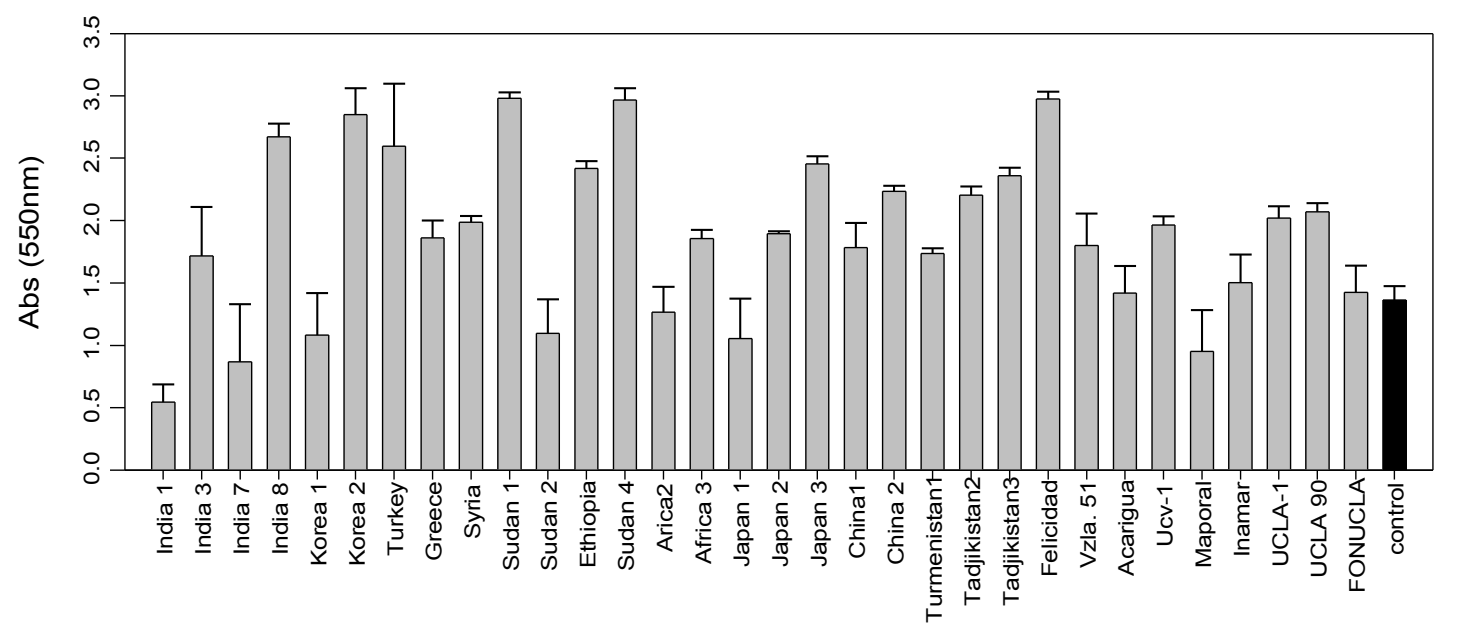

Figure: 3. Effect of $80 \%$ ethanolic extract from leaves (A), stem (B) and root (C) of 32 sesame accession on growth of $A$. sesami. Error bars indicate the standard deviation of the mean of three replications 24 measurement in total 
(A)

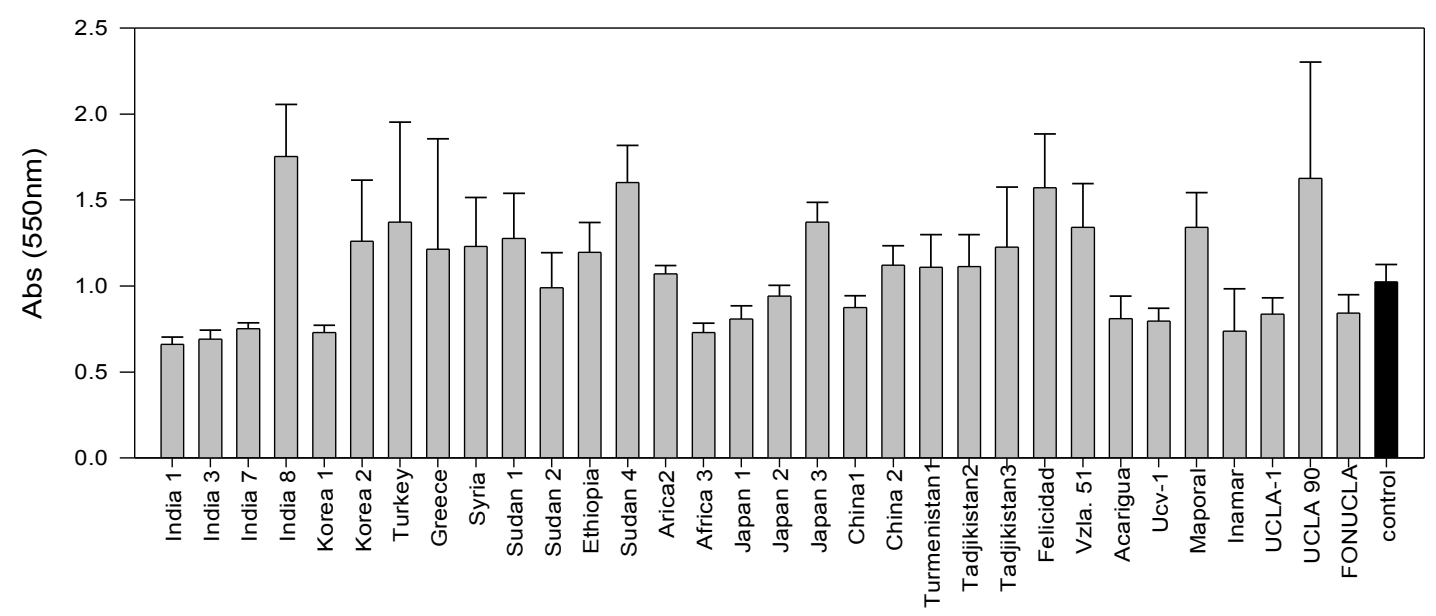

(B)

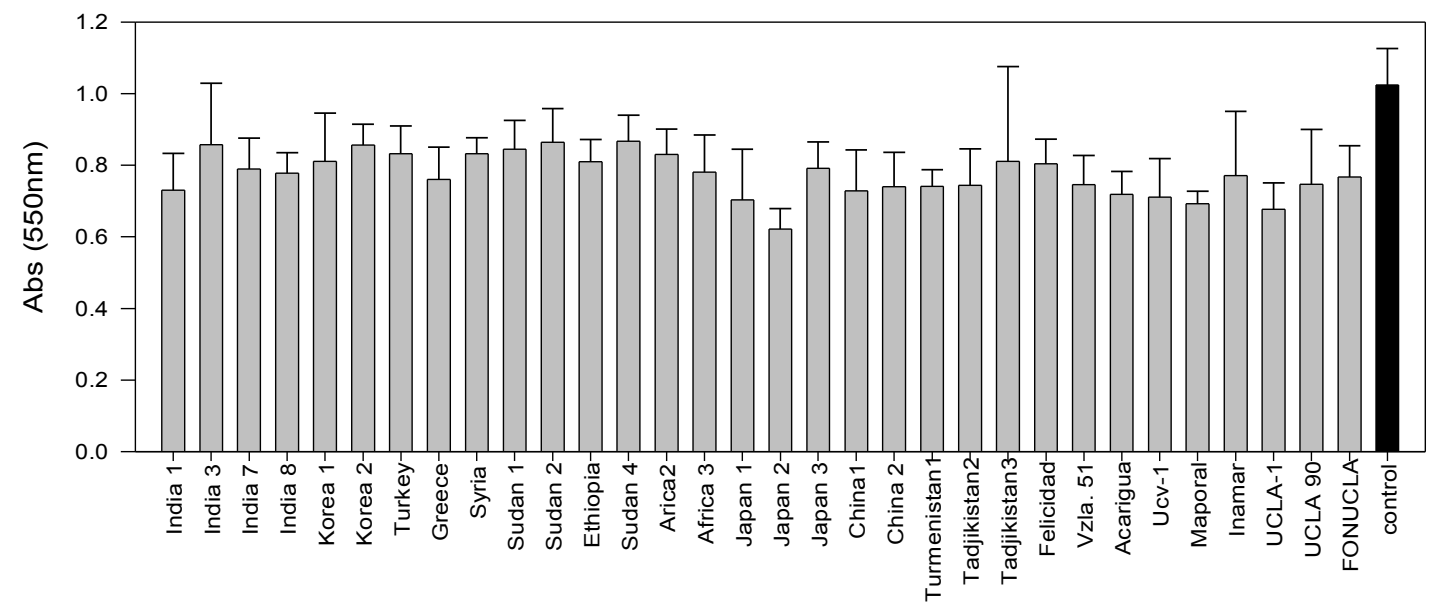

(C)

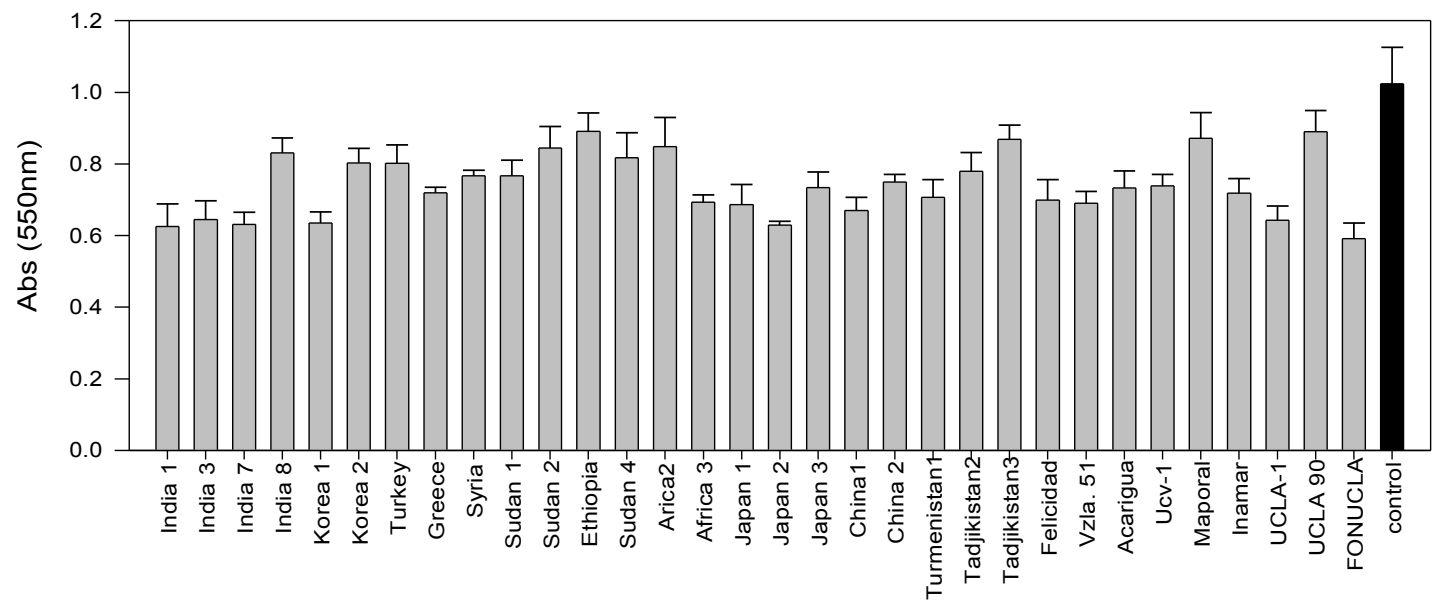

Figure: 4. Effect of $80 \%$ ethanolic extract from leaves (A), stem (B) and root (C) of 32 sesame accession on growth of F. oxysporum. Error bars indicate the standard deviation of the mean of three replications 24 measurement in total 
Chapter 3

Antifungal properties of sesame

(A)

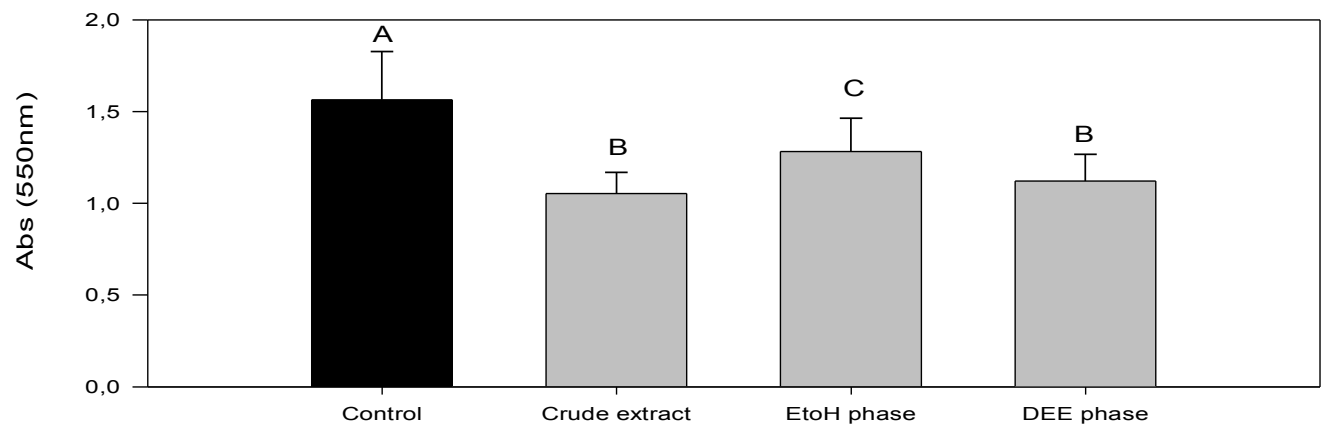

(B)

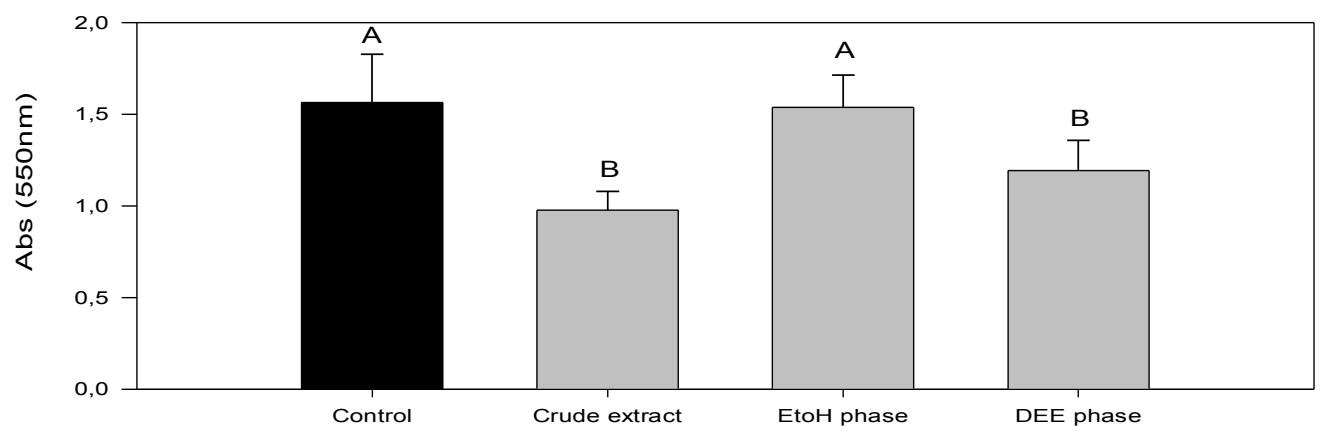

(C)

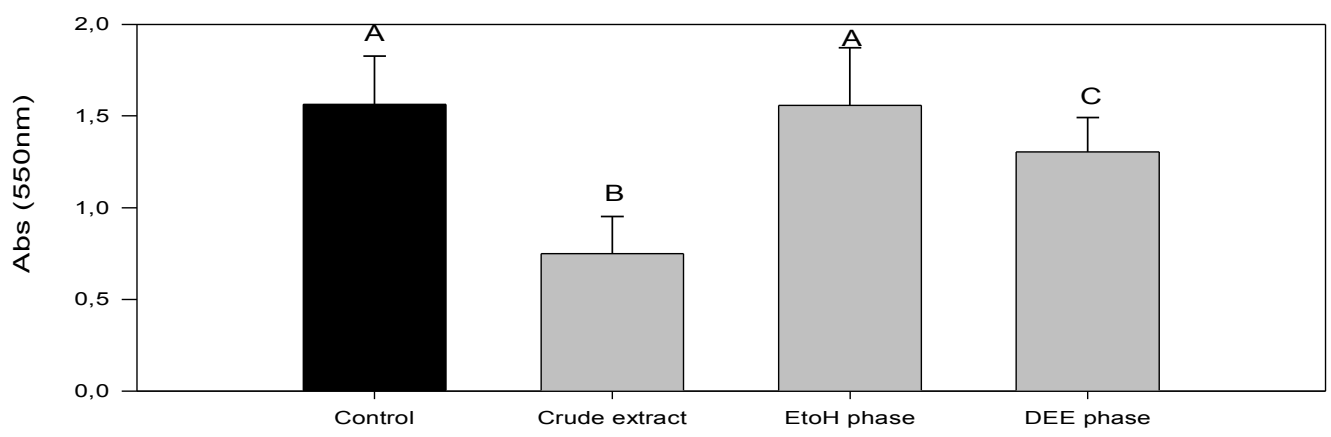

Figure: 5. Effect of crude ethanolic extract of a sesame accession ("UCLA1") Leaves (A), Stems (B) and roots $(C)$ and its fractionation on growth of $M$. phaseolina. Leaves stems and roots were extracted with $80 \%$ ethanol (crude extract) and fractioned with diethylether( diethylether phase), remaining ethanolic extract after diethylether extraction (ethanol phase). Growth was measured as absorbance changes in optical density recorded after 120 hours. Error bars indicate the standard deviation of the mean of three replications 24 measurement in total. Bars with the same letter indicate no differences based on One Way ANOVA with all pairwise multiple comparison procedures (Tukey Test) at .( $P<0,001)$. 
(A)

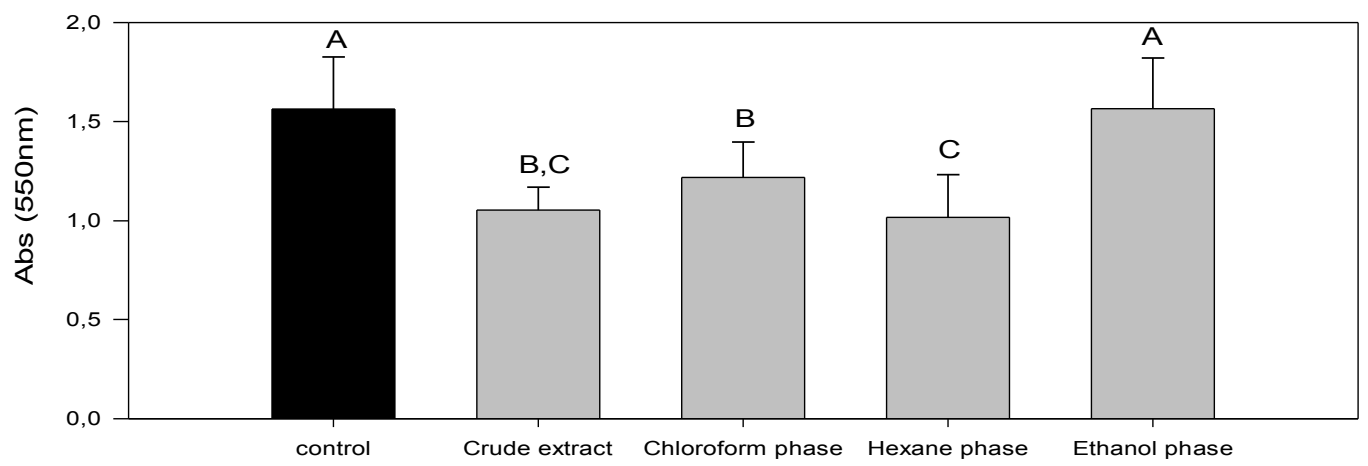

(B)

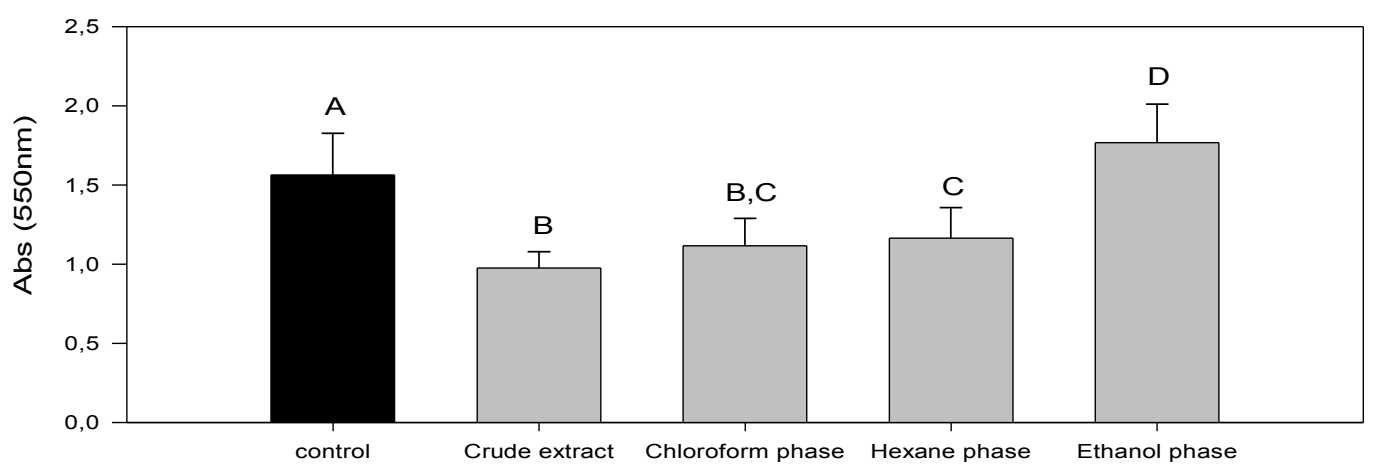

(C)

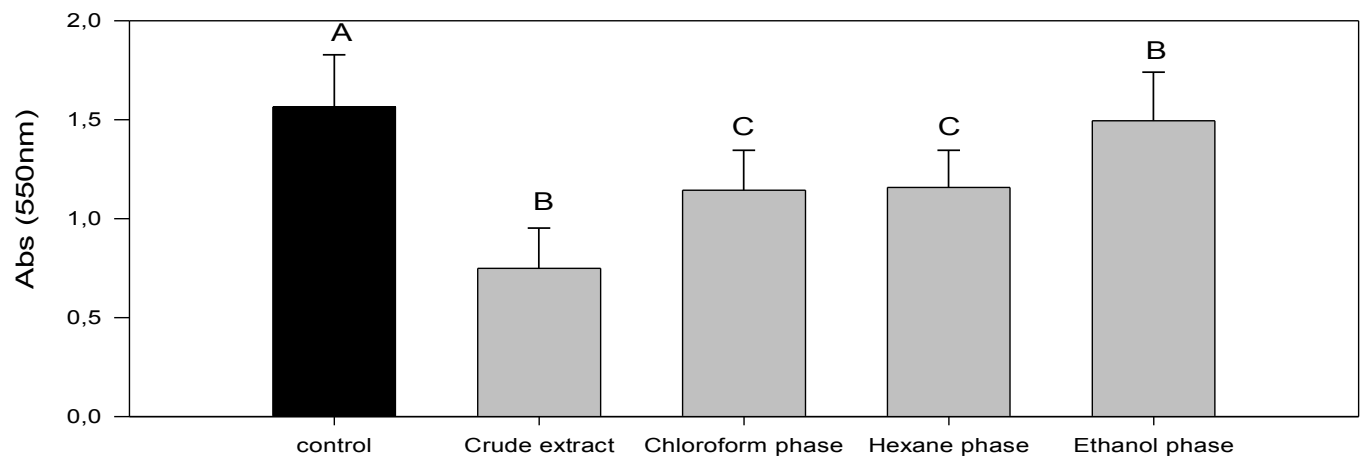

Figure 6 Effect of crude ethanolic extract of a sesame accession ("UCLA1") and its fractionation on growth of M. phaseolina. Leaves $(A)$ stems $(B)$ and roots $(C)$ were extracted with $80 \%$ ethanol (crude extract) and fractioned with hexane (hexane phase), remaining ethanolic extract after hexane extraction were fractioned with Chloroform(chloroform phase) and remaining ethanol phase after chloroform extraction(Ethanol phase). Growth was measured as absorbance under $550 \mathrm{~nm}$ and growth of fungus after 120 hours presented here. Error bars indicate the standard deviation of the mean of three replications 24 measurement in total.Bars with the same letter indicate no differences based on One Way ANOVA with all pairwise multiple comparison procedures (Tukey Test) at . $(\mathrm{P}<0,001)$. 

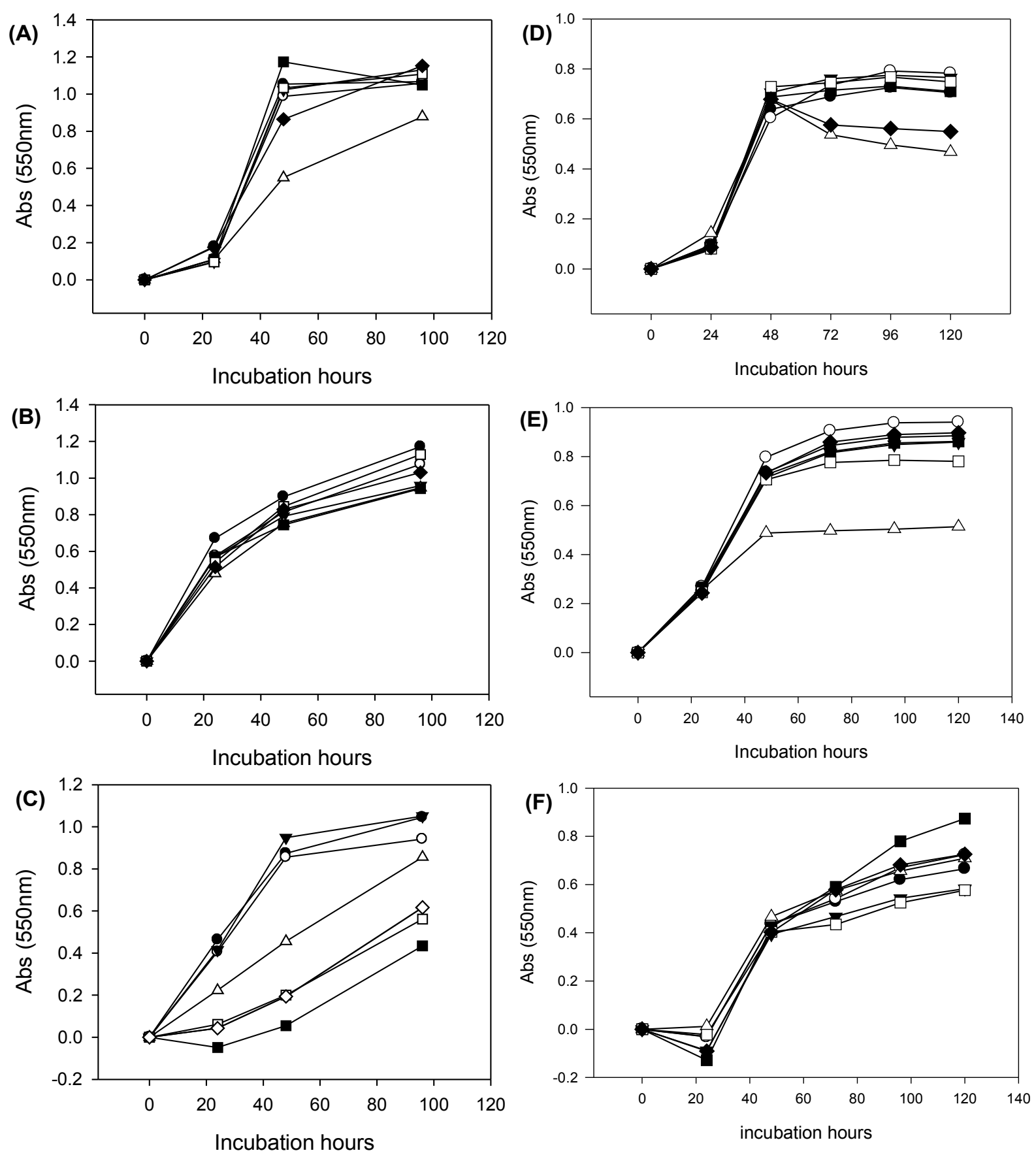

Figure: 7. Growth of M.phaseolina (left figures) and F.oxysporum ( right figures)in the presence of sesame accession(UCLA1) Leaves (A nad D), Stems (B and E) and roots (C and F).For the irreducibility of anti fungal effect plant were kept in UV or inoculated with fungus or sprayed with CuCL2. Control plant were without treatment . Each data point is the average of two replication with 10 plants each. 

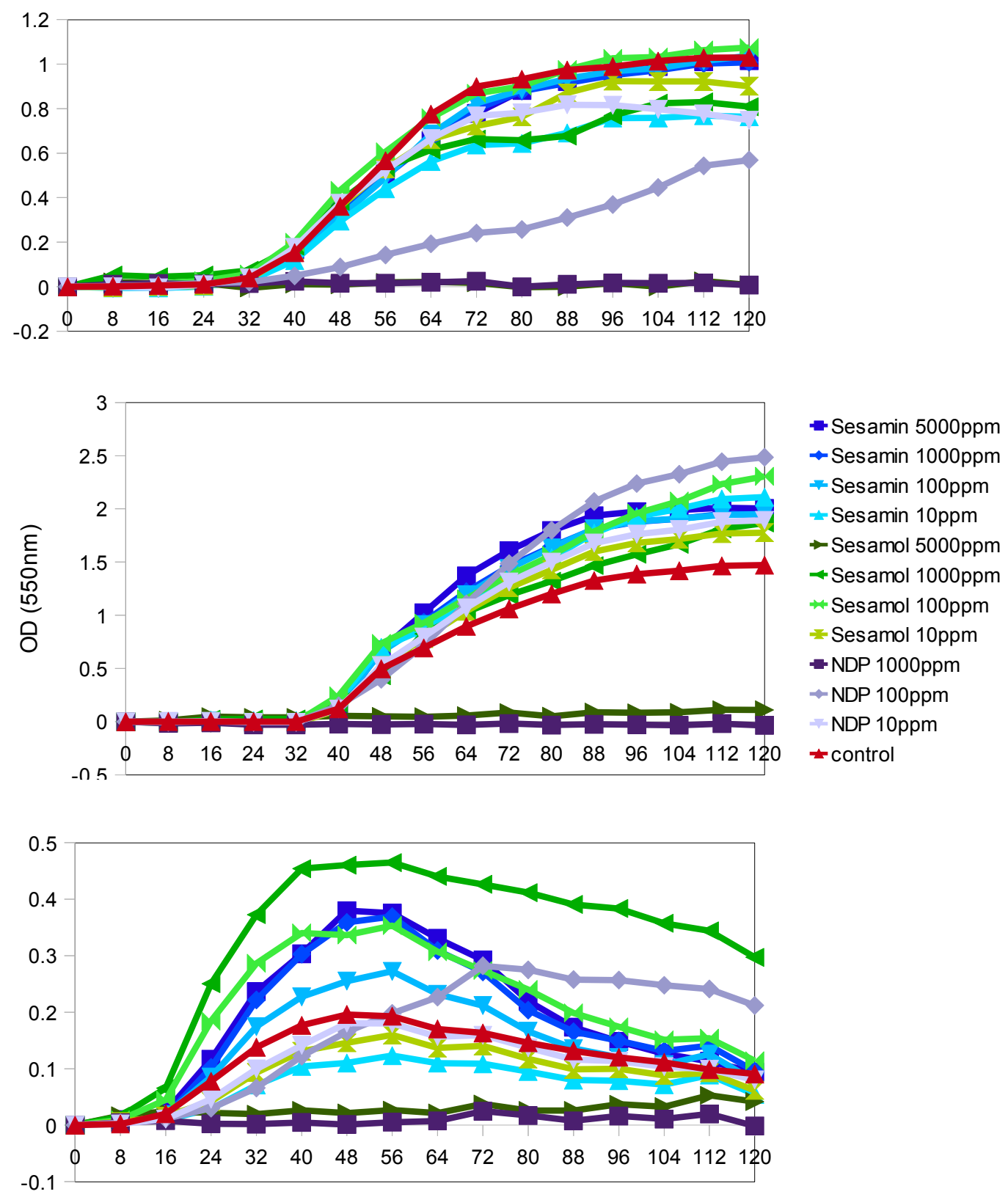

Incubation hours

Figure: 8. Effect of different concentration of sesamin, sesamol and DNP on growth of M. phaseolina (A) A. sesami (B) F. oxysporum Growth was measured as absorbance under and changes in optical density recorded as a result growth of fungus after every eight hours. 24 measurements in total. Data [resented is the average of two indpendent replication. 
(A)

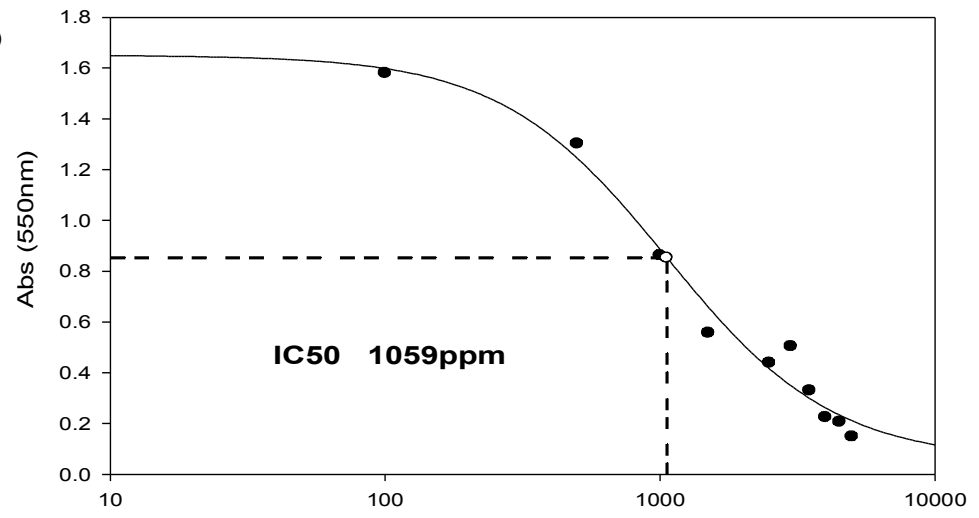

(B)

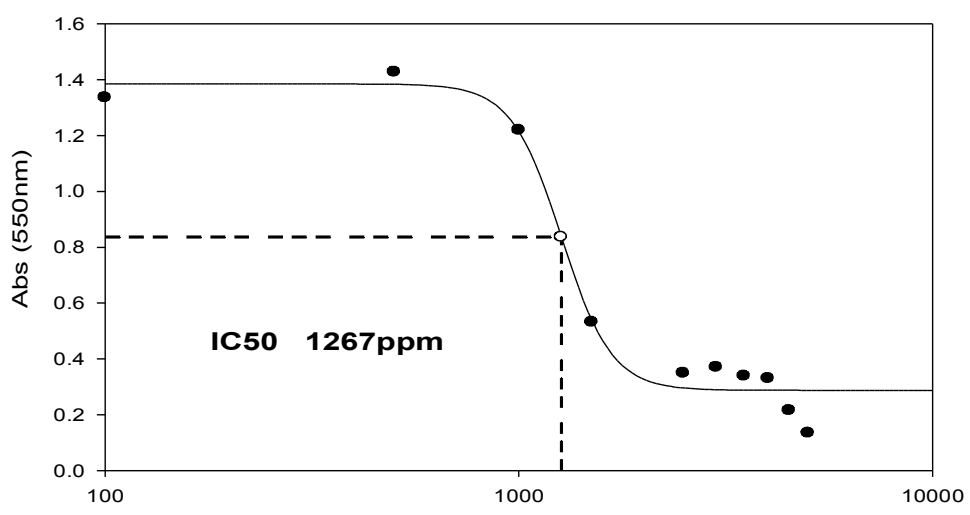

(C)

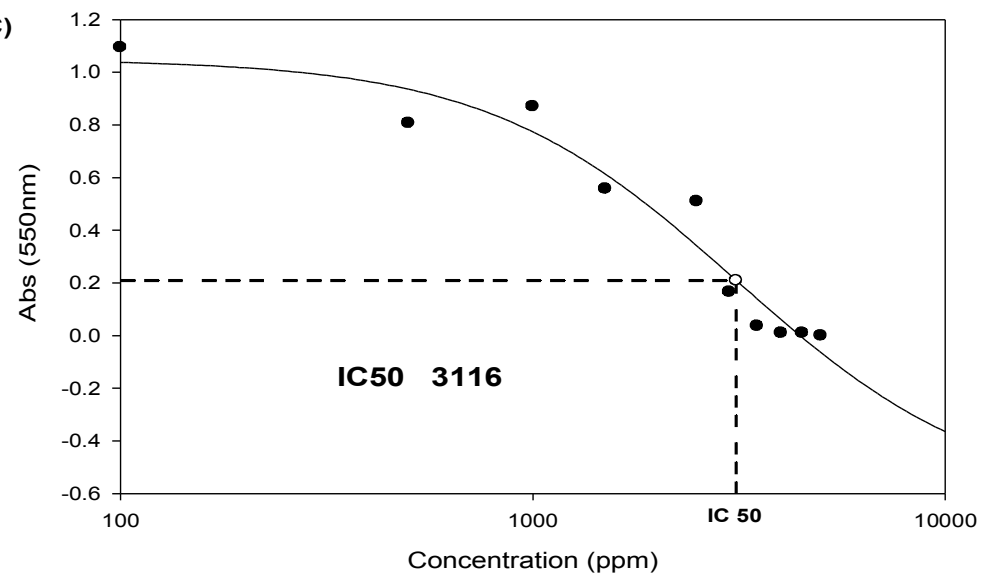

Figure 9. IC50 of sesamol for M. phaseolina (A) A. sesami (B) F. oxysporum. Calculated by using four parameter logistic equation with sigma plot 11 version 11.0 (systat software inc, USA) .Growth was measured as absorbance. Each data point is the average of three independent replication. 
(A)

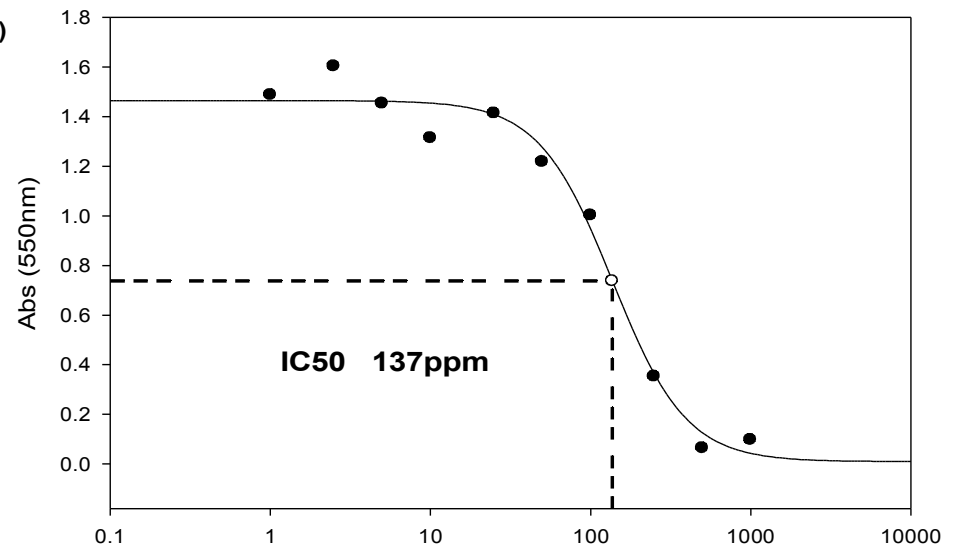

(B)

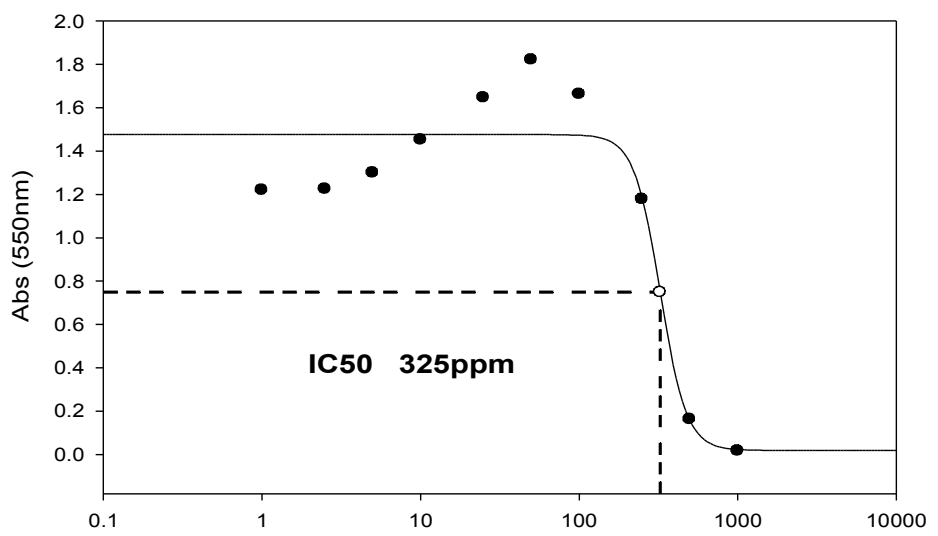

(C)

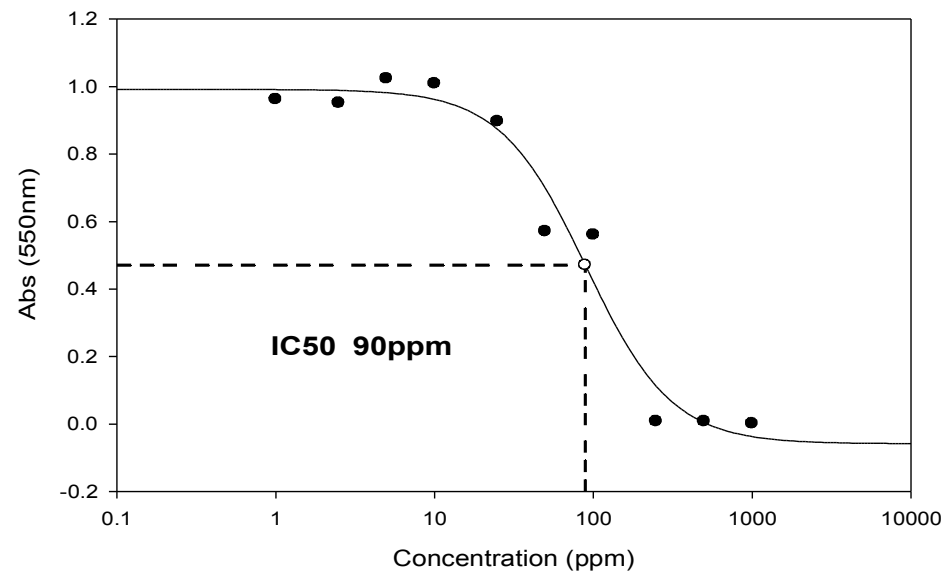

Figure 10. IC50 of DNP for M. phaseolina (A) A. sesami (B) F. oxysporum. Calculated by using four parameter logistic equation with sigma plot 11 version 11.0 (systat software inc, USA) .Growth was measured as absorbance. Each data point is the average of three independent replication 
(A)

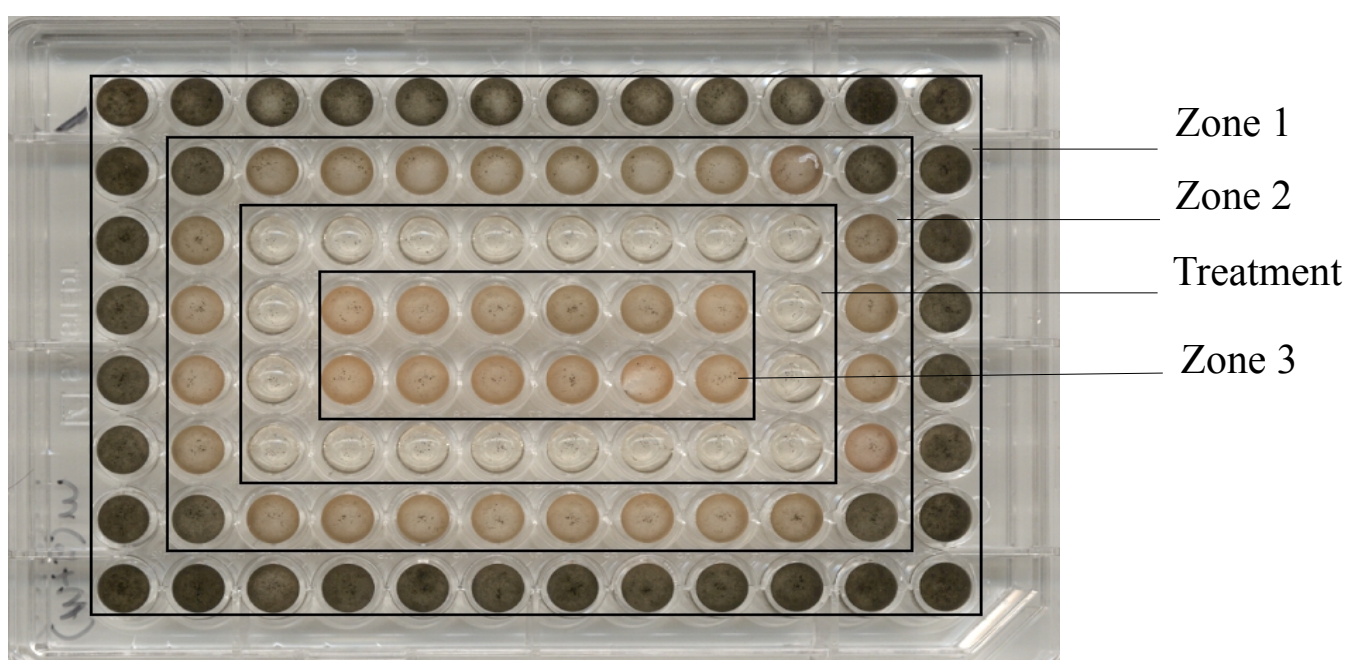

(B)

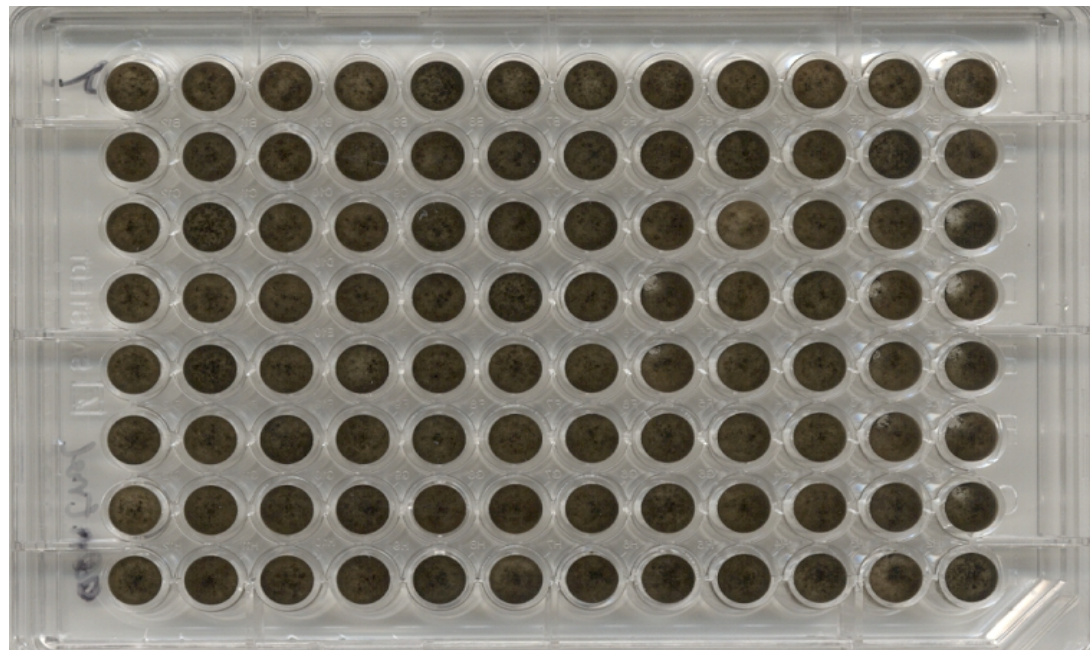

Control plate

Figure 11. Growth of $M$. phaseolina in microtiter plate. Changes in pigmentation as a result of cross contimination to adjacent zones (A) Groth in control plate(B) 
Chapter 3

Antifungal properties of sesame

(A)

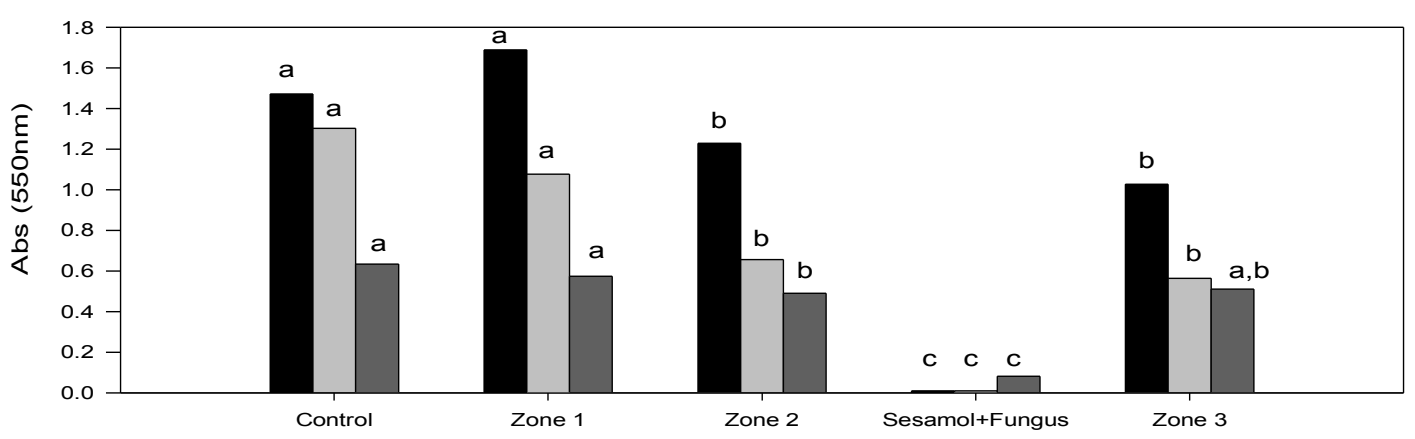

(B)

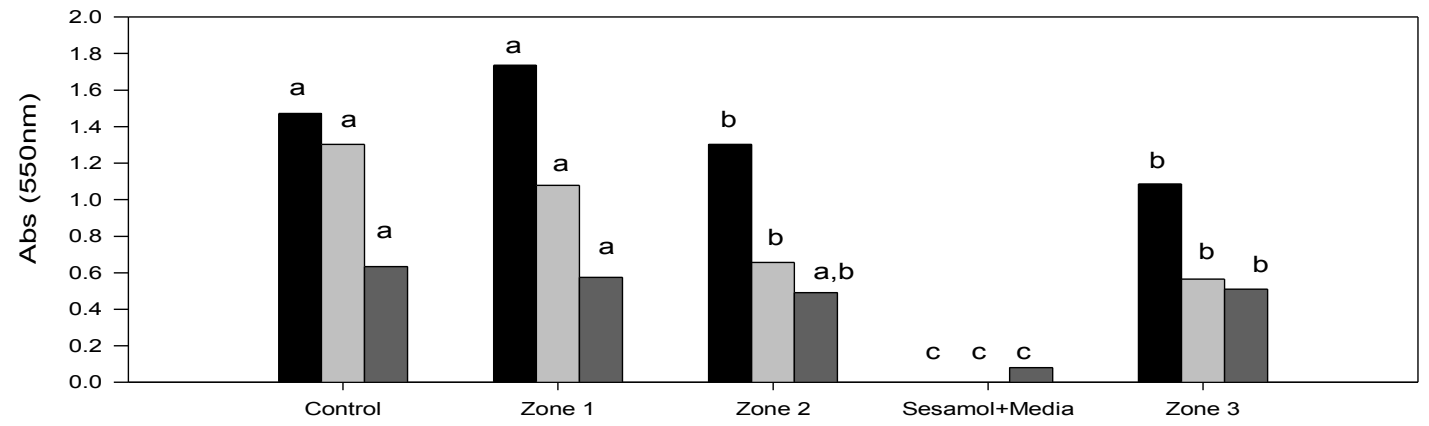

(C)

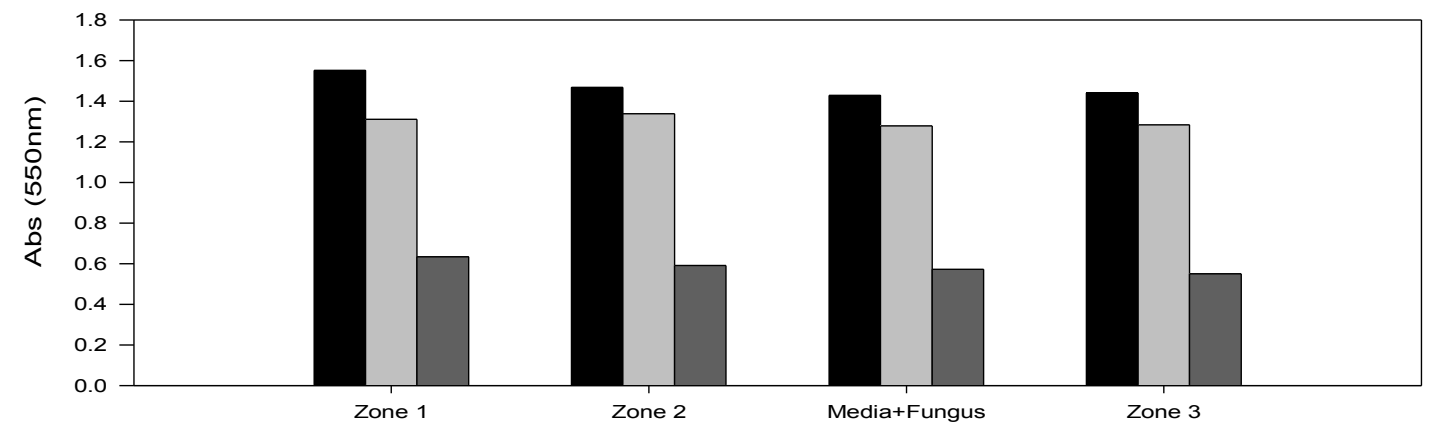

A. sesami

$\square$ M. phaseolina $\square$ F.oxysporum

Figure: 12. Changes in growth of fungus in different zone of microtiter plate as a result of cross contimination. Treatment zones contain sesamol and fungus with PDB medium (A) Sesamol with media (B) and fungus with media (C) Each bar is the mean of three replications 24 measurement in total. Bars with the same letter indicate no differences based on One Way ANOVA with all pairwise multiple comparison procedures (Tukey Test) at .( $P<0,001)$. 
(A)

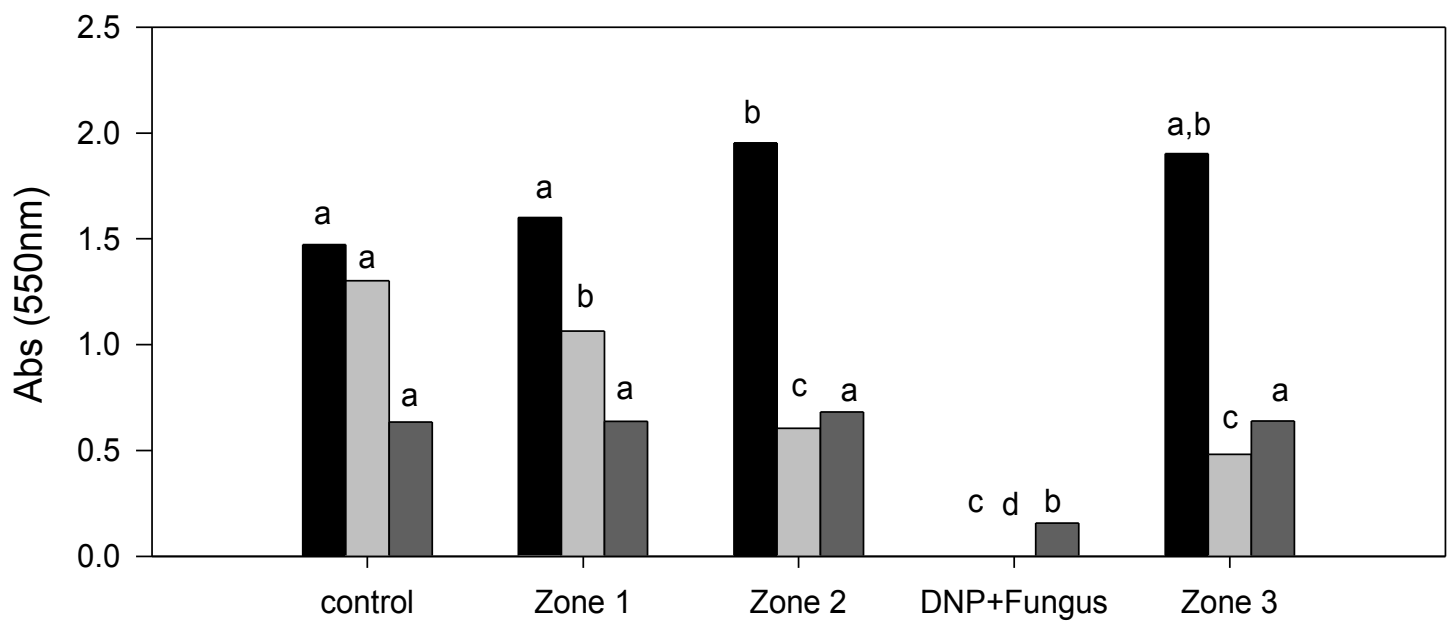

(B)

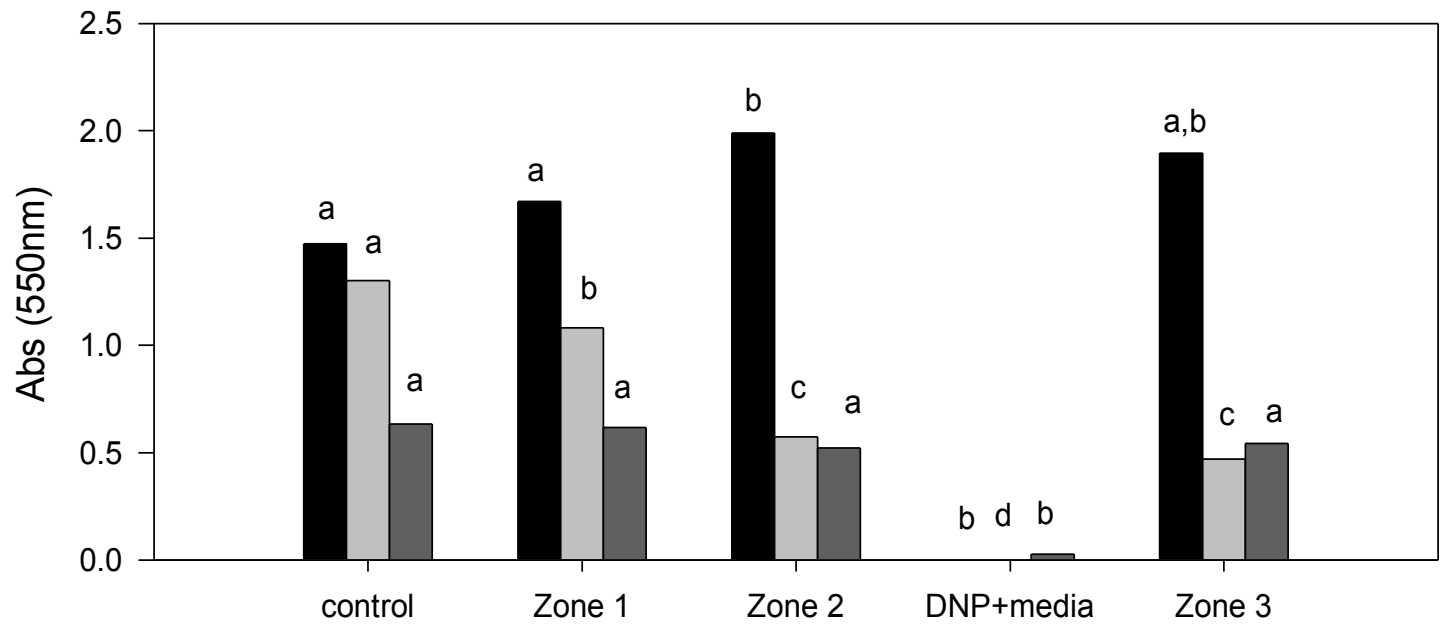

Figure: 13. Changes in growth of fungus in different zone of microtiter plate as a result of cross contimination. Treatment zones contain DNP and fungus with PDB medium (A) DNP with media (B) and fungus with media (C). Each bar is the mean of three replications 24 measurement in total. Bars with the same letter indicate no differences based on One Way ANOVA with all pairwise multiple comparison procedures (Tukey Test) at .( $P<0,001)$. 


\section{DISCUSSION}

\section{Antimicrobial activity of plant extract}

Plant extracts' antimicrobial activity have been shown in a number of publications. Sesame leaves extracts were found to have inhibitory effects against Streptococcus pneumoniae, Candida albicans (Ahmed et al., 2009; Shittu et al., 2006), Staphylococcus aureus (Ahmed et al., 2009), against symbiotic fungus (Leucoagaricus gongylophorus) of Atta sexdens L (Stelamaris et al., 1998). Sesame leaves, stem and root extracts showed inhibitory activity against M. phaseolina and F. oxysporum (Laurentin, 2007). Antimicrobial compound, 2-isopropenylnaphthazarin-2,3-epoxide, was isolated from hairy roots of Sesamum indicum which had been established by transformation of the mother plant with Agrobacterium rhizogenes (Ogsawara et al., 1993). Insect baits of sesame leave flour (15\%) showed promising result in the control of lemon leaf cutter anthills, Atta sexdens rubropilosa (Filho and Dorval, 2003). Fungal toxicant compounds were present in all the accessions but the final effect depends on balance proportion of each compound (Laurentin, 2007). The variation in effects observed among the different accessions in our study lead to the assumption that there is potential to improve plant disease resistance in sesame using metabolic pathway engineering and emphasis should be given in the intra species screening for the isolation of effective and novel fungi toxicant compounds.

\section{Antimicrobial activity of purified sesame lignans}

Sesamol helps the plant by inhibiting the growth of invading pathogens, significantly decreasing the charcoal rot ( $M$. phaseolina) symptoms of soybean in vivo experiment (Broker et al., 2000), inhabited growth and lipid production of Mucor circinelloides Wynn et al., 1997), showed anti feeding activity against stored product pests: Sitophilus granarius, Tribolium confusum, and Trogoderma granarium (Harmatha and Nawrot, 2002). Our in vitro study shows growth inhibition of $M$. phaseolina, A. sesami and $F$. oxysporum. Antimicrobial nature of sesamol is not fully understood and it may be acting 
physiologically in plants as defense molecule, as signaling molecule to induce physiological plant defense responses or may be functioning as potent systemic antifungal agent within the plant (Broker et al., 2000). Sesamol inhabits lipid biosynthesis/accumulation in Mucor circenelloides (Wynn et al., 1997 as cited by Jacklin et al., 2000) and F. moniliforme via accumulation of secondary metabolite (GA3) by acetyl-CoA destined for fatty acid by metabolic switching (Jacklin et al., 2000). Sesamin shows inhibition against Bombyx mori (L) and anti feeding activity against Spilarctia obliqua (Walker) larvae (MacRae and Towers,1984; Srivastava et al., 2001) and was found to be synergistic to several synthetic insecticides (MacRae and Towers,1984) potential insecticide for the control of velvet bean caterpillars Anticarsia gemmatalis (Nascimento et al., 2003).

\section{Inducive metabolites}

Plants are the ultimate source of constitutive or inducive metabolites. Inducive metabolites are called phytoalexins (Muller and Borger, 1940 as sited by Grayer and Kokubun, 2001) and are formed in the plant due to biotic or abiotic stress such as infection with fungi, exposure to UV or treatment with heavy metal ions (Grayer and Kokubun, 2001). Our induction experiments did not lead to final conclusion as, copper apparently remain in the tissues and causing growth inhibition of fungus in bioassay because some of the inhibition were also observed in $\mathrm{CuCl}_{2}$ control (plants sprayed with $\mathrm{CuCl}_{2}$ just before harvesting, washed and preserved) or the effect might be due to fast production of salicylic acid (SA). Plants sprayed with $\mathrm{CuCl}_{2}$ found to have higher SA of

$\mathrm{CuCl} 2$ treatment may be due to the high concentration of SA in the extract. SA is a phenolic compound and reported to have inhibitory in invitro assay. 


\section{Cross contamination by sesamol and DNP in neighbouring wells of microtiter plate}

Microtiter plate bioassay method is a rapid method for testing the efficacy of compound (Kuhajek, 2002; Laurentin, 2007). In our experiment with pure compound we found some cross contamination in adjacent wells as growth was inhibited while the inhibitory compound was present in adjacent wells. The effect in neighboring wells might be due to some volatile compounds passing to neighboring wells or the compound itself transfers to neighboring wells by capillary movement. Need some analytical studies for final answer. Treatment of Mucor circinelloides with sesamol in cultural medium promotes the accumulation of alcohol, ethanol and butan-2-ol (Wynn et al., 1997). However, we may exclude the inhibitory effect in adjacent wells by fungal produced compound in response of sesamol or DNP presence, as we found the same effect in adjacent wells when there was only compound present. The ultimate solution for this problem was to leave the nearest one row empty while doing bioassay with pure compound. 


\section{REFERENCES}

1) Ahmed, A. 2010 The biological role of Fusarium graminearum mycotoxins $A$. Ph.D thesis submitted to Georg August University, Goettingen, Germany.

2) Ahmed, T., Shittu, L. A. J., Bankole, M. A., Shittu, R. K., Adesanya, O. A., Bankole, M. N. and Ashiru, O. A. 2009 Comparative studies of the crude extracts of sesame against some common pathogenic microorganisms. Scientific Research and Essay, 4:584-589.

3) Al-Yemeni, M. N., M. A. Hussain and A. Y. Basahy. 2000 Mineral composition of some sesame seeds grown in the Gizan area of Saudi Arabia. Phyton. Int. J. Exp. Bot. 67:121-125 .

4) Bai, G. H. and Shaner, G. 1996 Variation in Fusarium graminearum and cultivar resistance to wheat scab. Plant Dis. 80:975-979.

5) Bateman, G.L., Kwasna, H. and Ward, E. 1996 Relationship among Fusarium spp. estimated by comparing restriction fragment length polymorphism in polymerase chain reaction amplified nuclear DNA. Can. J. Microbi. 42:12321240.

6) Bedigian, D. 2000 The Cambridge world history of food. in K. E Kiple and C.K. Ornelas-Kiple, .1:411-421.

7) Brooker, N. L., Long, J. H. and Stephan, S. M. 2000 Field assessment of plant derivative compounds for managing fungal soybean diseases. Biochem. Soc. Trans. 28:917-920..

8) Cho, E. K. and. Choi, S. H. 1987 Etiology of half stem rot in sesame caused by Fusarium oxysporum. Korean J. Plant Prot. 26:25-30.

9) Cowan, M. M. 1999 Plant products as antimicrobial agents. Cli. Microbiol. Rev. $4: 564-582$.

10) Filho, O. P. and Dorval, A. 2003 Effect of granulated formulations composed by chemical products and leaves and seeds of sesame, Sesamum indicum, to 
control nests of Atta sexdens rubropilosa Forel, 1908 (hymenoptera: formicidae). Ciência Florestal, Santa Maria, 13:67-70.

11) Grayer, R. J. and Kokubun,T. 2001 Plant-fungal interactions: the search for phytoalexins and other antifungal compounds from higher plants. Phytochem. 56:253-263.

12) Harmatha J. and Nawrot, J. 2002. Insect feeding deterrent activity of lignans and related phenylpropanoids with a methylenedioxyphenyl (piperonyl) structure moiety. Entomologia Experimentalis et Applicata, 104:51-60.

13) Jacklin, A., Ratledge, C. and Wynn, J. P. 2000 Lipid-to-gibberellin metabolic switching in Fusarium moniliforme via the action of sesamol. Biotechnol. Lett. 22:1983-1986.

14)J aved M. S., A. Wahid and M. Idrees. 1995. Fungi associated with sesamum seed and their frequency. Pak. J. Phytopathol. 7:174-176.

15) Jerald ,K., Pataky, Martin L. Carson. 2004 Plant Pathology Concept of laboratory Exercise. (Host Resistance) CRC Press Raton London New York Washington D.C. $295-311$

16) Jonsyn, F. E. 1988 Seedborne fungi of sesame (Sesamum indicum L) in Sierra Leone and their potential aflatoxin/mycotoxin production. Mycopathologia, 104:123-127.

17) Kolte, S. J. 1985 Disease of annual edible oil seed crops: rapeseed, mustard, safflower and sesame diseases. Vol II, CRC Press Inc., Boca Raton, Florida. 232pp.

18) Langham, D., Rodriguez, M. 1946 Dos nuevas variedades de ajonjolí Venezuela 51 y Venezuela 52. Circular N 15. Departamento de Genetica. Dirección de Agricultura. Maracay. Venezuela

19) Laurentin, H., Layrisse, A, Quijada, P, 2000 Evaluación de dos ciclos de selección recurrente para altos rendimientos de semilla en una 
población de ajonjolí. Agronomía Tropical (Maracay) 50:521-535

20) Laurentin, H. 2007 Genetic diversity in sesame: molecular markers, metabolic profiles and effect of plant extracts on soil-borne pathogenic fungi. A. Ph.D thesis, Georg August University, Goettingen, Germany.

21) MacRae, W. D. and Towers, G.H.N. 1984 Biological activities of lignans. Phytochem. 23:1207-1220.

22) Mazzani, B, 1952 Una nueva variedad de ajonjolí producica en el Instituto Nacional de Agricultura. Agronomía Tropical (Maracay) 1:269-277

23) Mazzani, B, Nava, C, Martinez, A, Layrisse, A, 1973 Maporal, una nueva variedad de ajonjoli para los Llanos Occidentales. Agronomia Tropical 23:501508

24) Mazzani, B. 1953 Inamar: nueva variedad de ajonjolí producidad en el Instituto Nacional de Agricultura. Agronomía Tropical (Maracay) 3:211-213

25) Montilla D., Cedeño T. 1991 Fonucla: una nueva variedad de ajonjolí (Sesamum indicum L.). Bioagro 3:52-54

26) Montilla D., Teran H.1996. UCLA1, una nueva variedad de ajonjolí (Sesamum indicum L.).Bioagro 8:26-29

27) Muller K. O. and Borger, H. 1940 Experimentelle untersuchungen uber die phytophthorainfestans resistenz der kartoffel.Arb. Biol. Reichsanst. Land Forstwirtsch 23:189-31.

28) Nascimento, I. R., Murata, A. T., Bortoli S. A and Lopes, L. M. 2003 Insecticidal activity of chemical constituents from Aristolochia pubescens against Anticarsia gemmatalis larvae. Pest Manag. Sc. 60:413-416.

29) Ogasawara, T., Chiba, K. and Tada, M. 1993 Production in high-yield of a naphthoquinone by a hairy root culture of Sesamum indicum. Phytochem. 33:109-1098.

30) Fiehn, O. 2002 Metabolomics the link between genotypes and phenotypes. Plant 
Molecular Biology 48: 155-171,2002.

31) Ribeiro, S. B., Pagnocca, F. C, Victor, S. R., Bueno, O. C., Hebling, M.J ., Bacci Jr, M., Silva,O. A., Fernandes, J. B., Vieira, P. C. and Silva,M. F. G. F. 1998 Activity of sesame leaf extracts against the symbiotic fungus of Atta sexdens $L$. An. Soc. Entomol. Brasil. 27:421-426.

32) Shittu, L. A. J.,Bankole, M. A. , Ahmed, T., Aile, K., Akinsanya, M. A., Bankole, M. N., Shittu, R. K., and Ashiru, O. A. 2006 Differential antimicrobial activity of the various crude leaves extracts of Sesam radiatum against some common pathogenic micro-organisms. Scientific Res. and Essay, 1:108-111.

33) Sinclair, J. B. 1982. Compendium of Soybean Diseases. American Phytopathol. Soc. St. Paul, MN. 2:30-33.

34) Springbett A. J., K. MacKenzie, J. A. Woolliams, and S. C. Bishop. 2003. The contribution of genetic diversity to the spread of infectious diseases in livestock populations. Genetics 165:1465-1474

35) Srivastava, S., Gupta, M. M., V. Prajapati, A. K. Tripathi and S. Kumar. 2001. Sesamin a potent antifeedant principle from Piper mullesua. Phytother. Res. 15:70-72.

36) Wynn, J. P., Kendrick, A. and Ratledge, C. 1997 Sesamol as inhibitor of growth and lipid metabolism in Mucor circenelloides via its action on malic enzyme. Lipids 32: 605-610 


\section{Chapter 4 - Generation of recombinant inbread lines (RILs) for genetic mapping and studies of the inheritance of metabolic synthesis in sesame (Sesamum indicum L.)}

\section{ABSTRACT}

A cross of two parent accessions that showed significant polymorphism revealed by AFLP was performed. Single seed descendents were selfed for five generations. AFLP markers were used to assess the relatioship between the parents and RILs. Three primer combinations produced 123 polymorphic bands between the parents. AFLP data obtained will be used for the construction of a linkage map by collaborating sesame breeders in Antalya University.

Metabolic fingerprinting was done by using high performance liquid chromatography (HPLC) with full-scan mass spectrometric (MS) detection. 15 reproducible polymorphic signals were detected in parents. 6 RILs were selected for the analysis of polymorphic metabolic signals.

\section{INTRODUCTION}

The spectrum of secondary metabolites produced by plants constitute a central part of the chemical phenotype, which plays an important role in defense against pathogens and pests. In sesame, the content of lignans and tocopherols is a quality criterion because these metabolites possess antioxidative activity and are believed to have health-promoting effects.

The relationship between metabolic and genomic diversity has rarely been studies before. In one of the first studies of its kind, performed with sesame, chemical and genetic diversity were not concordant (Laurentin et al 2008). Although the biosynthesis of lignans have been studied in detail, little is known about the inheritance of secondary metabolite synthesis in sesame. No linkage map of sesame is available, which hampers studies of the genetics of metabolic synthesis in this crop.

Molecular markers are crucial tools of plant breeders. In sesame most of molecular study were restricted to diversity assessment using anonymus markers. Isozyme 
(Isshiki 1997), Random Amplified polymorphic DNA (RAPD) (Bhat et al. 1999, Ercan A. G. 2004), microsatellite sequences (SSRs) (Dixit et al 2005), AFLP (Ghulm et al. 2006, Laurentin et al. 2008), agro-morphological and ISSR marker traits (Parsaeian et al. 2011) were used for the study of genetic diversity. Furthermore, inter-simple sequence repeats (ISSR) polymorphisms (Kim et al 2002) and AFLP (Laurentin and Karlovsky 2006) were used to determine genetic relationships among sesame accessions. AFLP markers were used to identify QTLs for some domestification traits including closed capsules (Bulent Uzan 2003). RAPD and ISSR markers linked with determinant growth habits were identified (Bulent Uzan and Ilhan Cagirgan 2009). Expressed sequence tag-simple sequence repeat (EST-SSR) have also been used as molecular markers in sesame (Li-Bin wei 2008).

Although a large number of studies used AFLP to assess genetic diversity in sesame, these markers have not been used for the construction of a linkage map so far.

\section{Goals:}

- Advance a cross of two sesame accessions selected due to genetic distance and difference in metabolic profiles to F6

- Generate preliminary AFLP data for the characterization of the RILs

- Generate metabolic profiles of a subset of the segregating population and compare with the profiles of the parents

\section{MATERIAL AND METHODS}

\section{Plant Growth conditions}

The F1 seeds were developed by two reciprocal crosses of parents Korea 1 is No. 92_3091 and Africa 3 is No. 95-223 in the National Germplasm Bank of Venezuela, thats show significant polymorphism reveled by AFLP. The Jaccard distance between the two accessions based on a large set of AFLP markers was 0.57 (Average pairwise similarity across our 32 accessions was 0.65) (Laurentin and Karlovsky 2006). The resulting seeds of two F1 capsules were mixed and grown to produce six F1 plants. No pollination control were practice. 20 seed were grown from each F1 plant. Recombination Inbread lines (RILs) were developed by single seed selections 
from individual plants of an F2 population, single seed descents were repeated for five generations. Each generation took 6 months to develop seeds. 3 seeds from each 120 F6 plants were grown, scored for morphological trait (flower colour) and leaves were collected ( pooled from 3 plants )for genomic studies while for metabolic studies leaves were not poled but reproducible signals in three replicate were taken for analysis.

\section{DNA extraction}

DNA were extracted from the $50 \mathrm{mg}$ freeze dryed leaves of both parents and recombination inbread lines (RILs) with cetyltrimethl ammonium bromid (CTAB) methods modified by Ginwal and Neha (1990). Modification of this method include addition of $8 \mathrm{M}$ lithium chloride solution $(300 \mu \mathrm{L} / 1 \mathrm{ml} \quad \mathrm{CTAB})$ and use of $4 \%$ polyphenolpyrollidine (PVP) insted of $2 \%$ PVP. DNA concentration was determined on $2 \%$ agarose gel. AFLP were done with the method described by Vos et al. (1995) with the following steps

\section{AFLP procedure}

\section{Digestion of genomic DNA}

Five microliter of genomic DNA (50 ng) was digested with $0.3 \mu \mathrm{L}$ of EcoRI $(10 \mu / \mu \mathrm{L})$, $0.125 \mu \mathrm{L}$ of Mse $(10 \mu / \mu \mathrm{L})$ with $2 \mu \mathrm{L}$ of Tango buffer $(10 \mathrm{X})$ in $10 \mu \mathrm{L}$ of reaction mixture. The reaction was carried out via incubation for $1.5 \mathrm{~h}$ at $37^{\circ} \mathrm{C}$ in the climatic cupboard followed by $65{ }^{\circ} \mathrm{C}$ for $1.5 \mathrm{hr}$.

\section{Ligation of adaptors}

Digested DNA was ligated with $0.05 \mu \mathrm{L}$ of EcoR1 adaptor (25uM) and $0.5 \mathrm{ul}$ of Mseadaptor $(25 \mu \mathrm{M})$ together with $0.25 \mathrm{v}$ of Ligation buffer (10x) 0.05 ul of T4 ligase (5 $\mu / \mu \mathrm{L}$ ) and $1.65 \mu \mathrm{L}$ of $\mathrm{ddH}_{2} \mathrm{O}$ and incubation continued for $3 \mathrm{~h}$ at $37^{\circ} \mathrm{C}$. Then, the sample were diluted 10 times after $3 \mathrm{~h}$ of ligation to be used in the pre-amplification process. 


\section{Pre-amplification}

Pre amplification was done with $5 \mu \mathrm{L}$ of diluted ligation mixture with $5 \mu \mathrm{L}$ mixure of amplification products including $0.12 \mu \mathrm{L}$ of E-primer (25uM)[5'-GACTGCGTACCAATT CA-3'], $0.12 \mu \mathrm{L}$ of M-primer $(25 \mu \mathrm{M})\left[5^{\prime}-G A T G A G T C C T G A G T A A C-3 '\right], 3.02 \mu \mathrm{L}$ of $\mathrm{ddH}_{2} \mathrm{O}, 0.5 \mu \mathrm{L}$ of $\mathrm{MgCl}_{2}(50 \mathrm{mM}), 1 \mu \mathrm{L}$ PCR buffer (10x), $0.2 \mu \mathrm{L}$ dNTP mix (10 mM) and $0.04 \mu \mathrm{L}$ of Taq $(5 \mu \mathrm{L})$ with the PCR program [25 cycles: denaturation: $94^{\circ} \mathrm{C} 30$ sec, annealing: $56{ }^{\circ} \mathrm{C} 1 \mathrm{~min}$, elongation: $72{ }^{\circ} \mathrm{C} 1 \mathrm{~min}$ ]. PCR samples were then diluted 10 times.

\section{Selective amplification}

Selective amplification was carried out with $2.5 \mu \mathrm{L}$ of diluted pre-amplified DNAtemplate with $7.5 \mu \mathrm{L}$ mixure of amplification products comprising $0.3 \mu \mathrm{L}$ of E-primer $(20 \mu \mathrm{M})$ [EcoR1-AGC, EcoR1-ACC, EcoR1-ACA 3 nucleotide extension labelled with dye D680, D750, D635, respectively], $0.3 \mu \mathrm{L}$ of M-primer (20 uM) [M-primer with CA 2 nucleotide extension], $5.66 \mu \mathrm{L}$ of $\mathrm{ddH}_{2} \mathrm{O}, 0.5 \mu \mathrm{L}$ of $\mathrm{MgCl} 2(50 \mathrm{mM}), 1 \mu \mathrm{L}$ PCR buffer (10x), $0.2 \mu \mathrm{L}$ dNTP mix (10 mM) and $0.08 \mu \mathrm{L}$ of Taq $(5 \mu \mathrm{L} / \mu \mathrm{L})$ with the PCR program [(denaturation: $94^{\circ} \mathrm{C} 30 \mathrm{sec}$, annealing: $65^{\circ} \mathrm{C}, 30 \mathrm{sec} / \mathrm{dt}-0.7^{\circ} \mathrm{C} / \mathrm{cycle}$, elongation: 72 ${ }^{\circ} \mathrm{C} 1$ min 11 cycles)( 30 cycles: denaturation: $94{ }^{\circ} \mathrm{C} 30 \mathrm{sec}$, annealing: $56{ }^{\circ} \mathrm{C} 1 \mathrm{~min}$, elongation: $\left.72{ }^{\circ} \mathrm{C} 1 \mathrm{~min}\right]$.

\section{Separation of DNA fragments}

Beckman Coulter CQ 8000AFLP sequencer was used for fragment separation. A 2.5 $\mu \mathrm{L}$ of each amplification with $30 \mu \mathrm{L}$ of separation loading solution, $1 \mu \mathrm{L}$ of size standard (600) and one drop of mineral oil were loaded in the sample plate. Optimized Frag4 (recommended by manufacturer fro size standerd 600) separation method was used.

\section{Extraction method for metabolic fingerprinting}

Fresh leaves from both parents and recombination inbread lines (RILs) were homogenized with pistel and mortar in the presence of liquid nitrogen and subjected for metabolites extraction with $80 \%$ methanol $(1 \mathrm{~g} / 5 \mathrm{ml})$ grounded tissues, vortexed 
and shaken. The upper DEE phase were transferred to new eppendorf tube after centrifugation for $5 \mathrm{~min}$ at $13000 \mathrm{~g}$ and dried completely in concentrator and stored at $-20^{\circ} \mathrm{C}$ to ensure the stability. Sample were redissolved in $200 \mu \mathrm{L}$ of HPLC solvents (MeOH:H2O) for $1 \mathrm{hr}$, the upper phase after vertexed and centrifuged at 12000rpm for 5 min were used for quantification.

\section{HPLC and MS}

Non targated metabolic profilling were done with the HPLC system equipped with autosampler (ProStar 410, Varian, Darmstadt, Germany), binary pump system (ProStar 210, Varian), degasser (Degassit, MetaChem Technologies) and a column oven (Jetstream 2 plus, Techlab, Germany) coupled to a ion trap mass spectrometer (500-MS, Varian) via electrospray ionization (ESI).10 $\mu \mathrm{L}$ of the sample were injected into a reversed-phase column Polaris C18-Ether (100 $\times 2 \mathrm{~mm}$ i.d., $3 \mu \mathrm{m}$ particle size, Varian) with a compatible guard column (MetaGuard Polaris C18-Ether, Varian) kept at $40{ }^{\circ} \mathrm{C}$.

$10 \mu \mathrm{L}$ of the sample were injected onto a reversed-phase column Polaris C18-Ether with a compatible guard column. Methanol, acetonitrile and acetic acid were used for the mobile phases with following concentration. Binary gradient of $7 \mathrm{mM}$ acetic acid in $95 \%$ water : $5 \%$ acetonitrile $(A)$ and $7 \mathrm{mM}$ acetic acid in methanol $(B)(0-2.20$ min $90 \% A: 10 \% B, 2.20-25.0$ min from $90 \% A: 10 \%$ B to $2 \% A: 98 \%$ B, $25-30$ min $2 \%$ A : $98 \% \mathrm{~B}$, followed by washing and re-equilibration steps at a flow rate of 0.2 $\mathrm{ml} / \mathrm{min}$ ). ESI source were operated either with negative or positive spray polarity, the parameters were set as follows (negative/ positive): needle voltage $-3500 \mathrm{~V} /+5000 \mathrm{~V}$, shield voltage $-600 \mathrm{~V} /+600 \mathrm{~V}$, capillary voltage -/+50 V drying gas (nitrogen) 20 psi (138 kPa) at $250{ }^{\circ} \mathrm{C}$ and nebulizing gas (air) 50 psi (345 kPa). The MS analyzer was operated in full scan mode, mass range m/z 100-1000, scan speed $5000 \mathrm{Da} / \mathrm{sec}, 3$ scans averaged, multiplier voltage set to $1385 \mathrm{~V}$. For data acquisition MS workstation / MS Data Review 12 (Varian) was used. Conversion and processing raw data was performed with CODA, normalization was performed using Perl scripts as described (Laurentin et al. 2007). 


\section{RESULTS AND DISCUSSION}

\section{Advancement of RILs and segretation of flower color}

Sesame is a short duration crop, from seeding to harvesting it takes 3 to 4 month but in our green hause conditions in germany each generation took 6 months. It is a self pollinating crop in nature although low level (4.02-5.10\%) of cross pollination have been reported (Pathirana 1994); therefore, pollination control was not performed in our study. One parent (Africa3) had purple flower and another parents (Korea1) had yellow flower. Three plants from each of the 120 F6 RILs (360 plants) were grown and scored for flower colour. $97.5 \%$ of RILs were found to be homozygous for this trait, producing either yellow or purple flower (46.15\% purple and $53.85 \%$ yellow) (Figure 1). $2.5 \%$ of RILs produces both kind of flowers.
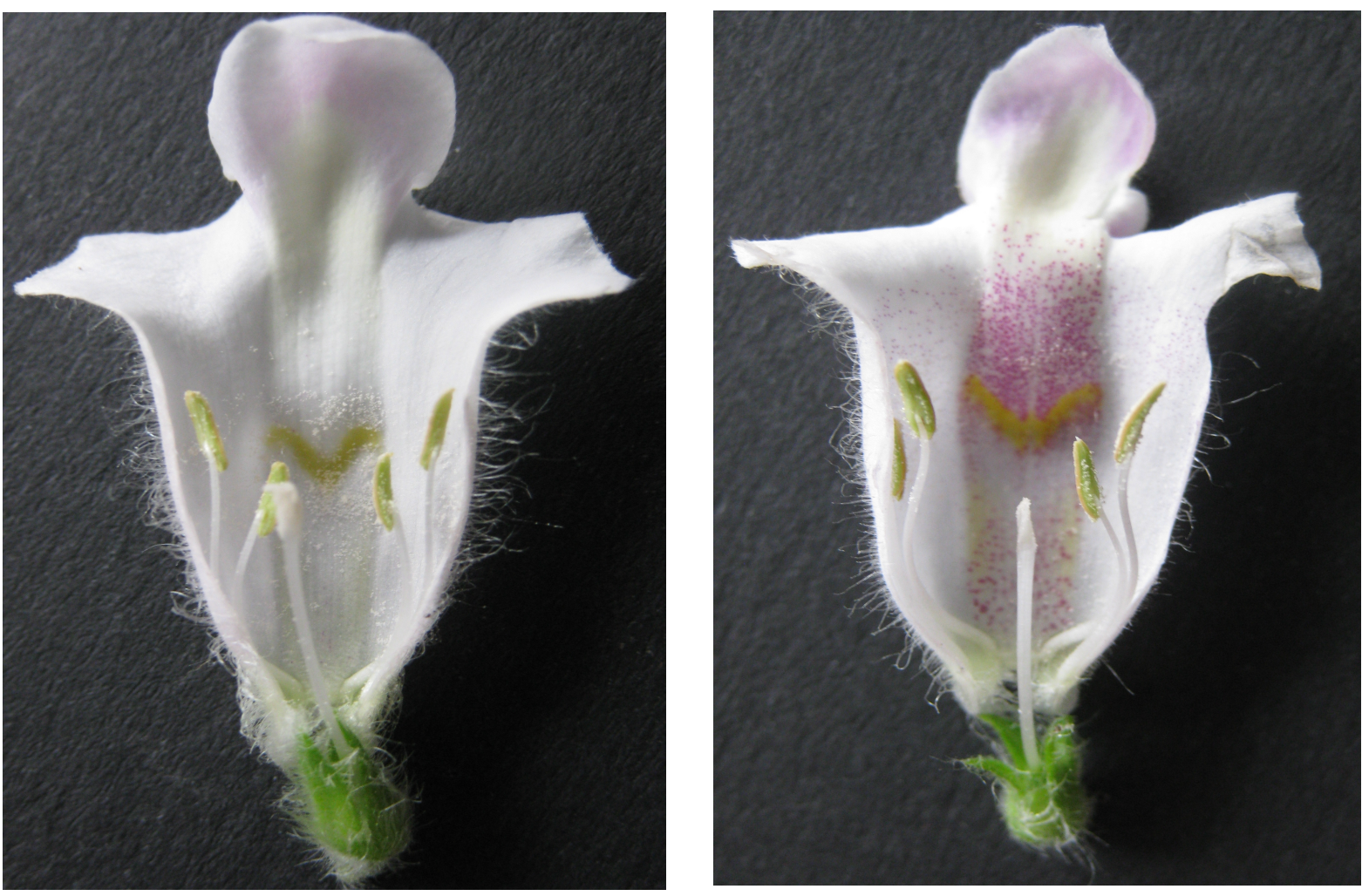

Figure 1. Flower color of parents

\section{Optimization of DNA extraction}

To generate the DNA fingerprint DNA quality is prerequisite. We tried different DNA isolation protocol with lyophilized sesame leaves samples and found modified CTAB 
protocol with 4\%PVP worked well. Modified CTAB protocol reduces the viscosity of DNA pretty well. Addition of lithium chloride in extraction buffer removed the RNA and high concentration removed the polyphenolic compound (Ginwal and Neha 1990). Three repetitive washing with chloroform:isoamyalkohol give best results. We did not face any problem in cutting genomic DNA with EcoR1 and Mse enzyme. Initially we used 0.125 EcoR1 and Mse1 in 10ul reaction, but found out increasing the concentration of EcoR1 to $0.3 \mathrm{ul}$ give good digestion (Figure 2)
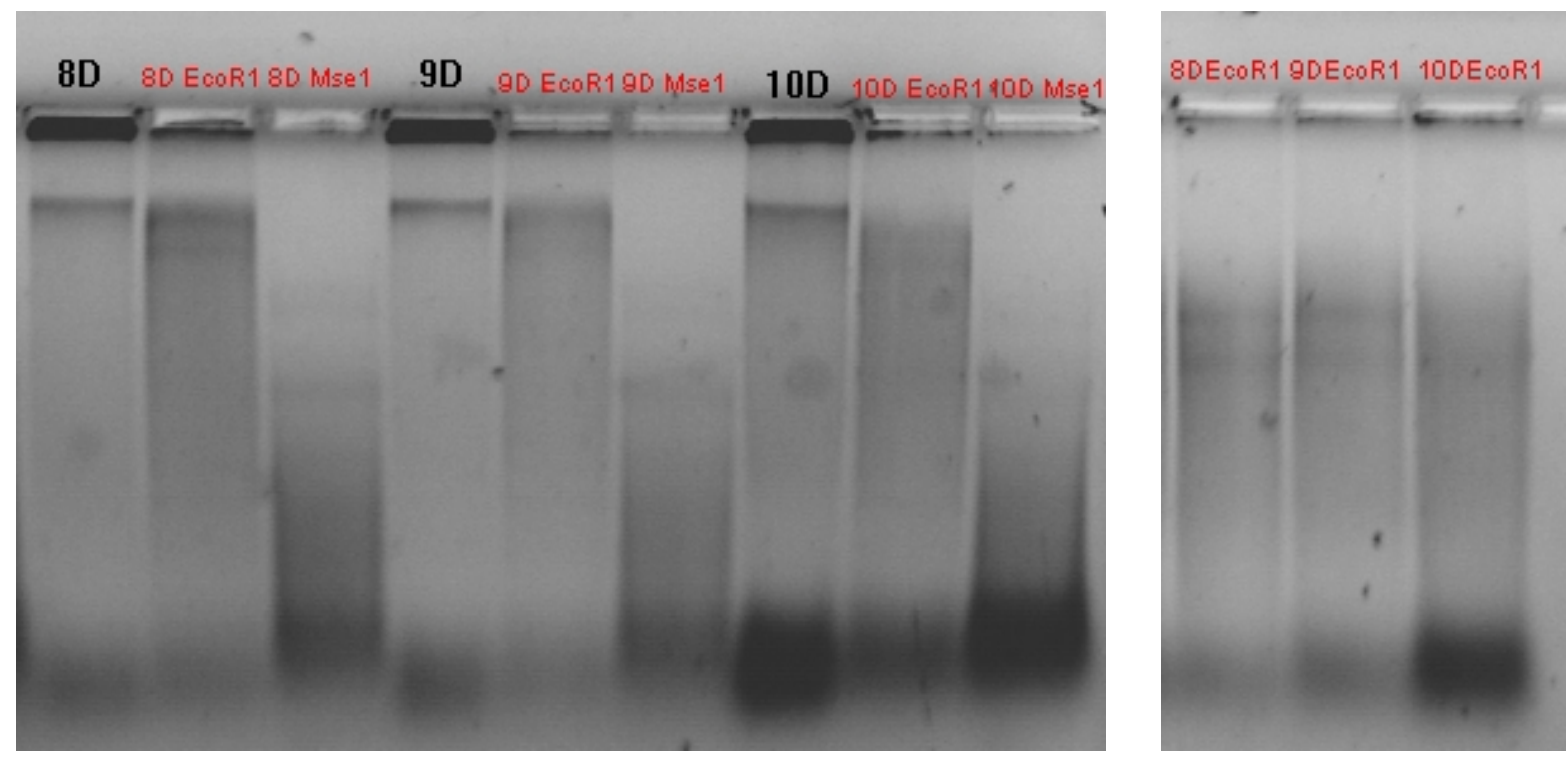

\subsection{5ul EcoR and Mse1/sample $1.7 \% \mathrm{gel}$ $40 \mathrm{~min} 80 \mathrm{~V}$}

0.3ul EcoR1

$1.7 \% \mathrm{gel}$ $40 \mathrm{~min} 80 \mathrm{~V}$

Figure 2. A gel picture showing total genomic DNA add digestion with EcoR1 and Mse1 restriction enzyme.

\section{Optimization of AFLP}

Reproducibility of fragments were checked based on replicates of parental DNA, Reproducibility between replicate without manual correction were pretty good(Figure 3). Too high peaks, too low peak, potato peak, shoulder peak were the cause of bad reproducibility between replication. 60 samples from RILs were run for AFLP, 40 good quality runs were filtered out for further analysis. 

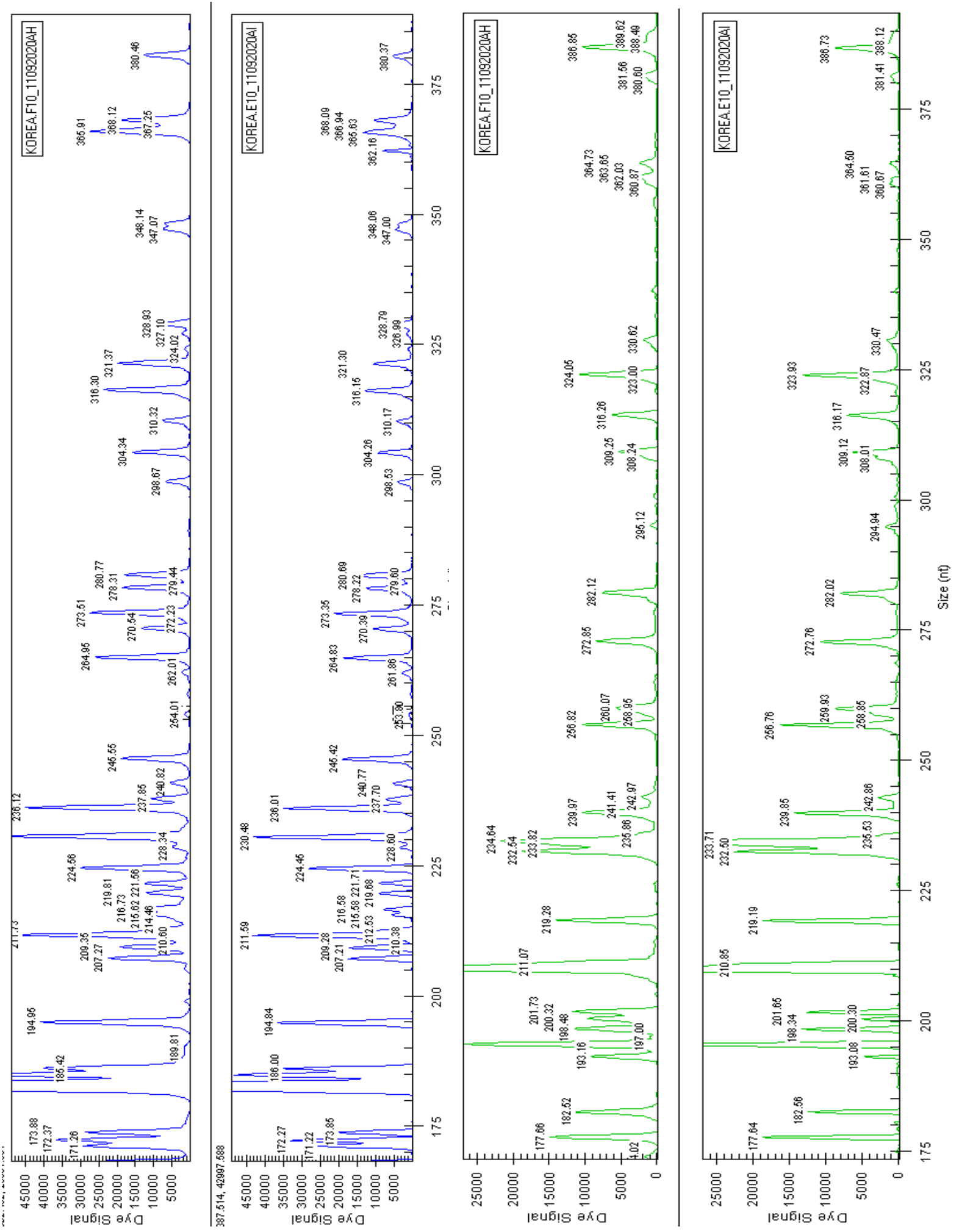

Figure 3. Comparison of replicates of AFLP

DNA from Korea1 accession was extracted twice. Each DNA was used for AFLP with two different primer combinations (green and blue). 


\section{Segregation of parental AFLP fragments}

Three primer combination produced 670 DNA bands, out of which 123 bands were polymorphic between parents. Jaccard coefficient of genetic distance between the parents was determined to be 0.20 (see chapter No. 1). A larger distance of 0.50 was reported before by $\mathrm{H}$. Laurentin and Karlovsky (2006). The discrepancy between these results probably results from a low number of primer combinations used. The number of markers for the construction of the genetic map has to be increased, which will likely lead to a correction of the distance value for the parents.

No negative correlation was found between the occurrence of polymorphic fragments of the parents and individual RILs (Figure 4). A likely reason for this finding is that many AFLP markers of the parents were disrupted by recombination in the process of generating RILs; consequently, the number of polymorphic markers inherited by a particular RIL does not correspond to the proportion of the parental genomes constituting its genome. Interestingly, all RILs inherited at least 30\% (for Korea1) or $25 \%$ (for Africa3) of polymorphic bands of the parental genomes. This could be a statistical consequence of the recombination events, provided the number of recombination events was much larger than the number of markers monitored in this study. Most importantly, no RIL showed an AFLP pattern identical to one of the parent, showing that no selfing occurred during the original cross. All of the lines designated as RILs are true recombinants.

No RIL was found to possess all monomorphic AFLP markers present in the genomes of their parents (Figure 5A). On the other hand, all RILs had new AFLP markers not present in any parent (Figure 5B). On the phenotypic level, similar observation was made by El Bramawy and Shaban (2008) who observed transgression in their analysis of RILs in sesame for resistance, yield and its attributes.

Absence of monomoprhic markers in RILs and presence of new markers that have not been observed in any of the parents can be explained by recombination events that occurred within DNA fragments amplified as AFLP markers. If crossing occurred at a specific restriction enzyme cutting site (restriction site will be destroyed), both markers potentially delimited by this restriction site will not be amplified and are 
absent in RILs (Figure 6A ). While on other side there were some fragments present in both parents but missing in Rlls. in crossing new restriction enzyme cutting site form and will amplify in AFLP (Figure 6B ) Figure 6 explains how new fragment could produces and lost in recombination.

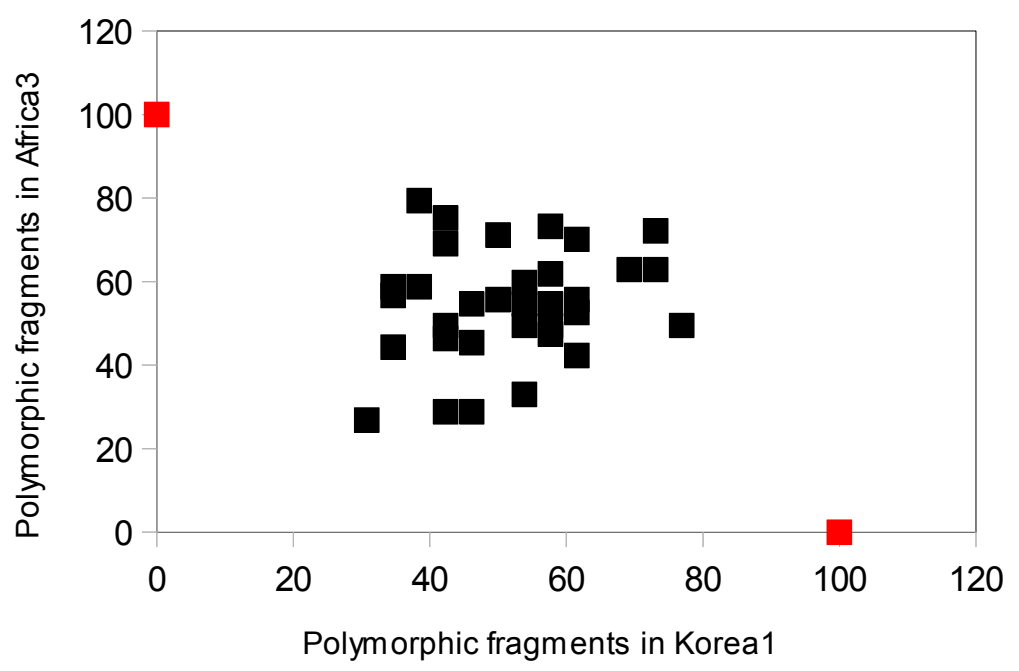

Figure 4. Polymorphic fragments of Korea1 plotted vs. polymorphic fragments of Afria3 (relative values). Black squares show the results for RILs, read squares were used to mark parental accessions. 
(A)

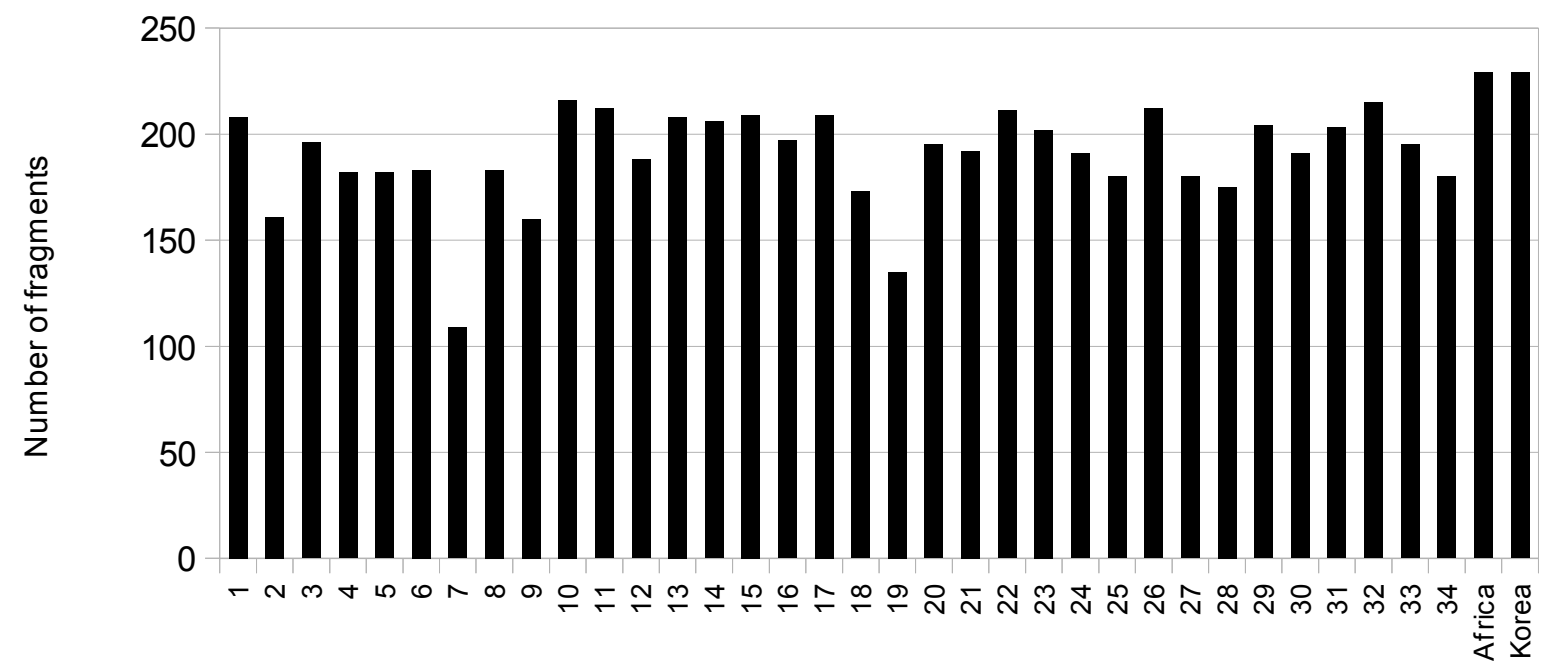

Individuals name

(B)

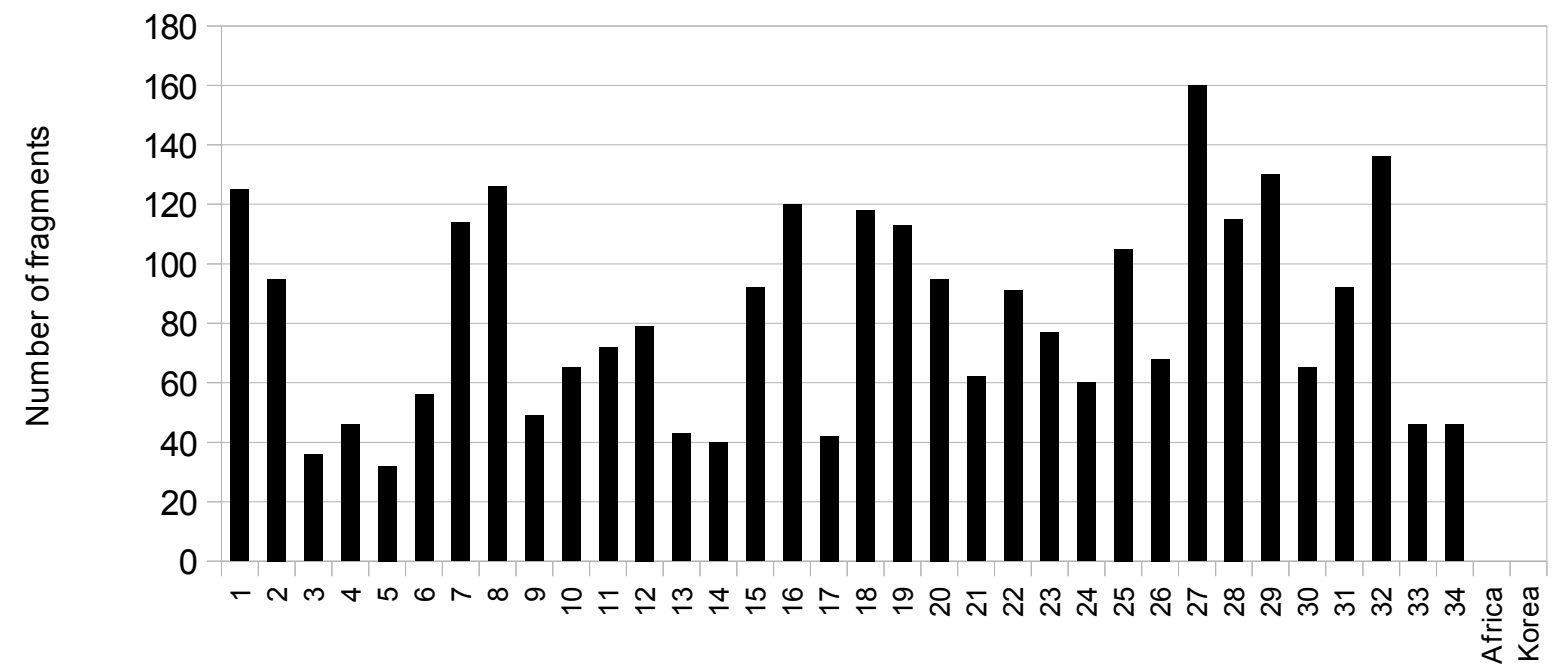

Individuals name

Figure 5. Effect of recombination on the occurrence of AFLP bands. Common fragments of both parents found in RILs (A) Fragments that were not found in parents but present in RILs (B) 
Figure 6A.

Disappearance of pseudo-monomophic markers in RILs

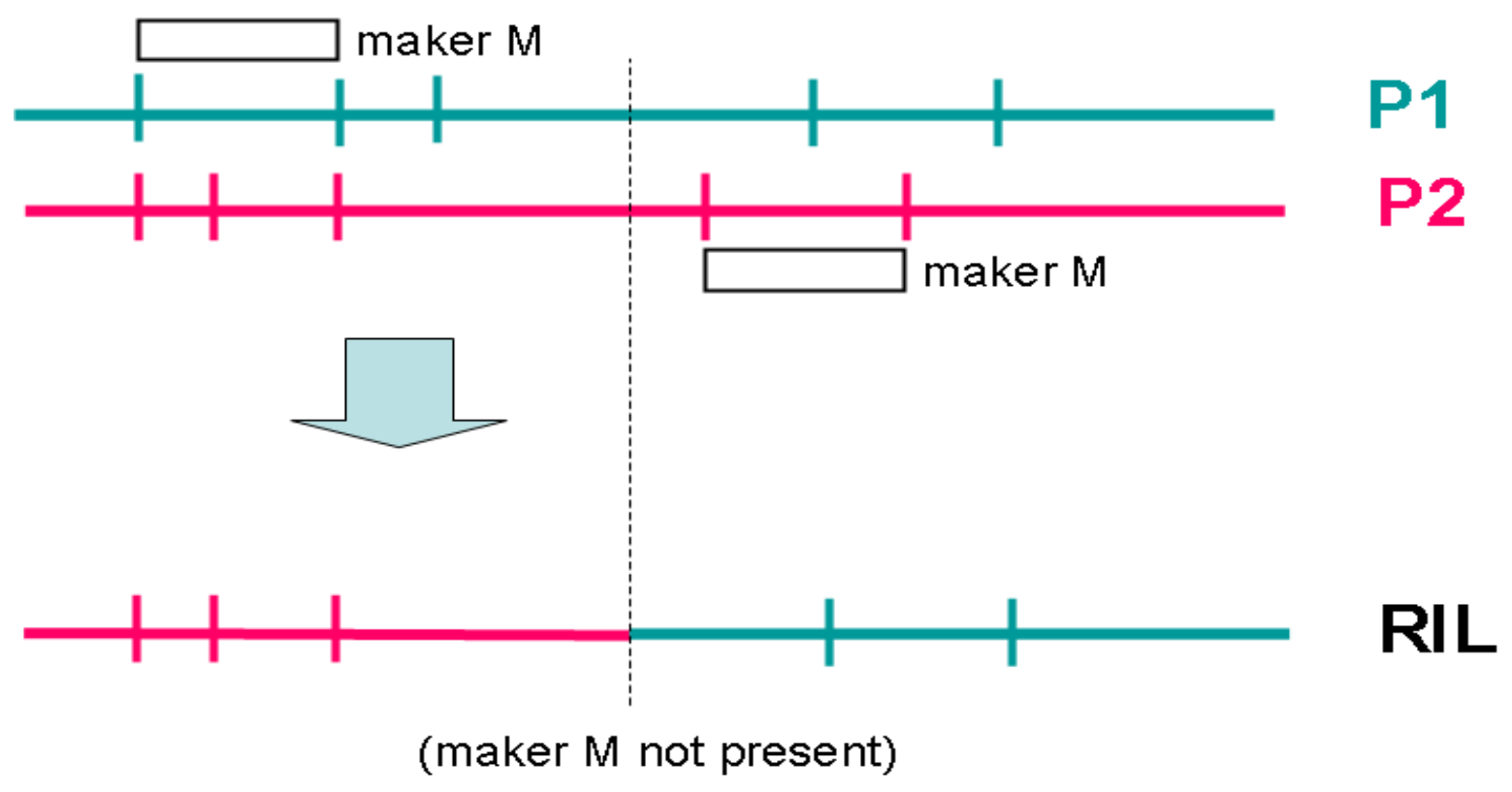


Figure 6B.

\section{Appearance of new markers in RILs}

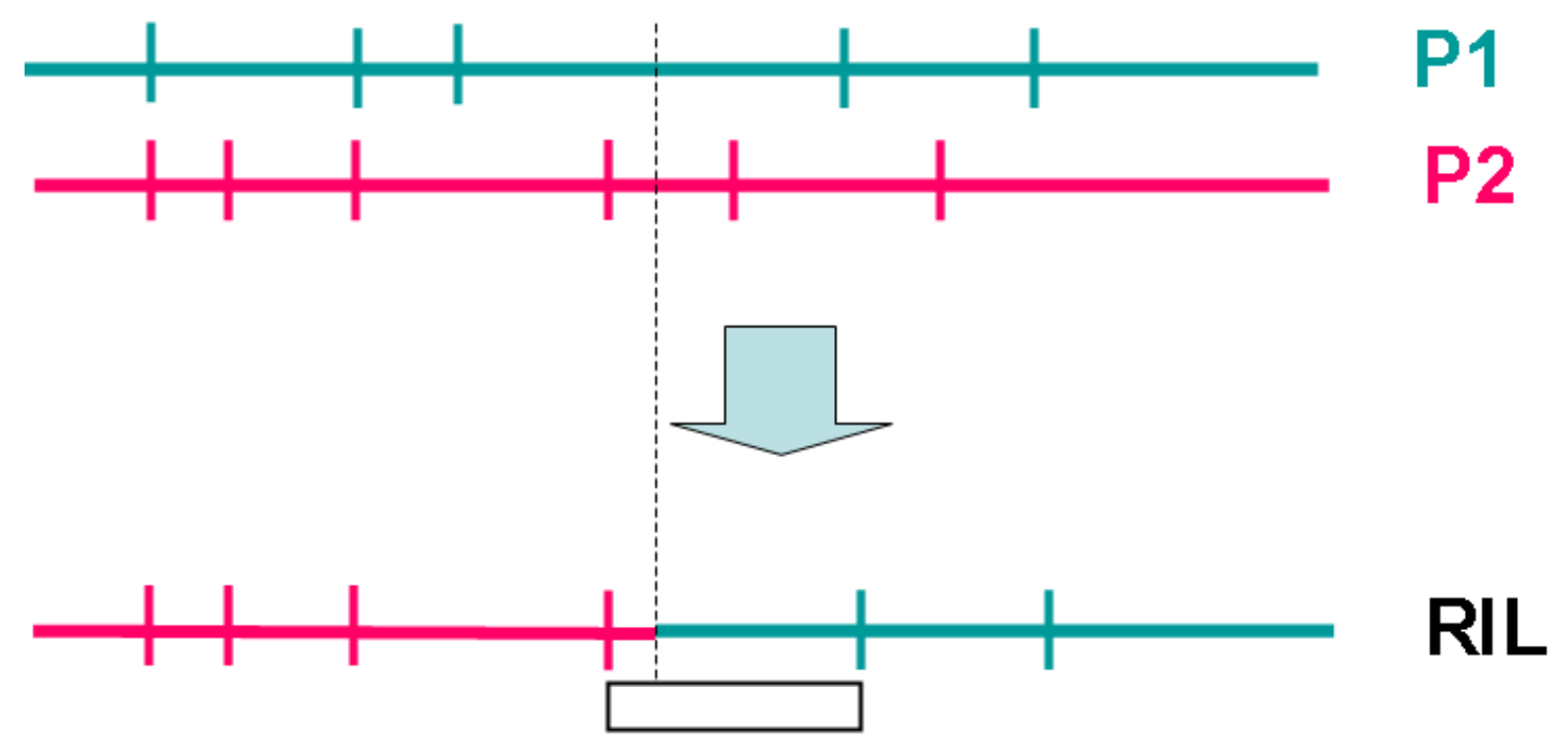

New maker not present in the parents 


\section{Nontargeted metabolic profiling}

The metabolic fingerprinting is some times used for this kind of analysis (Fiehn 2002); however, fingerprinting is usually used to distinguish individual/genotypes without analyzing individual markers separately. We therefore use the term nontargeted metabolic profiling. A total of 503 signals were detected in negative mode after processing raw data with CODA and Perl script. The data were reduced to most prominent and reproducible signals by setting a high limit for minimum signal intensity (75,000 counts) and a quality factor MSQ which assign each signal a value between 0 (noise) and 1 chromatographic peak with an optimal shape). An MSQ value of 0.8 was set as a limit in this analysis. Reproducibility was applied as a further selection criterion: only signals appearing in all three biological replicas were counted. This selection process resulted in 15 polymorphic signals (present in one of the parents only) and 40 monomorphic signals (present in both parents).

Manual inspection of the peak table revealed that the molecular masses of the ions of the 55 signals obtained by the selection process were conspicuously high (see Table. 1. This was probably an artifact resulting from the use of a fixed intensity threshold. Signal intensity is correlated with $\mathrm{m} / \mathrm{z}$ ratio due to the sensitivity curve of the MS detector. Using intensities normalized by the detector sensitivity may correct for this effect; however, for the purpose of this study the molecular masses of the ions generating analytical signals are not important.

The relatively low number of polymorphic signals as compared to monomorphic signals showed that the metabolic profiles of the parents contain more identical components than components specific to genotypes/accessions. Polymorphic signals segregated into RILs in a random fashion as expected. Two polymorphic signals found in the Korea1 parent were not found in any RIL; however, this can be just the consequence of a low number of RILs investigated. The total number of polymorphic signals found in RILs was remarkably constant: all RILs except one generated 3 or 4 signals, which is much less than the average number of polymorphic signals per parent. The low number of metabolic signals in RILs can be explained by the participation of many elements (enzymes, regulatory signals) in their biosynthesis. Mixing parental genomes in RILs may interrupt these networks needed for the 
synthesis of the metabolites with a consequence that the recombinants produce less metabolites than their parents. The remarkably constant number of signals observed in the RILs may be an artifact of the selection of signals by intensity.

Interestingly, most monomorphic signals found in the parents were also found in nearly all RILs. Moreover these signals were found in all three biological replicates (see Fig. 6). The stability of monomorphic signals contrast the instability of polymorphic signals. Obviously, monomorphic signals are produced by metabolites generated by pathways that are identical in both parents. Exchange of part of these pathways between the two parental genomes, which unavoidably occurred due to recombination events, did not appear to disrupt the biosynthesis pathways generating monomorphic metabolites. It would be interesting to determine the structures of these metabolites. We speculate that these biosynthesis pathways are robust because metabolites they generate contribute to the fitness of sesame or to the traits selected for by sesame breeders or growers in both growing areas from which the parental accessions originate.

Table 1. Presence of polymorphic metabolic signals in sesame RILs

\begin{tabular}{|c|c|c|c|c|c|c|c|c|}
\hline M/Z rage & A & B & C & D & E & F & Korea1 & Africa3 \\
\hline $309.5-310.9$ & & + & & & & & + & \\
\hline $405.6-407.0$ & & & + & + & & & + & \\
\hline $497.6-499.0$ & + & + & & + & & + & + & \\
\hline $527.6-529.0$ & + & & & & & & + & \\
\hline $545.5-547.0$ & & & & & + & + & + & \\
\hline $713.6-715.0$ & & & & & & & + & \\
\hline $735.5-737.0$ & & & & + & + & & + & \\
\hline $821.5-823.0$ & & & & + & & + & + & \\
\hline $839.5-841.0$ & & & & & & & + & \\
\hline $487.5-488.9$ & + & + & & & + & & & + \\
\hline $583.5-585.0$ & & & + & + & + & + & & + \\
\hline $619.6-621.0$ & & & & & & & & + \\
\hline $865.5-867.0$ & & & & + & & & & + \\
\hline $973.5-974.0$ & + & & & + & & & & + \\
\hline $985.6-987.0$ & & & + & & & & & + \\
\hline
\end{tabular}




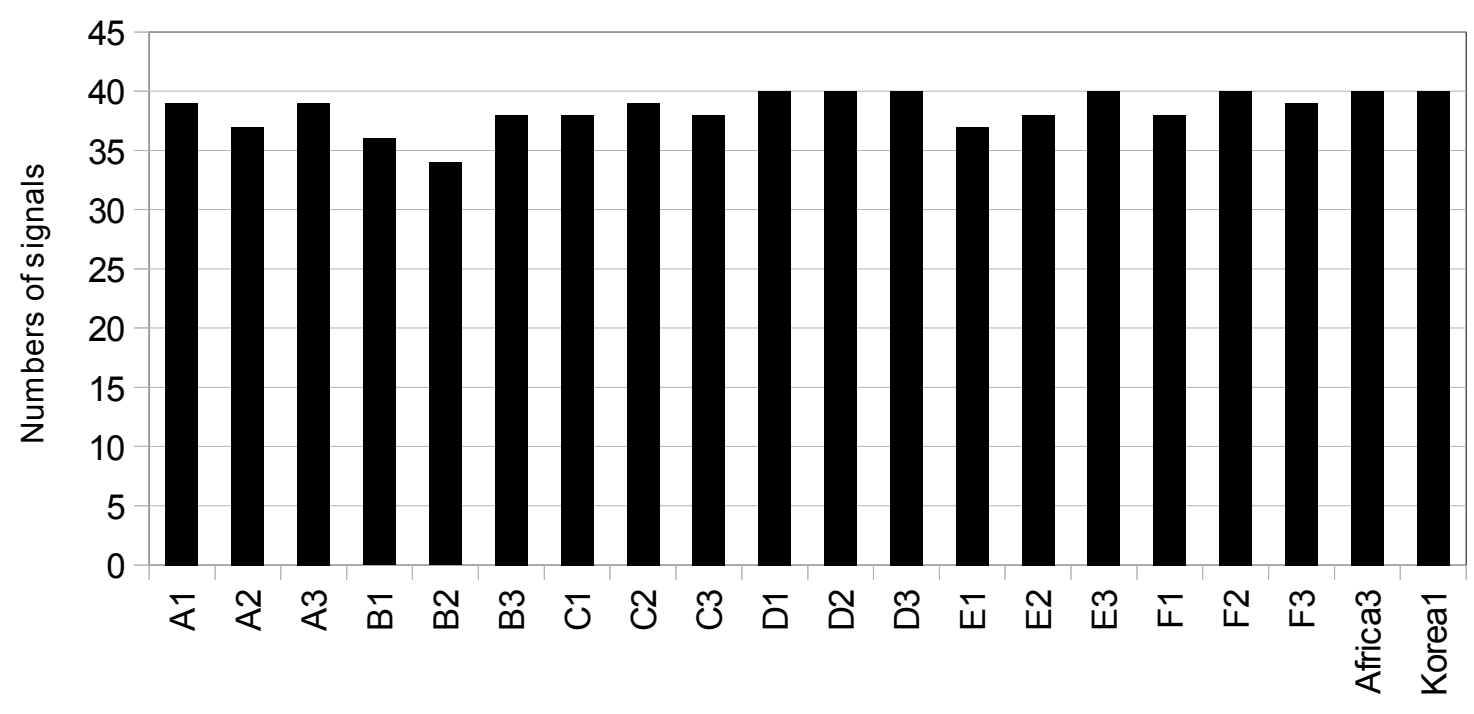

Individuals name

Figure 6. Common reproducible signals in three replication of parents. Signals of both parents found in RILs

We envision that the AFLP data will extended by further primer combinations and eventually used for the construction of a linkage map by collaborating sesame breeders in Antalya University. Once a linkage map is available, it will be possibly to locate genetic determinants controlling the synthesis of secondary metabolites on this map and to use this information in marker-assisted breeding for improved content of lignans and other metabolites, as well as for map-assisted cloning of genes encoding the relevant biosynthetic pathways. 


\section{References}

1) Bhat, KV., Babrekar PP., Lakhanpaul, S. 1999 Study of genetic diversity in Indian and exotic sesame (Sesamum indicum L.) germplasm using random amplified polymorphic DNA (RAPD) markers. Euphytica 110:21-33

2) Bin-Wei, L., Zhang, H. Y., GUO, W. Z. 2008 Developing EST-Derived Microsatellites in Sesame (Sesamum indicum L.) Acta agronomica sinica . $34: 2077-2084$

3) Dixit, A,, Jin MH., Chung, JW. 2005 Development of polymorphic microsatellite markers in sesame (Sesamum indicum L.). Mol Ecol Notes $5(4): 736-738$

4) El-bramawy, M. A. S and Shaban, W. I. 2008 Short communication. inheritance of yield, yield components and resistance to major disease in Sesamum indicum L. Spanish Jouurnal of Agricultural research. 6(4):623-628

5) Ercan, A. G., Taskin, M. and Turgut, K. 2004 Analysis of genetic diversity in Turkish sesame (Sesamumindicum L.) populations using RAPD markers Genetic Resources and Crop Evolution 51: 599-607.

6) Fiehn, O. 2002. Metabolomics-the link between genotypes and phenotypes. Plant Molecular Biology. 48:155-171

7) Ginwal, H.S. and Neha, M. 2010 An efficient genomic DNA isolation protocol for RAPD and SSR analysis in Acorus calamus L. Indian journal of Biotechnology. 9:213-216

8) Ghulam, M. A. Sirato, Y., Masumi, S. K. 2007. Assessment of genetic diversity in sesame (Sesamum indicum L.) detected by Amplified Fragment Length Polymorphism markers. Electron. J. Biotechnol.10(1):12-23.

9) Hirai, M. Y., Klein, M., Fujikawa, Y., Yano, M., Goodenowe, D. B., Yamazaki, Y., et al. 2005. Elucidation of gene-to-gene and metabolite-to-gene networks in Arabidopsis by integration of metabolomics and transcriptomics. Journal of Biological Chemistry, 280(27), 25590-25595.

10)Isshiki, S. and Umezaki, T. 1997 Genetic variations of isozymes in cultivated 
sesame (Sesamumindicum L.)Euphytica 93: 375-377

11)Kim, DH., Zur, G., Danin-Poleg, Y. et al. 2002 Genetic relationship of sesame germplasm collection as revealed by inter-simple sequence repeats. Plant Breed 121:259-262.

12)Laurentin, H. E. and karlovsky, P. 2006 Genetic relationship and diversity in sesame (Sesamum indicum L.) germplasm collection using amplified fragment length polymorphism. BMC Genetics 7:10

13)Laurentin, H., A. Ratzinger, and Karlovsky, P. 2008 Relationship between metabolic and genomic diversity in sesame. BMC Genomics. 9:250.

14) Parsaeian, M., Mirloh,i A., Saeidi, G. 2011 Study of genetic variation in sesame (Sesamum indicum L.) using agro-morphological traits and ISSR markers. Genetika. 47(3):359-67.

15) Pathirana, R. 1994 Natural cross-pollination in sesame (Sesamum indicum L.) Plant breeding.112(2):167-170

16) Uzan, B. and Cagirgan, M. J. 2009 Identification of molecular markers linked to determinate growth habit in sesame. Euphytica.166(3): 379-384

17)Uzun, B., Lee D., Donini, P. et al. 2003 Identification of a molecular marker linked to the closed capsule mutant trait in sesame using AFLP. Plant Breed 122:95-97 


\section{Summary}

\section{Summary}

Biological diversity exist between species and within species among populations and individuals. Intraspecies diversity has been extensively studied at the genome level but intraspecies diversity in metabolic constitution has received very limited attention was studied only in a handful of publications. To our knowledge no studies have been published on phytohormones in sesame. Apart from the academic interest in metabolic diversity, stress hormone play an important role in defense against pathogens. Phytohormones level are also relevant from practical point of view because seeds of sesame sometimes germinate spontaneously while capsules still attach to the plants and green. This is highly undesirable characteristic because valueable seeds are lost. We determined the diversity in phytohormone level among 16 sesame accessions of different geographical origin. We able to detect ABA, JA, SA and SAG in leaves and roots while GA4 only in leaves. One of the accession orignating from Japan ("Japan 2") produced high level of JA, SA as well as SAG. This accession was producing high amount of chitinase as well, which is essential for the degradation of chitin, a major component of the fungal cell wall. Characterization of accessions by AFLP reveled that "Japan 2" was not genetically more distant from the other accessions than the average distance within the collection. Previous findings of our research team founds untargeted metabolic profiling of sesame revealed a high variability in (Lauerntin et al. 2006). Moreover, the differences among metabolic profiles of the accessions were not concordant with their genetic distance.

Circadian clock known to control the various biological process We established the effect of circadial rhythm on phytohormone levels and determined the difference among organ. Circadial ABA, JA, IAA, SA and SAG levels detected by HPLC at eight different time point during the day with three independeat replicate showed no statistical significant diurnal variation. However variation in phytohormone concentration was found to vary in different parts.

Secondary metabolites as resistant factor against microorganisms are relevant in disease resistance. Accessions that produce high levels of such compounds are a 


\section{Summary}

valuable source for sesame breeding. To determine the variation in accessions that produce high levels of such ecological metabolites, we tested the effects of extracts of 32 sesame accessions against pathogenic fungi, including a root pathogen specialized on sesame Macrophomina phaseolina, a leaf pathogen with a broad host range Alternaria alternata and a vascular pathogen Fusarium oxysporum. The diversity of the effects observed for different accessions lead to the assumption that there is potential to improve plant disease resistance in sesame using metabolic pathway engineering. In a continuation of this research toward purification of metabolites that are responsible of inhibitory effect, crude $80 \%$ ethanol extracts fractioned with different organic solvents revealed that inhibitory effect was most prominent in the diethylether fraction. $4 \mathrm{~L}$ of the crude extract as produced and fractioned as the first step towards purification. Two purified sesame lignans were also tested against the M. phaseolina, A.alternata, F.oxysporum. Sesamin had no effect up to a concentration of $5 \mathrm{mg} / \mathrm{ml}$ while sesamol (and 2,4-dinitrophenol used as a control) had strong inhibitory effects. IC50 value of these compounds were determined. We concluded that sesamol may help the plant by inhibiting the growth of invading pathogens.

Inbread lines were developed by crossing two parents that showed significant polymorphism revealed by AFLP. Single seed descents were selfed for five generations. A subset of the RILs obtained was characterized by ALFP. All RILs studied were hybrids, showing that no selfing occurred during the original crossing experiment. Polymorphic AFLP markers of parents segregated into RILs randomly as expected. However, some monomorphic markers were missing in some RILs, and new markers were detected in RILs that were missing in both parents. These results can be explained by recombination events that occurred between restriction sites delimiting AFLP markers. The RILs will be used by our collaborating partner to construct a linkage map of sesame (Professor Sami Doganlar and his team at Antalya University, Turkey) 


\section{Summary}

\section{Zusammenfassung}

Biologische Diversität existiert sowohl zwischen mehreren Arten als auch innerhalb einer Art, innerhalb von Populationen und Individuen einer Population. Die intraspezifische Diversität wurde bislang ausgiebig auf der Ebene des Genoms untersucht. Sie ist im Kontext metabolischer Zusammenhänge in Pflanzen bisher kaum untersucht und es existieren nur wenige Veröffentlichungen zu diesem Thema. Uns sind bisher keine Publikationen zu Phytohormonen in Sesam bekannt. Neben dem wissenschaftlichen Interesse an der metabolischen Diversität in Sesam, spielen Stresshormone eine wichtige Rolle in der pflanzlichen Abwehr. Der Phytohormonspiegel im Samen ist unter agronomischen Gesichtspunkten relevant, da es vorkommen kann, dass Sesamsamen spontan auskeimen, während sie sich noch an der grünen Pflanze befinden. Diese Eigenschaft ist unerwünscht, da der wertvolle Samen auf diese Weise verloren geht. Im Rahmen dieser Arbeit wurde die Variation im Phytohormonniveau in 16 Akzessionen mit unterschiedlicher geographischer Herkunft untersucht. In Blättern und Wurzeln konnten ABA, JA, SA und SAG nachgewiesen werden, während GA4 lediglich in Blättern vorkam. Eine der Akzessionen aus Japan („Japan 2“) produzierte JA, SA und SAG in hohem Ausmaß. Hier konnten außerdem hohe Gehalte an Chitinasen festgestellt werden. Chitinasen sind für den Abbau von Chitin, dem Hauptbestandteil der pilzlichen Zellwand, verantwortlich. Eine Charakterisierung der Akzessionen mittels AFLP-Analyse zeigte, dass sich „Japan 2“ genetisch nicht mehr von anderen Akzessionen unterschied, als das Mittel der Unterschiede innerhalb aller gesammelten Proben. Bereits in früheren Untersuchungen unserer Arbeitsgruppe im Rahmen einer ungerichteten Metabolitenanalyse, konnte eine hohe Variabilität bei Sesamakzessionen gezeigt werden (Laurentin et al. 2006). Darüber hinaus, stimmen die Unterschiede im metabolischen Profil der Akzessionen nicht mit dem Grad ihrer genetischen Verwandtschaft überein.

Es ist bekannt, dass tageszeitliche Unterschiede viele biologische Prozesse kontrollieren. Wir haben die tageszeitlichen Effekte auf den Phytohormonstatus untersucht und dabei die Unterschiede in Pflanzenorganen berücksichtigt. Tageszeitliche Konzentrationen von ABA, JA, IAA, SA und SAG wurden zu 8 unterschiedlichen Tageszeitpunkten in 3 unabhängigen Replikaten mittels HPLC 


\section{Summary}

untersucht. Wir konnten keine statistisch signifikanten Unterschiede erkennen. Die Untersuchungen zeigten jedoch eine Variation in den Phytohormonkonzentrationen in unterschiedlichen pflanzlichen Organen.

Sekundäre pflanzliche Metabolite spielen als Resistenzfaktoren gegen Mikroorganismen eine wichtige Rolle. Sesamakzessionen, die diese Substanzen im hohen Ausmaß produzieren, stellen eine wichtige züchterische Ressource da. Um die Variation innerhalb der Akzessionen zu untersuchen, die ein hohes Niveau an sekundären Inhaltsstoffen aufweisen, haben wir die Effekte von 32 Pflanzenextrakten aus Sesamakzessionen gegen phytopathogene Pilze untersucht. Darunter befand sich ein Wurzelpathogen mit Spezialisierung auf Sesam (Macrophomina phaseolina), ein Blattpathogen mit breitem Wirtspflanzenkreis (Alternaria alternata) und Gefäßpathogen (Fusarium oxysporum). Die Diversität der Effekte, die für die unterschiedlichen Akzessionen beobachtet werden konnten, führt zu der Annahme, dass die Resistenzeigenschaften der Pflanzen durch gezielte züchterische Beeinflussung der metabolischen Aktivität verbessert werden können. In weiterführenden Untersuchungen zur Aufreinigung der Substanzen mit inhibitorischer Wirkung wurden Pflanzenextrakte in $80 \%$ Ethanol mit verschiedenen organischen Lösungsmitteln fraktioniert. Die meisten inhibitorischen Effekte konnten der Diethylether-Fraktion zugeschrieben werden. Im ersten Schritt wurden 4L des Extraktes hergestellt. Zwei aufgereinigte Lignane aus Sesam wurden gegen $M$. phaseolina, A. alternata und F. oxysporum getestet. Sesamin zeigte keinen Effekt bis zu einer Konzentration von $5 \mathrm{mg} / \mathrm{ml}$, während Sesamol (und 2,4-Dinitrophenol als Kontrolle) einen starken inhibitorischen Effekt aufwies. Für diese Substanzen wurden IC50 Werte ermittelt. Man kann festhalten, dass Sesamol dazu dienen kann, das Wachstum invasiver Pathogene einzuschränken.

Durch die Kreuzung von zwei Elternlinien, die in der AFLP-Analyse einen signifikanten Polymorphismus aufwiesen, wurden Inzuchtlinien erzeugt. Die Nachkommen dieser Kreuzung wurden in 5 Generationen selbstbefruchtet. Das so entstandene Set aus RILs wurde mittels AFLP charakterisiert. Alle untersuchten RILs waren Hybride. Dies zeigt, dass während der ersten Kreuzung der Elternlinien keine Selbstung erfolgte. Wie erwartet, spalteten polymorphe AFLP-Marker der Elternlinien in den RILs zufällig auf. Monomorphe Marker fehlten in einigen RILs. Des Weiteren 


\section{Summary}

traten neue Marker auf, die zuvor nicht in den Elternlinien festgestellt werden konnten. Das Auftreten neuer Marker kann durch Rekombination zwischen Restriktionsfragmenten erklärt werden, welche die AFLP-Marker begrenzen. Die RILs werden nun von unseren Kooperationspartnern zum Aufbau einer genetischen Karte verwendet (Prof. Sami Doganlar und seine Arbeitsgruppe, Universität Antalya, Türkei). 


\section{Acknowledgements}

This is a result of years of research in Goettingen since the day I was accepted in Professor Dr. Petr Karlovsky group. I want to convey my gratitude to all those who supported me during my stay in prestigious institute. Today the last hours before printing I got the opportunity to acknowledge my supervisor and other members of group whose contribution make this thesis possible.

Special thanks to my Ph.D supervisor Prof. Dr. Petr Karlovsky for his kind supervision, utmost guidance and advices and providing me a relaxed, supportive and working environment.

I gratefully acknowledge Dr. Laurentin for providing genetic material and guidance in my early days of research, Dr. Richard for his help in research, discussions and guidelines during my whole Ph.D work and making this thesis possible to complete and thanks Dr. Chaterjee for helping in metabolic profiling and great emotional support.

Thanks to Petra for arranging room to stay before I arrive to goettingen. Thanks to $\mathrm{Dr}$ Anke for moral support (I will miss your black forest cake that you make especially for me). Thanks to Heike, for technical support and thanks Ruth and Dr. Nayuf for helping in AFLP you both really spend a lot time with me. Thanks Muhammad for review my thesis. Thanks Husam, for irrigating my plant In December when I was to Pakistan and providing good company.

I am indebted to every body will miss you all in Pakistan. My deepest appreciation for my friends together with whom I feel like a family members Mubeen Akhter and Muhammad Zaghum Zia. Their friendship is for me like a light in dark. I cant forget this four years time in Germany we spend together. I will always miss you both and my cute little niece khadija. Thanks to Asma and Tayyab Tahir for great emotional support and thanks all families and friends who created a family atmosphere far from home.

And of course thanks to DAAD and Higher Education Commission Pakistan (HEC) for giving me the opportunity to make my dream true. 


\section{Scientific contribution}

Diversity and Variance in Phytohormone Content of Sesame (Sesamum indicum) (Rehana Syed, Richard Splivallo, Petr Karlovsky)

poster acccepted for tropentag 2011, Bonn, Germany

Antifungal Properties of Sesame (Sesamum indicum L.) Crude Extract and

Purified Sesame Lignans.(Rehana Syed, Richard Splivallo, Petr Karlovsky)

Poster presentation in Tropentag 2010, Zurich, Swizerland

\section{Author's Contributions}

Because this work involved special chemical-analytical methods, I relied on the support of my colleagues Dr. Subhankar Chatterjee and Dr. Richard Splivallo. Genetic materials was provided and the initiation of the cross was performed by Dr. Hernan Laurentin. I specify their contribution to the experimental chapter as follows:

\section{Chapter 02.}

Dr. Richard Splivallo performed phytohormone analysis and helped me with statistical analysis.

\section{Chapter 03.}

Dr. Subhankar Chatterjee performed metabolic profilling

\section{Manuscript 04.}

Dr. Hernan Laurentin performed cross and Dr. Subhankar Chatterjee performed metabolite profiling. 


\section{Curriculum Vitae}

\section{Personal details}

Name: Rehana naz

Sex: Female

Date of birth: 11-07-1976

Nationality: Pakistan

\section{Education}

2007-2011

Doctoral Studies in Agricultural Sciences (IPAG) - Molecular

Phytopathology and Mycotoxin Research Unit, University of

Goettingen, Germany

Thesis title: Chemical and genetic diversity in sesame (Sesamum indicum L.)

\section{3-2004}

Masters of Science in Agriculture

Department of Plant Pathology, Sindh Agriculture University Tandojam, Pakistan Thesis title: Evaluation of different fungicides against soil born disease of sesame (Sesamum indicum L.) caused by Macrophomina phaseolina.

\section{7-2002}

Bachelor of Science in Agriculture

Department of Plant Pathology, Sindh Agriculture University Tandojam, Pakistan

\section{Present position}

Assistant Professor in the Department of Plant Pathology, Sindh Agriculture University Tandojam, Pakistan . 